Alaska Division of Geological \& Geophysical Surveys

MISCELLANEOUS PUBLICATION 144

\title{
DIGITAL ELEVATION MODEL OF SITKA HARBOR AND THE CITY OF SITKA, ALASKA: PROCEDURES, DATA SOURCES, AND QUALITY ASSESSMENT
}

by

P.J. Hickman, E.N. Suleimani, and D.J. Nicolsky

July 2012

\author{
Released by \\ STATE OF ALASKA \\ DEPARTMENT OF NATURAL RESOURCES \\ Division of Geological \& Geophysical Surveys \\ 3354 College Rd. \\ Fairbanks, Alaska 99709-3707
}

$\$ 4.00$

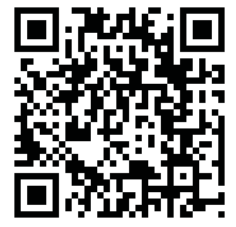





\title{
MISCELLANEOUS PUBLICATION 144
}

\section{DIGITAL ELEVATION MODEL OF SITKA HARBOR AND THE CITY OF SITKA, ALASKA: Procedures, Data Sources, and Quality Assessment}

\author{
by P.J. Hickman ${ }^{1}$, E.N. Suleimani ${ }^{2}$, and D.J. Nicolsky ${ }^{2}$ \\ ${ }^{1}$ Geographic Information Network of Alaska, University of Alaska Fairbanks \\ ${ }^{2}$ Alaska Earthquake Information Center, University of Alaska Fairbanks
}

Project contact:

Peter Hickman

Geographic Information Network of Alaska (GINA)

University of Alaska Fairbanks

909 Koyukuk Street

Fairbanks, AK 99775

Phone: 907-474-1567

E-mail: pete@gina.alaska.edu

http://www.gina.alaska.edu 



\section{Contents}

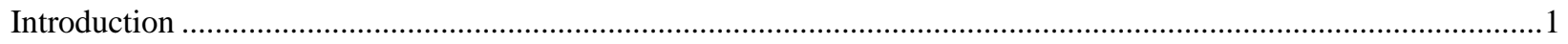

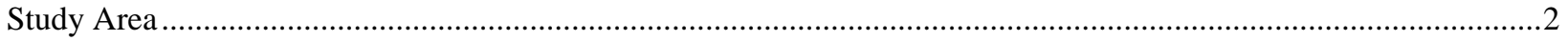

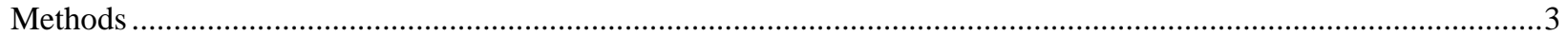

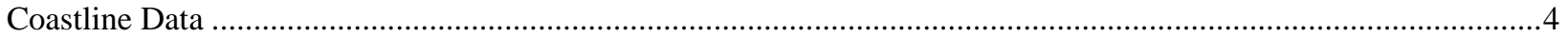

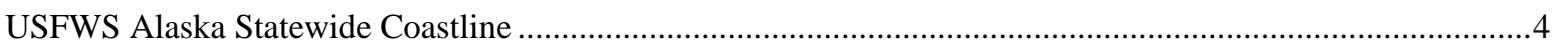

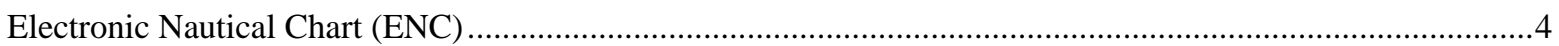

Delta Aerial Surveys, Ltd. Triangulated Irregular Network (TIN) .....................................................................

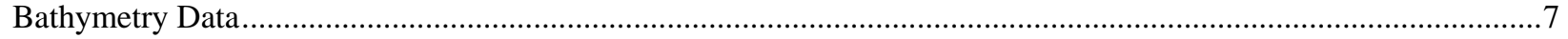

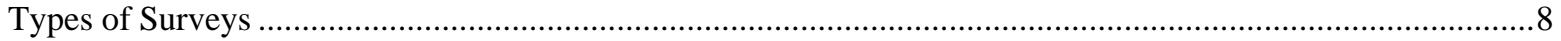

U.S. Army Corps of Engineers (USACE) hydrographic surveys .............................................................

National Ocean Service Bathymetric Attributed Grid (NOS BAG) surveys ...............................................8

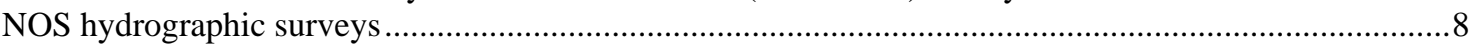

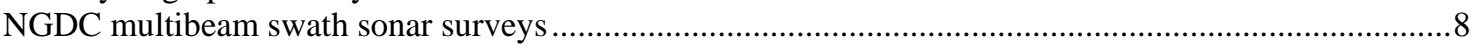

NGDC Trackline and NOAA Electronic Navigational Chart (ENC) soundings .........................................8

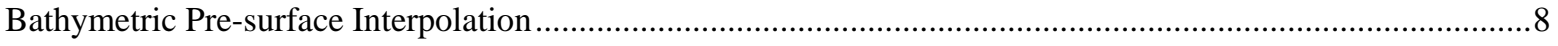

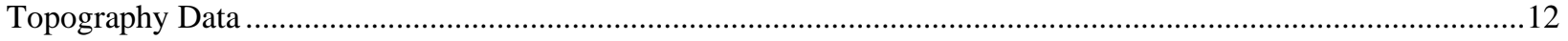

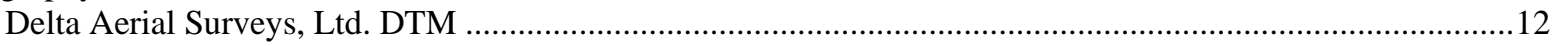

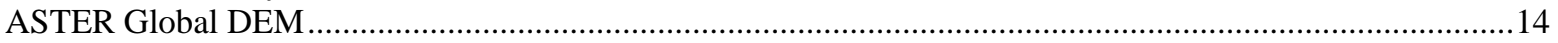

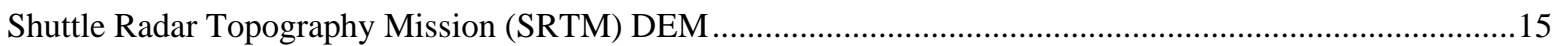

SRTM/ASTER DEM Mosaic ..................................................................................................................16

Japonski Island Triangulated Irregular Network ……….................................................................................17

Manually Digitized Elevation Points .....................................................................................................21

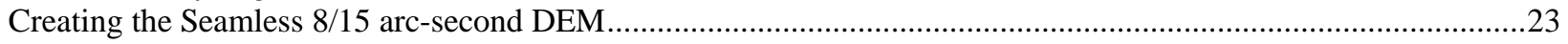

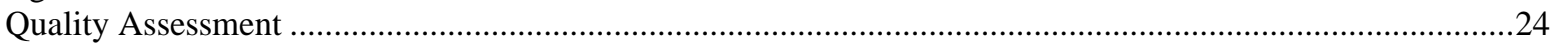

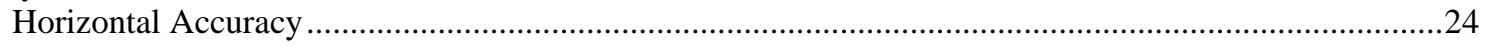

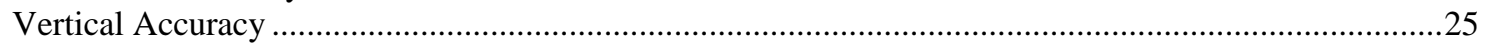

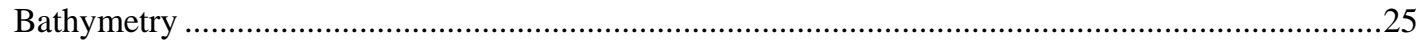

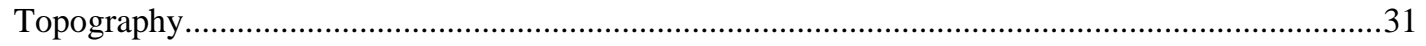

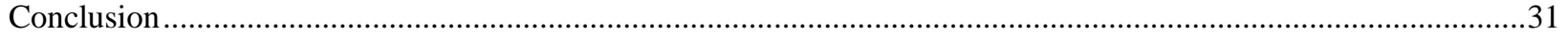

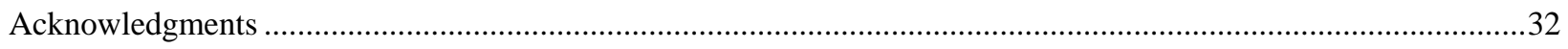

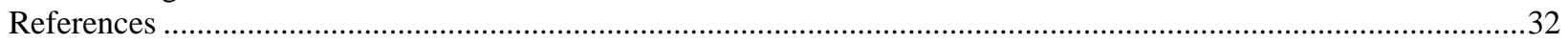

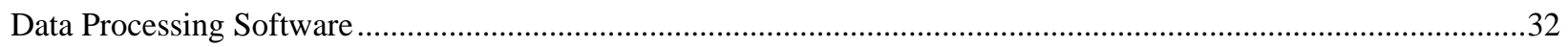

Appendix A — Hydrographic Surveys Evaluated in Developing the Sitka 8/15 arc-second DEM....................................33

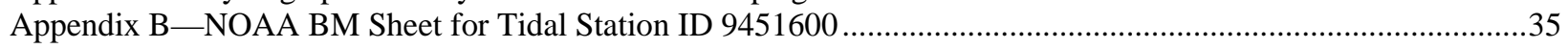

Appendix C—NGDC Workflow Documentation....................................................................................................36

Appendix D—List of Abbreviations and Acronyms ............................................................................................38

\section{FIGURES}

Figure 1. Photo with view to the northwest over Sitka Harbor, the city of Sitka, and Japonski Island, Alaska ......1

2. Map of study area with delineated extents of nested 8,3 , and $8 / 15$ arc-second DEMs............................

3. $\quad$ Map showing $8 / 15$ arc-second DEM boundary .........................................................................................

4. Digital orthophoto mosaic showing U.S. Fish \& Wildlife Service (USFWS) Statewide Alaska Coastline overlaid on the City and Borough of Sitka ......................................................................... 4

5. Digital orthophoto mosaic comparing the Office of Coast Survey (OCS) Electronic Nautical Chart (ENC) coastline dataset and the U.S. Fish \& Wildlife Service coastline dataset ....................................5

6. Digital orthophoto mosaic comparing the 0.00 elevation hard breakline extracted from the Delta Aerial Surveys, Ltd. DTM, the OCS ENC coastline dataset, and the USFWS coastline dataset ..............5

7. Digital orthophoto mosaic showing coverage limits of extracted 0.00 elevation Delta Aerial Surveys Triangulated Irregular Network (TIN) breakline, Alaska Earthquake Information Center (AEIC), and USFWS coastline datasets.

8. Orthophoto showing subsample of every tenth point in the final coastline shapefile used to generate the longitude, latitude, and 0.00 elevation values at each point 
9. Shaded-relief map of first iteration bathymetric pre-surface of Sitka Harbor and Sitka Sound. Inset photos show the three types of interpolation errors identified by our review: gridding errors, stripping or banding error, and errors in survey data

10. Map of survey coverage after removal of overlap. Surveys used to create the final bathymetric presurface are labeled on map by survey name.

11 Shaded-relief map of second iteration bathymetric pre-surface of Sitka Harbor and Sitka Sound. Inset A demonstrates correction of gridding errors identified in first iteration grid. Inset B shows correction of stripping errors identified in first iteration grid. Inset C illustrates correction of bathymetric pre-surface after discarding erroneous data points

12. Map showing approximate coverage of topographic data sources used to build the $8 / 15$ arc-second bathymetric-topographic DEM.

13. Horizontal distribution of Delta Aerial Surveys photogrammetrically derived topographic data points

14. Vertical distribution of Delta Aerial Surveys photogrammetrically derived topographic data points ...13

15. Shaded-relief model of the ASTER GDEM WCS subset .......................................................................14

16. Shaded-relief model of SRTM DEM coverage used for visual evaluation ..........................................15

17. Shaded-relief model of the SRTM/ASTER DEM mosaic showing the "No Data" holes filled in using values extracted from the ASTER GDEM .............................................................................. 16

18. Perspective view, looking to the east, of Japonski Island and the Sitka Airport .....................................17

19. Delta Aerial Surveys topography data coverage of Japonski Island ....................................................18

20. Summary statistics of the Sitka Airport runway tarmac elevations derived from the SRTM/ASTER

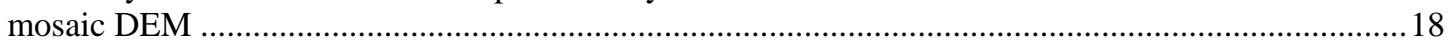

21. Summary statistics of the Sitka Airport runway tarmac elevations derived from DOTPF survey monuments

22. Japonski Island Triangulated Irregular Network (TIN)...................................................................20

23. Diagram showing datasets used to create a new elevation Triangulated Irregular Network (TIN) of

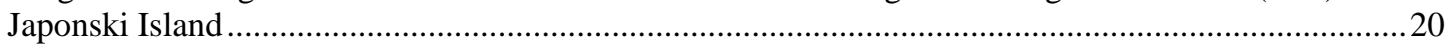

24. Japonski Island $5 \mathrm{~m}$ Digital Elevation Model (DEM) ..........................................................................21

25. View, looking to the north, of Sitka Harbor, showing the western anchorage breakwaters....................21

26. Orthophoto showing middle of the western anchorage breakwaters, using U.S. Army Corps of Engineers (USACE) survey data, with manually digitized points .........................................................22

27. Orthophoto showing western anchorage breakwater with $8 / 15$ arc-second grid overlay ........................22

28. Shaded-relief map of the final seamless $8 / 15$ arc-second bathymetric-topographic grid of

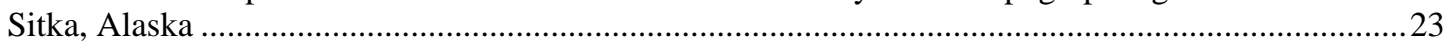

29. Shaded-relief map of the final 8/15 arc-second grid, centered on Sitka Harbor and Japonski Island ....24

30. Shaded-relief map of the 20051 arc-second grid, centered on Sitka Harbor and Japonski Island..........24

31. Map showing three-dimensional perspective of the Sitka 8/15 arc-second DEM, rendered using ArcScene......

32. Map showing same perspective as in figure 31, with the 8/15 arc-second DEM superimposed over the NGDC Southeast Alaska 3 arc-second DEM ................................................................................25

33. Map showing same perspective as in figures 31 and 32, with the addition of the study area boundary to clearly identify the transition, or seam, between the 8/15 and 3 arc-second DEMs............25

34. Histogram comparing NOS H11117 depth values (m) to the Sitka 8/15 arc-second DEM ...................26

35. Histogram comparing NOS H11118 depth values (m) to the Sitka 8/15 arc-second DEM ...................26

36. Histogram comparing NOS H11119 depth values (m) to the Sitka 8/15 arc-second DEM ....................27

37. Histogram comparing NOS H11120 depth values (m) to the Sitka 8/15 arc-second DEM ...................27

38. Histogram comparing NOS H11121 depth values (m) to the Sitka 8/15 arc-second DEM ....................28

39. Histogram comparing NOS H11122 depth values (m) to the Sitka 8/15 arc-second DEM ...................28

40. Histogram comparing NOS H11123 depth values (m) to the Sitka 8/15 arc-second DEM ..................29

41. Histogram comparing NOS H11130 depth values (m) to the Sitka 8/15 arc-second DEM ...................29

42. Histogram comparing NOS H11271 depth values (m) to the Sitka 8/15 arc-second DEM ....................30

43. Histogram comparing NOS H11354 depth values (m) to the Sitka 8/15 arc-second DEM ......................30

44. Histogram comparing the DOTPF topographic survey control elevation values to the Sitka 8/15 arc-second DEM 


\title{
DIGITAL ELEVATION MODEL OF SITKA HARBOR AND THE CITY OF SITKA, ALASKA: Procedures, Data Sources, and Quality Assessment
}

\author{
by P.J. Hickman ${ }^{1}$, E.N. Suleimani ${ }^{2}$, and D.J. Nicolsky ${ }^{2}$ \\ ${ }^{1}$ Geographic Information Network of Alaska, University of Alaska Fairbanks \\ ${ }^{2}$ Alaska Earthquake Information Center, University of Alaska Fairbanks
}

\section{Introduction}

The Alaska Earthquake Information Center (AEIC) and the Geographic Information Network of Alaska (GINA), with the assistance of the National Geophysical Data Center (NGDC), have developed an 8/15 arc-second horizontal-resolution bathymetric-topographic digital elevation model (DEM) centered on Sitka Harbor and the city of Sitka, Alaska (fig. 1). This DEM has been developed to support the ongoing AEIC project, "Tsunami Inundation Mapping of Alaska Coastal Communities.” The DEM has been designed to fit within a nested hierarchy of similar DEMs of larger spatial extent but coarser resolution (Caldwell and others, 2010). The grid was assembled from a wide variety of bathymetric and topographic data sources. This report summarizes in detail the various datasets, data processing tasks and techniques, the surface interpolation, and quality assessment of the seamless 8/15 arc-second bathymetric-topographic DEM.

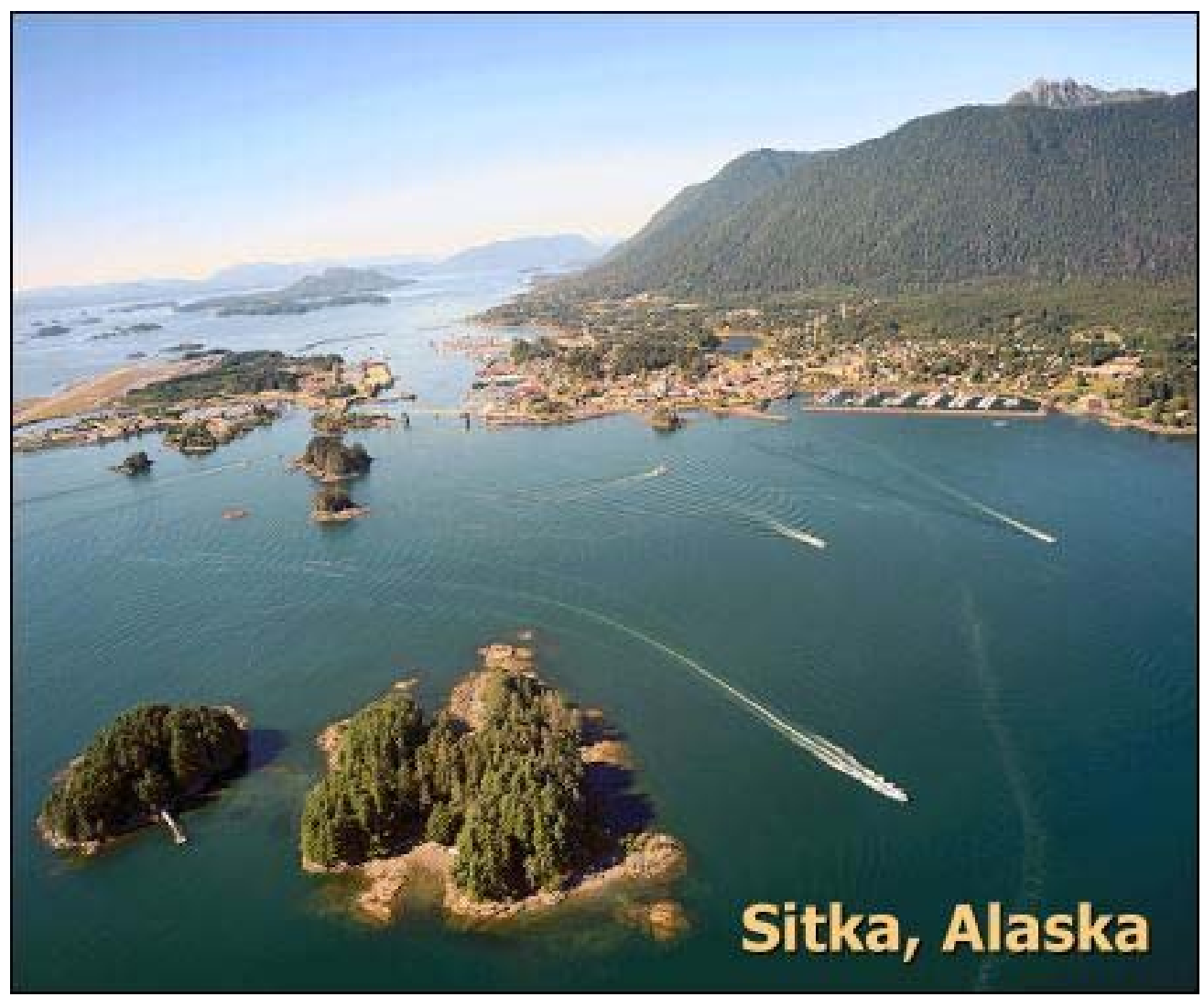

Figure 1. View to the northwest over Sitka Harbor, the city of Sitka, and Japonski Island, Alaska. Photo source: http://www.sitka.net/images/photos/sitkaaerial.jpg 


\section{Study Area}

The city of Sitka is located predominantly on two islands of the Alexander Archipelago. Most of the city is located on Baranof Island; however, several schools as well as the city's airport are located on the much smaller Japonski Island to the southwest of the city. The two islands are connected by bridge.

The 8 arc-second grid (fig. 2) developed by NGDC (Caldwell and others, 2010) encompasses the communities Craig, Elfin Cove, Ketchikan, Port Alexander, Sitka, and Skagway. NGDC also developed the 3 arc-second DEM. We developed the 8/15 arc-second grid to cover only Sitka Harbor and the city of Sitka for numerical modeling of tsunami waves and the mapping of tsunami inundation zones for the city.

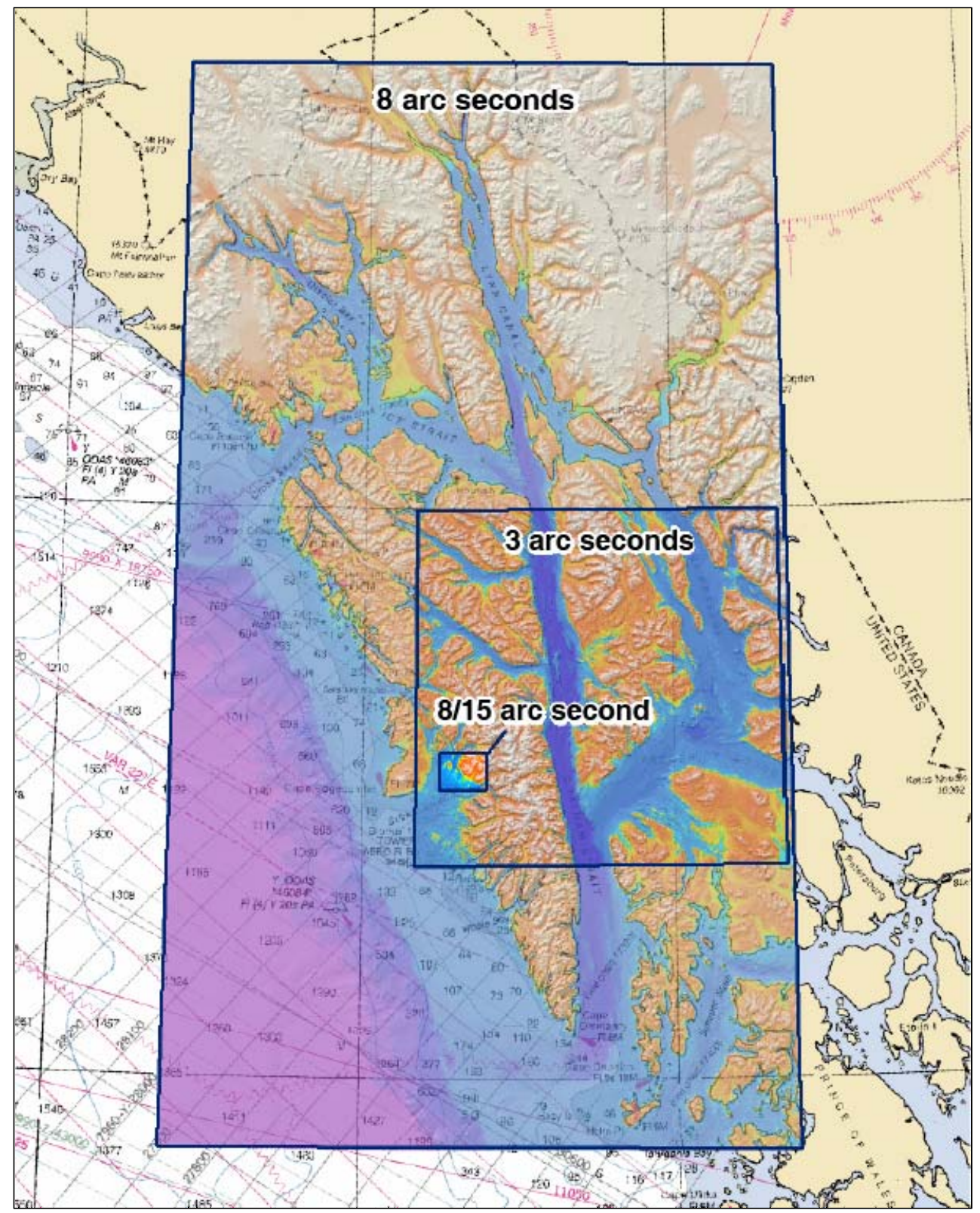

Figure 2. Map showing study area in Southeast Alaska, with the extents of the nested 8, 3 and 8/15 arc-second DEMs delineated with dark blue boxes. 


\section{Methods}

The methods we used to compile the 8/15 arc-second DEM of Sitka City and Sitka Harbor follow the "Coastal DEM Development-Best Practices" white paper produced by NGDC

(http://www.ngdc.noaa.gov/mgg/coastal/ngdc dem best_practices.pdf). A detailed outline of the workflow is provided as Appendix $\mathrm{C}$ of this report. Specifications for the final grid are listed below.

\begin{tabular}{|l|l|r|}
\hline 8/15 DEM Bounding Coordinates & West & $-135.516667^{\circ}$ \\
\hline & North & $57.150000^{\circ}$ \\
\hline & East & $-135.216667^{\circ}$ \\
\hline $\begin{array}{l}\text { Area 5 Percent Greater Than } \\
\text { Bounding Coordinates (fig. 3) }\end{array}$ & South & $57.016667^{\circ}$ \\
\hline & West & $-135.521931^{\circ}$ \\
\hline & North & $57.150869^{\circ}$ \\
\hline & East & $-135.208440^{\circ}$ \\
\hline Coordinate System & South & $57.017947^{\circ}$ \\
\hline Horizontal Datum & Geographic decimal degrees \\
\hline Vertical Datum & World Geodetic System 1984 (WGS84) \\
\hline Vertical Units & Mean Higher High Water (MHHW) \\
\hline Cell Size & Meters \\
\hline
\end{tabular}

We collected datasets covering an area 5 percent greater than the DEM boundary (fig. 3). We did this because surface interpolation algorithms are prone to interpolation error along data boundaries where there are data points on one side of the boundary but not on the other side of the boundary. We clipped the output surface to the DEM boundary after the final interpolation to trim off potential interpolation errors that may exist along the margins of the grid.

The following sections of this report provide a detailed discussion of the data sources and processing steps used in each phase during development of the Sitka 8/15 arc-second grid.

Figure 3. Map

showing the $8 / 15$ arcsecond DEM boundary (red box). We collected data for an area 5 percent greater than the study area (blue box). We clipped the final grid to the study area boundary to minimize the potential for interpolation errors along the grid margins.

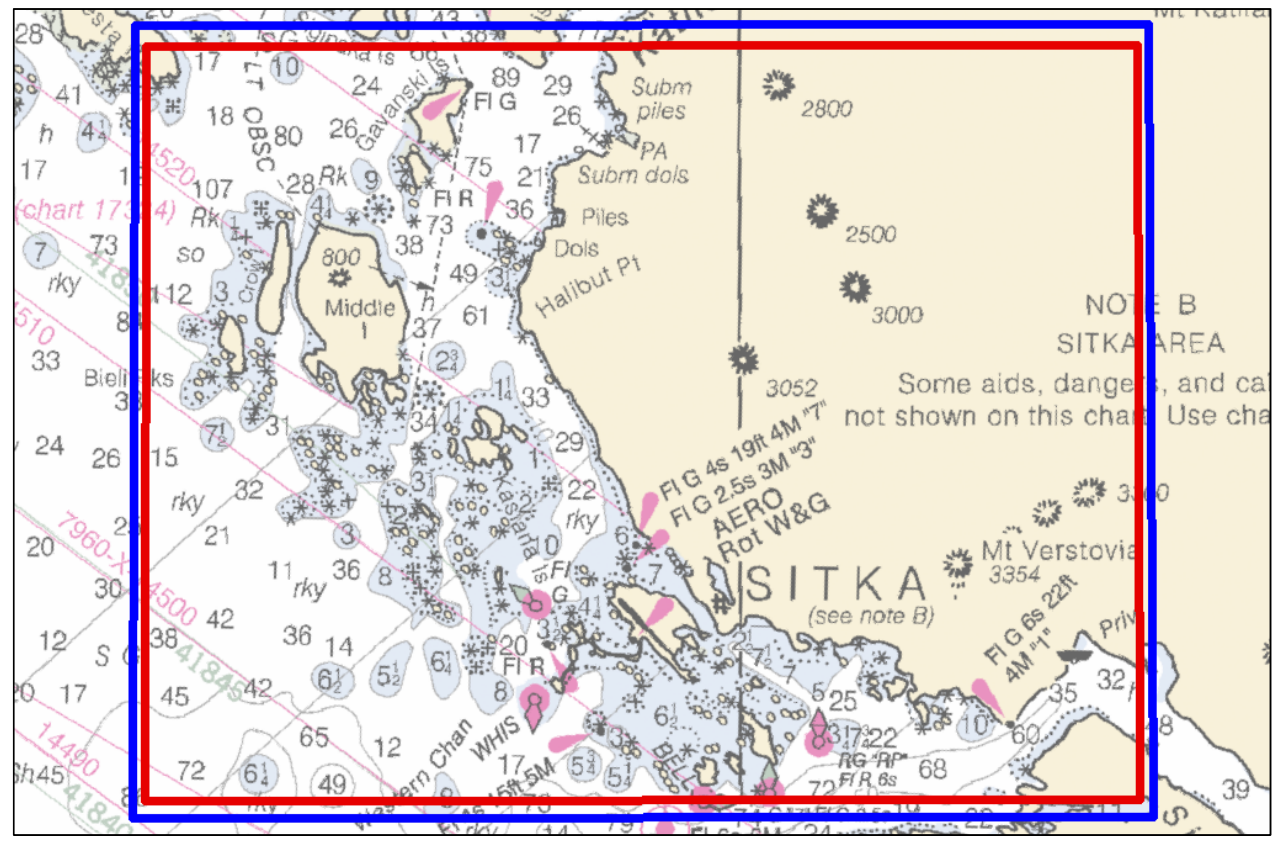




\section{Coastline Data}

Placement of the coastline is one of the most important components of coastal DEM development. This is especially true for the purpose of tsunami inundation mapping since the coastline separates two essentially different types of datasets: topography and bathymetry. Three digital coastline datasets were evaluated for use in this project. These are described below. The evaluation process entailed visual inspection of each coastline dataset overlaid upon a digital orthophoto mosaic obtained from the City and Borough of Sitka.

\section{USFWS Alaska Statewide Coastline}

The first coastline dataset we evaluated we received from NGDC. It was in ESRI Shapefile format and contained line-vector geometry in the Geographic Coordinate System referenced to the WGS84 horizontal datum. According to the metadata for this dataset, it was created by the USFWS for the purpose of providing a detailed coastline for the entire State of Alaska. It is intended for use in general mapping and resource analysis (USFWS, 2006). The tidal datum for this dataset is not specified in the metadata. Upon visual inspection, this dataset was determined to be unusable for this project without extensive manual editing (fig. 4).

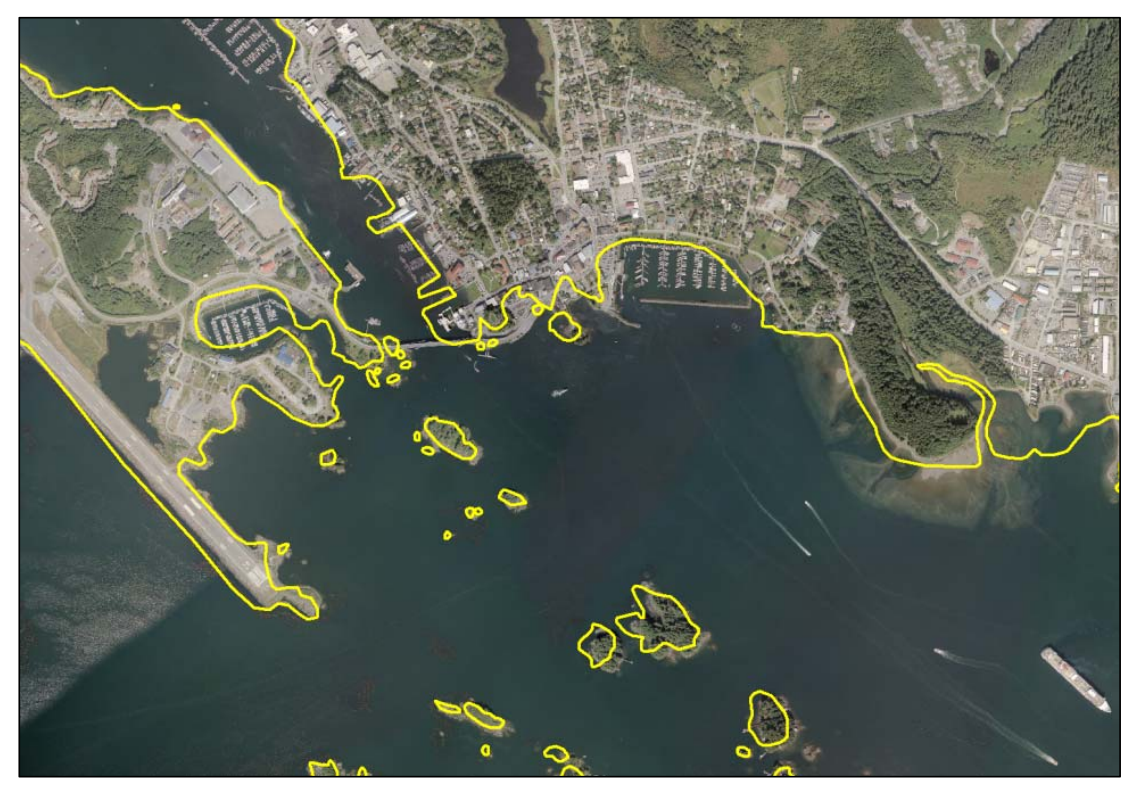

Figure 4. U.S. Fish \& Wildlife Service (USFWS) Statewide Alaska Coastline (yellow line) overlaid on the City and Borough of Sitka digital orthophoto mosaic.

\section{Electronic Nautical Chart (ENC)}

The second potential coastline dataset we evaluated was the Electronic Nautical Chart (ENC) of the study area. Like the USFWS coastline dataset, this was also obtained from NGDC in ESRI Shapefile format. These shapefiles contained line-vector geometry in the Geographic Coordinate System referenced to the WGS84 horizontal datum. A review of the Office of Coast Survey (OCS) ENC format online

(http://shoreline.noaa.gov/data/datasheets/ocsshore.html) revealed that features in this format are originally drawn in reference to the Mean High Water (MHW) vertical datum. We visually evaluated this dataset and found it to be in much better agreement with the digital orthophotos than was the USFWS coastline, but it contained large gaps where there was no data at all. These would also require manual editing to correct (fig. 5), making this dataset less desirable for use in this project. 


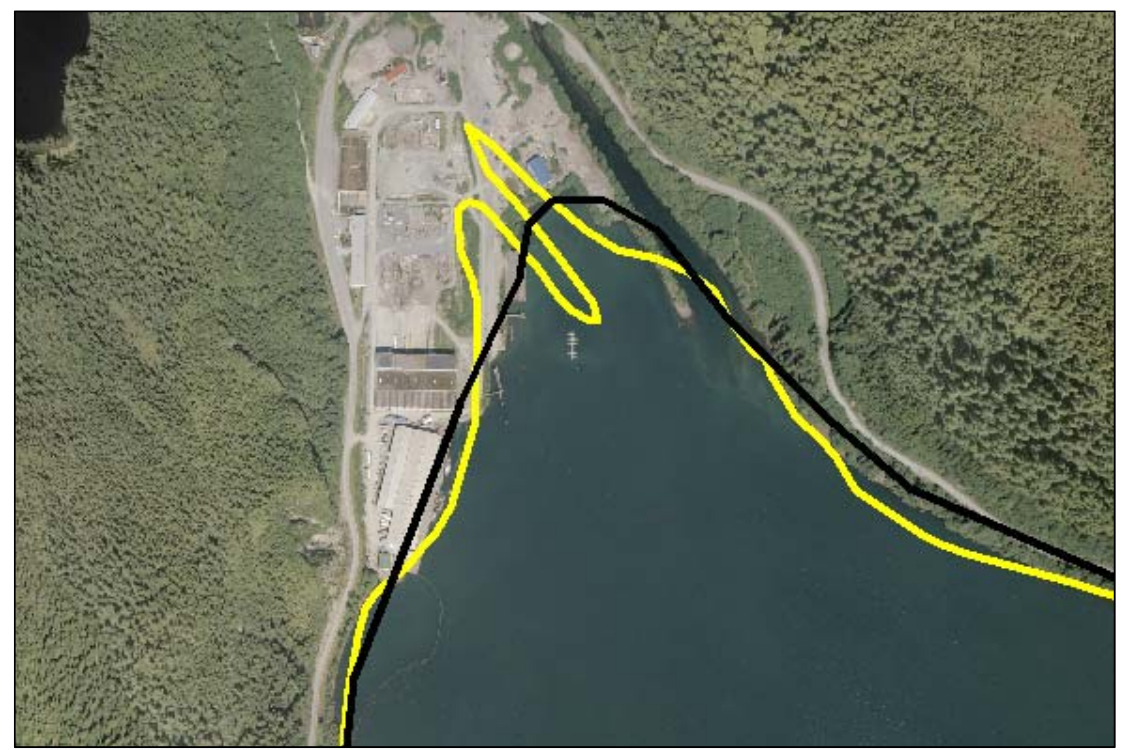

Figure 5. Comparison of the Office of Coast Survey (OCS) Electronic Nautical Chart (ENC) coastline dataset (black line) and the U.S. Fish \& Wildlife Service (USFWS) coastline dataset (yellow line).

\section{Delta Aerial Surveys, Ltd. Triangulated Irregular Network (TIN)}

We discovered the third source of digital coastline data during our review of potential data resources. Early on in the project startup, data had been obtained from the City and Borough of Sitka that included a Digital Terrain Model (DTM) developed by Delta Aerial Surveys, Ltd. The DTM was originally constructed to orthorectify the city's 2003 digital aerial photography. The DTM came packaged with a Triangulated Irregular Network (TIN) containing hard breaklines, one of which corresponded to 0.00 elevation. Our visual inspection of this breakline overlaid on the digital orthophotos revealed that it is by far our best available coastline. Further, according to the metadata for this dataset, this 0.00 elevation breakline is the result of photogrammetric interpretation of the Mean Higher High Water (MHHW) line (fig. 6).

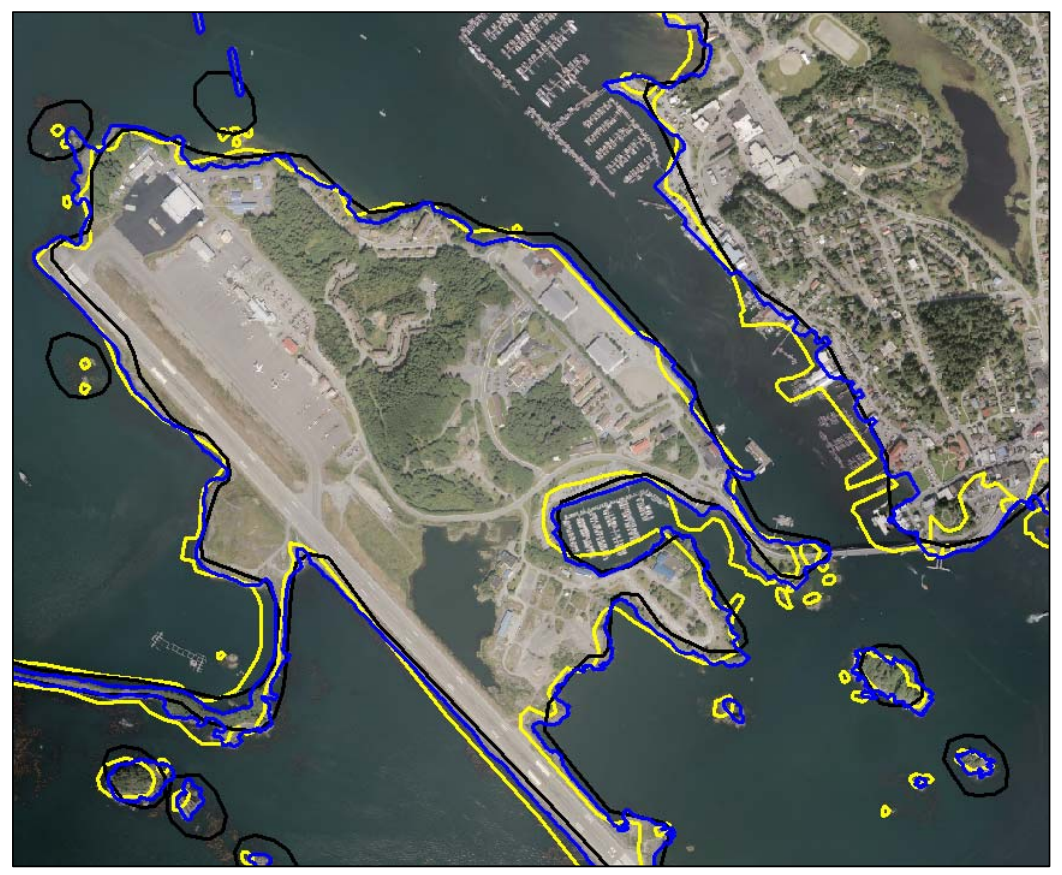

Figure 6. Comparison of the 0.00 elevation hard breakline extracted from the Delta Aerial Surveys, Ltd. DTM (blue line), the OCS ENC coastline dataset (black line), and the USFWS coastline dataset (yellow line). 
However, because the 2003 city of Sitka digital orthophoto mosaic extends out only a short distance from the shore and the DTM was built to support the orthorectification of the aerial photos, the coastline dataset we generated by extracting the 0.00 elevation hard breakline from the DTM TIN lacked most of the more than 250 islands within the study area, including most of Japonski Island. We decided to screen-digitize all islands containing infrastructure, and after that, accept the USFWS coastline for the rest of the islands within the study area that were missed by the DTM (fig. 7).

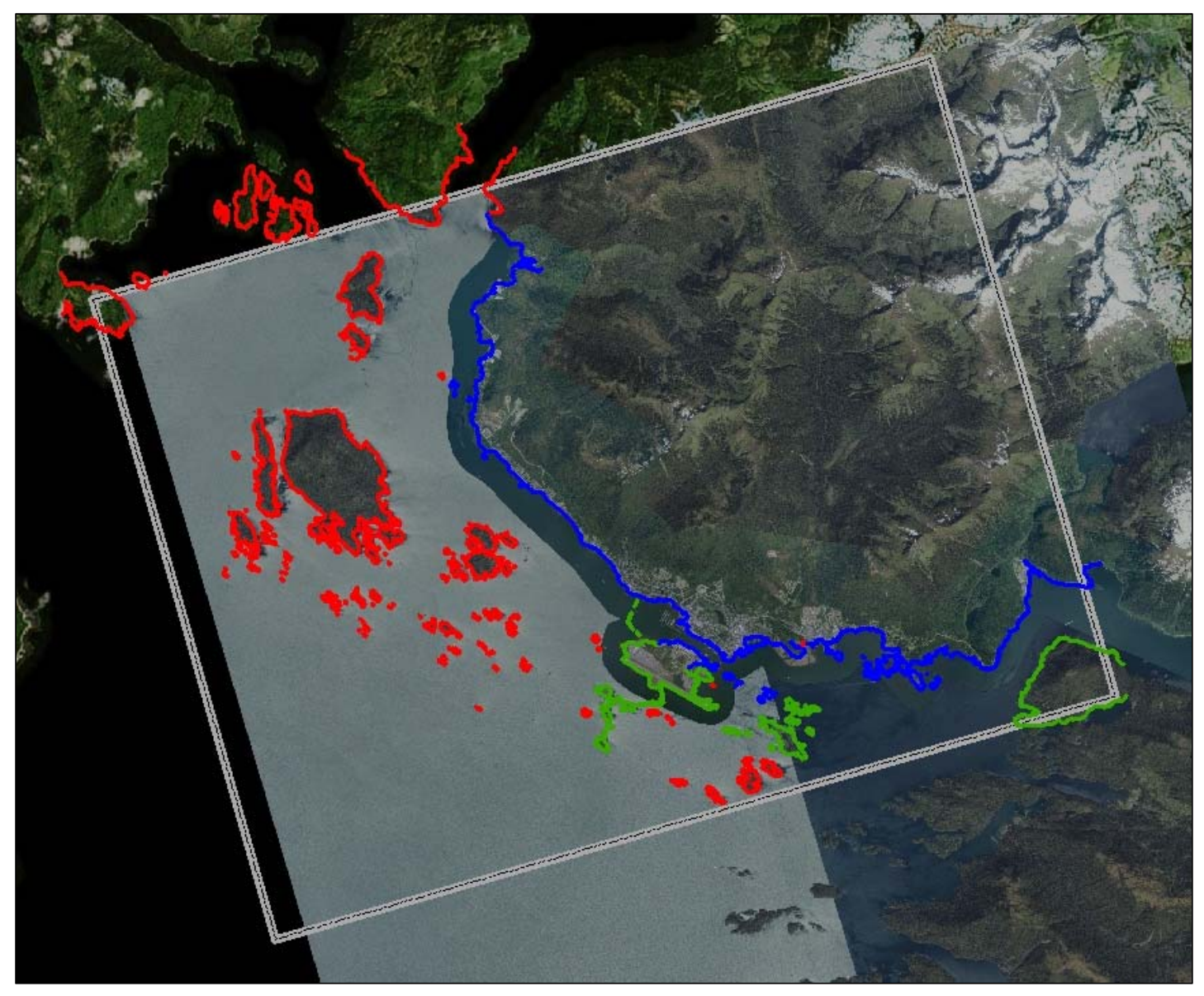

Figure 7. Map showing the coverage limit of the extracted 0.00 elevation Delta Aerial Surveys, Ltd. Triangulated Irregular Network (TIN) breakline (blue line), Alaska Earthquake Information Center (AEIC)(screen-digitized; green line), and USFWS coastline datasets (red line). We used the Statewide Digital Mapping Initiative (SDMI) Web Map Service (WMS) "Best Data Layer" (http://www.alaskamapped.org), produced by GINA, to underlay the City and Borough of Sitka orthophoto mosaic as the basis for screen-digitization of human populated islands missed by the Delta Aerial Surveys, Ltd. DTM and the city's orthophotos.

We merged the selected digital coastline datasets described in the sections above into a final coastline shapefile. We then divided this line at $1 \mathrm{~m}$ intervals and plotted points at the ends of each interval. We used the ArcGIS Add-X-Y-Coordinates tool to calculate the latitude and longitude coordinate and then assigned a value of 0.00 for the elevation of each point. We used FME software to generate a comma-delimited text file from the shapefile. Each line of text in this file represents a single point feature of the shapefile and lists the $\mathrm{x}$ (longitude of the point), $y$ (latitude of the point) and $\mathrm{z}$ (elevation of the point). This process resulted in 203,140 coastline data points, each with longitude and latitude in reference to the WGS84 horizontal datum and an elevation value of 0.00 in reference to the MHHW vertical datum (fig. 8). 


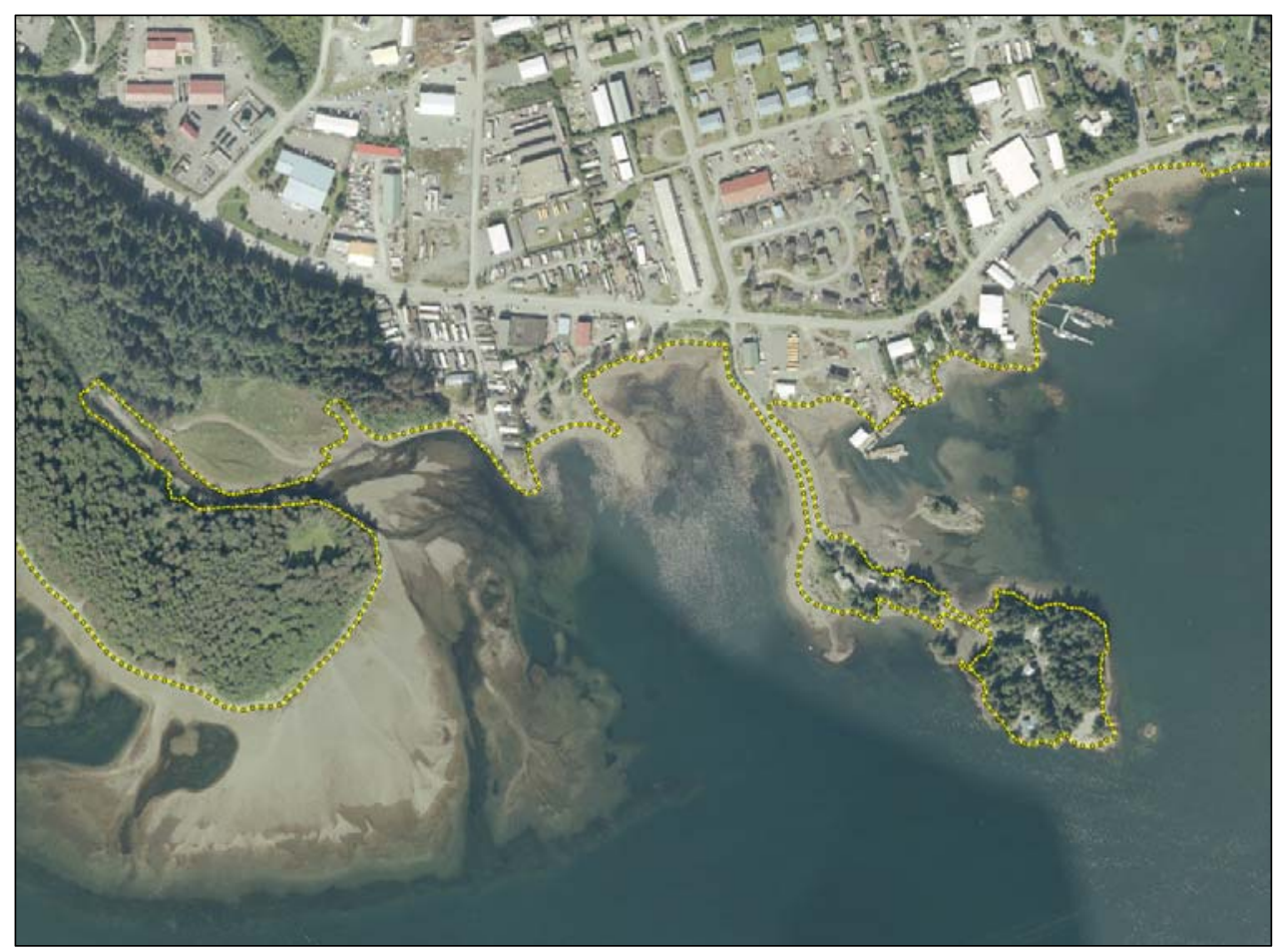

Figure 8. Orthophoto showing a subsample of every tenth point in the final coastline shapefile used to generate the longitude, latitude, and 0.00 elevation values at each point. This final coastline was used in the DEM development process to precisely define the locations where bathymetry datasets meet topography datasets.

\section{Bathymetry Data}

NGDC provided all hydrographic survey datasets used in this project. These datasets had been pre-processed to include conversion from raw sonar format (such as *.mb41) into text files containing three comma- or spacedelimited columns of $\mathrm{x}$ (longitude in decimal degrees), $\mathrm{y}$ (latitude in decimal degrees) and $\mathrm{z}$ (depth value in meters). NGDC pre-processing also entailed geographic transformation of these datasets into one common horizontal datum of World Geodetic System 1984 (WGS84) and one common vertical datum of Mean Higher High Water (Pamela Grothe, oral commun.) (Appendix B). Table 1 provides an overview of the broad range of spatial resolutions and timeframes of these surveys. Detailed documentation of the methods NGDC used to convert these survey datasets into a common file format, coordinate system, and horizontal and vertical datum, can be found in the NGDC report summarizing the development of a similar DEM product for Prince William Sound, Alaska (Caldwell, and others, 2011).

Table 1. Summary of the hydrographic survey datasets provided by NGDC listing the range of spatial resolutions and the range of dates of these datasets.

\begin{tabular}{|l|l|l|l|}
\hline \multicolumn{1}{|c|}{ Source } & \multicolumn{1}{c|}{ Data Type } & \multicolumn{1}{c|}{ Dates of Surveys } & \multicolumn{1}{c|}{ Spatial Resolution } \\
\hline NGDC & NOS & From 1924 to 2008 & From $<10 \mathrm{~m}$ to $>1 \mathrm{~km}$ \\
\hline NGDC & Multibeam & From 2004 to 2009 & Gridded to $50 \mathrm{~m}$ \\
\hline USACE & Hydrographic Surveys & From 2001 to 2008 & From $0.1 \mathrm{~m}$ to $100 \mathrm{~m}$ \\
\hline NGDC & Trackline & From 1971 to 1977 & $\begin{array}{l}\text { From several meters to several } \\
\text { kilometers }\end{array}$ \\
\hline NGDC & ENC & From 1977 to 2009 & $\begin{array}{l}\text { From several meters to several } \\
\text { kilometers }\end{array}$ \\
\hline
\end{tabular}




\section{Types of Surveys}

\section{U.S. Army Corps of Engineers (USACE) hydrographic surveys}

Seven high-resolution USACE hydrographic surveys of Sitka's harbors, breakwaters, and bathymetry surrounding the breakwaters, were evaluated for use in developing this 8/15 arc-second DEM. Dates of these surveys ranged from 2001 to 2009. The horizontal spatial resolution of these surveys ranged from $\sim 0.3$ to $1.5 \mathrm{~m}$ point spacing. When combined, these surveys contained a total of 41,194 bathymetry data points, which ranged in depth from -0.11 to $-21.23 \mathrm{~m}$ below MHHW.

\section{National Ocean Service Bathymetric Attributed Grid (NOS BAG) surveys}

Nineteen NOS BAG surveys were evaluated for use in developing this DEM. The dates of these surveys ranged from 2004 to 2009. The average data-point spacing of these surveys ranged from $\sim 3$ to $10 \mathrm{~m}$ horizontally, while depth values ranged from -3.5869 to $-169.241 \mathrm{~m}$ below MHHW. Combined, these surveys contained a total of 1,530,252 bathymetry data points.

\section{NOS hydrographic surveys}

We evaluated 44 NOS surveys, dating from 1924 to 2004, for use during development of this DEM. The horizontal data-point spacing of these surveys ranged from $\sim 10 \mathrm{~m}$ to $>1 \mathrm{~km}$. Depth values for these surveys ranged from -0.0759 to -208.0201 meters below MHHW. We used 240,600 of these data points in the development of this DEM.

\section{NGDC multibeam swath sonar surveys}

We evaluated two multibeam swath sonar surveys provided by NGDC. The survey collected by the U.S. Coast Guard Cutter Healy did not contain any data points within the study area boundary (fig. 3). The other survey, collected by the Research Vessel Ewing during 2004, contained only 4,533 data points that fall within study area boundary. These data points are uniformly spaced at $50 \mathrm{~m}$ along longitude and $90 \mathrm{~m}$ along latitude, with depth values ranging from -29.94 to -212.1 m below MHHW.

\section{NGDC Trackline and NOAA Electronic Navigational Chart (ENC) soundings}

We evaluated two trackline surveys for use in developing this DEM. None of the data points from either trackline survey fell within the study area boundary. We also evaluated 33 ENC files, but these were all overlapped by higher quality or more current survey datasets. As a result, neither trackline nor ENC datasets were used to develop the DEM.

\section{Bathymetric Pre-surface Interpolation}

Following NGDC best practices (Caldwell and others, 2010), the first step in coastal DEM development is to smooth the hydrographic survey data. Smoothing of the hydrographic survey data is done by first constructing what is termed a bathymetric pre-surface. The purpose of the bathymetric pre-surface is to fill in areas where there may be very sparse bathymetric survey data (for example, the point spacing of some ENC-based datasets may be as large as $1.5 \mathrm{~km}$ ). The bathymetric pre-surface also fills in the inter-tidal zone, which often lacks survey points because shallow water restricts access to this zone by boat or ship. We used Generic Mapping Tools (http://www.soest.hawaii.edu/gmt/, GMT), a command-line open-source geo-processing toolkit, to generate an interpolated grid based on hydrographic survey datasets. NGDC provided the GMT script used to create the bathymetric pre-surface. A detailed description of the geo-processing the script performs can be found in the final report, "Digital Elevation Models of Southeast Alaska” (Caldwell and others, 2010).

We used all available hydrographic survey datasets to construct the first version of the bathymetric pre-surface. As well as conducting an internal quality assessment, we sent this version to NGDC for review and approval. Careful review of this dataset revealed the following three types of errors: (A) gridding errors, (B) banding or striping errors, and (C) errors in source survey data (fig. 9). 


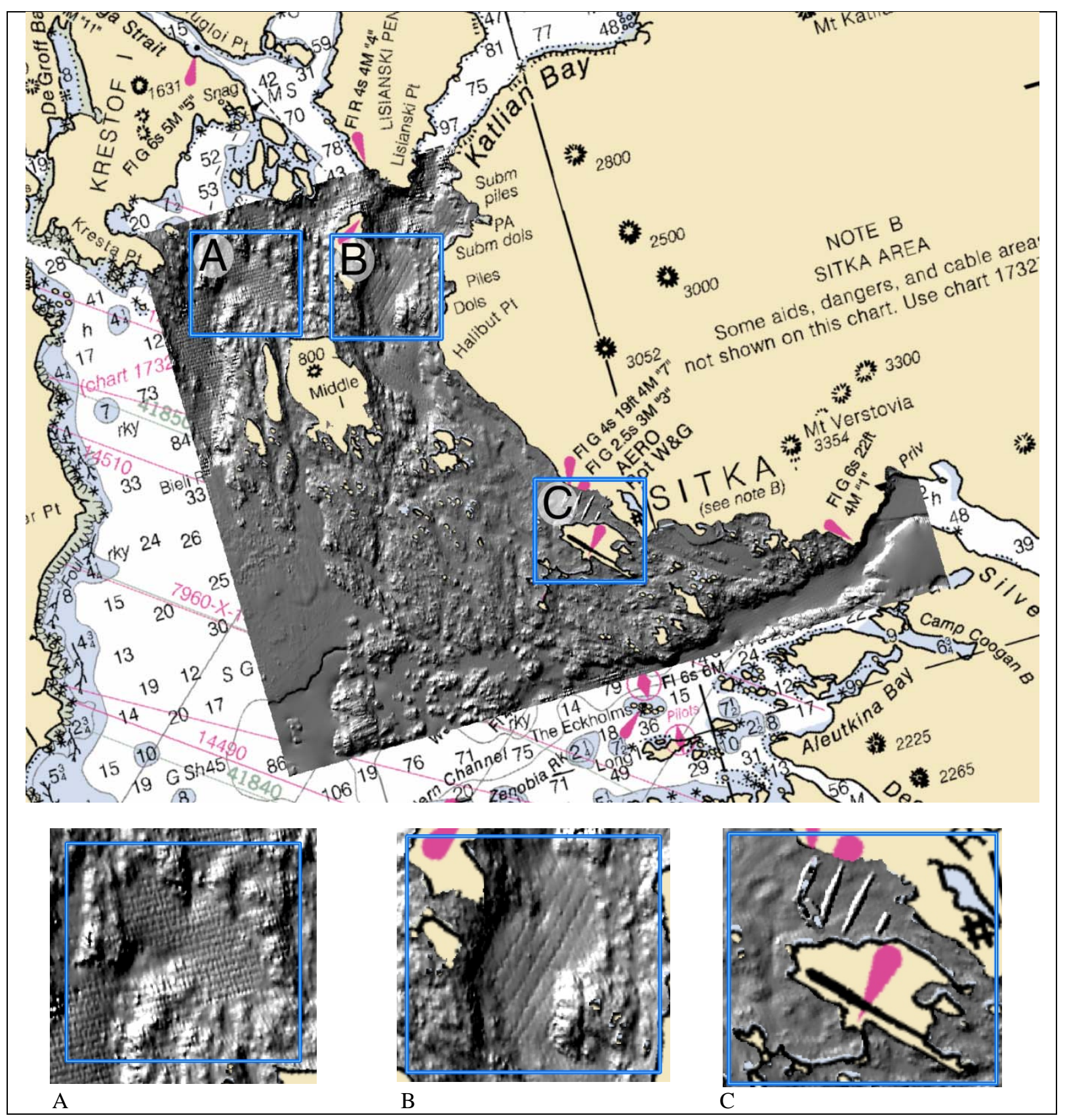

Figure 9. Top: Shaded-relief map of the result of the first iteration bathymetric pre-surface of Sitka Harbor and Sitka Sound. All hydrographic survey datasets were incorporated in this iteration. The resulting grid was reviewed internally by the AEIC/GINA team for quality assessment, as well as sent to NGDC for comment. Bottom: Inset photos $A, B$, and $C$ are larger-scale examples of the three types of interpolation errors identified by our review: gridding errors, stripping or banding error, and errors in survey data.

Consultation with NGDC led to our decision to simply discard data considered to be erroneous (for example, one survey was found to contain features in Sitka Harbor that are not supported by ancillary data). NGDC also suggested removal of overlap from among individual surveys. To accomplish the removal of overlapping data points, each hydrographic survey was brought into ArcGIS (http://www.esri.com) to spatially select and remove all overlap between surveys. Only points from surveys of the most current date and highest spatial resolution were retained (fig. 10). This process resulted in total count of 5,196,606 non-overlapping hydrographic survey data points. We then used GMT to generate another bathymetric pre-surface grid. Figure 11 depicts the areas 
where errors that were identified in the first iteration have been corrected in the second iteration. Appendix A contains a tabular listing of all hydrographic surveys used to generate the final bathymetric pre-surface.

Upon approval of the bathymetric pre-surface, we converted the grid to a point shapefile using the Raster-toPoint tool in ArcGIS. This tool calculates the centroid of each cell of an input raster and places a point feature at that location. Additionally, the tool adds an attribute field to the shapefile table containing the raster's cell value.

We then calculated the longitude and latitude for each point feature using the ArcGIS Add-X-Y-Coordinate tool. The resulting shapefile contained 972,743 points features uniformly spaced at 8/15 arc-second intervals; each attributed with an X and Y geographic coordinate in the WGS84 horizontal datum and the Z depth value in the MHHW vertical datum. We then used FME software to convert the point shapefile into a comma-delimited textfile with the .xyz file extension. This is the format we used to input bathymetric data into MB-Systems software (http://www.ldeo.columbia.edu), which we used later in the project to interpolate the seamless 8/15 arc-second bathymetric-topographic DEM.

The above-described stepwise process of (1) creating a point shapefile from a raster DEM using the ArcGIS Raster-to-Point tool, (2) projecting this point shapefile into the Geographic Coordinate System referenced to the WGS84 horizontal datum, (3) ensuring depth or elevation values are referenced to the MHHW vertical datum, (4) calculating the longitude and latitude for each point using the ArcGIS Add-X-Y-Coordinate tool, and (5) using FME software to generate a comma-delimited XYZ text file from the shapefile, was used repeatedly throughout the project and will be referred to for the remainder of this report as the DEM2XYZ process.

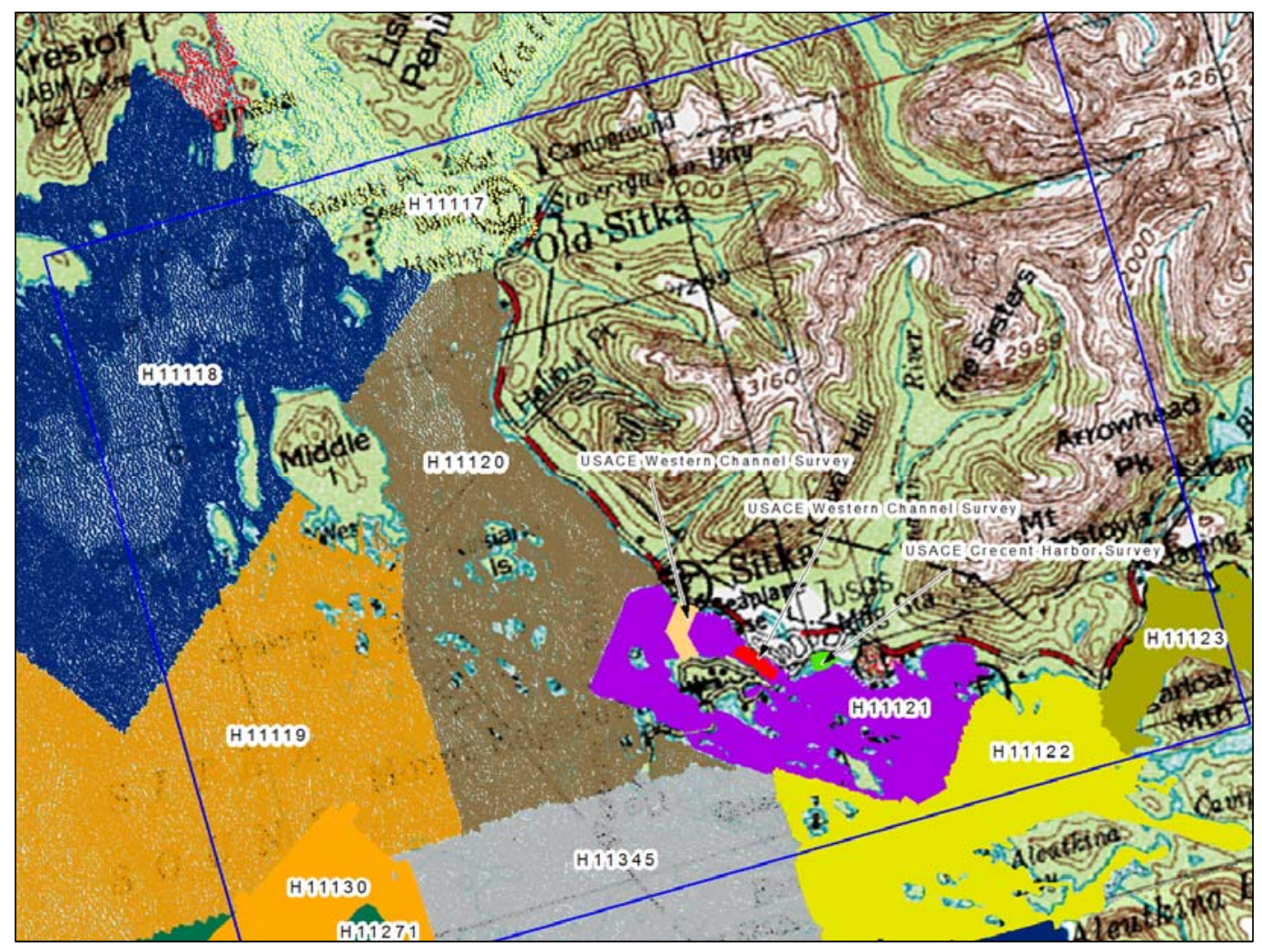

Figure 10. Map showing survey coverage after removal of overlap. All surveys used to create the final bathymetric pre-surface are labeled on this map by the survey name. 


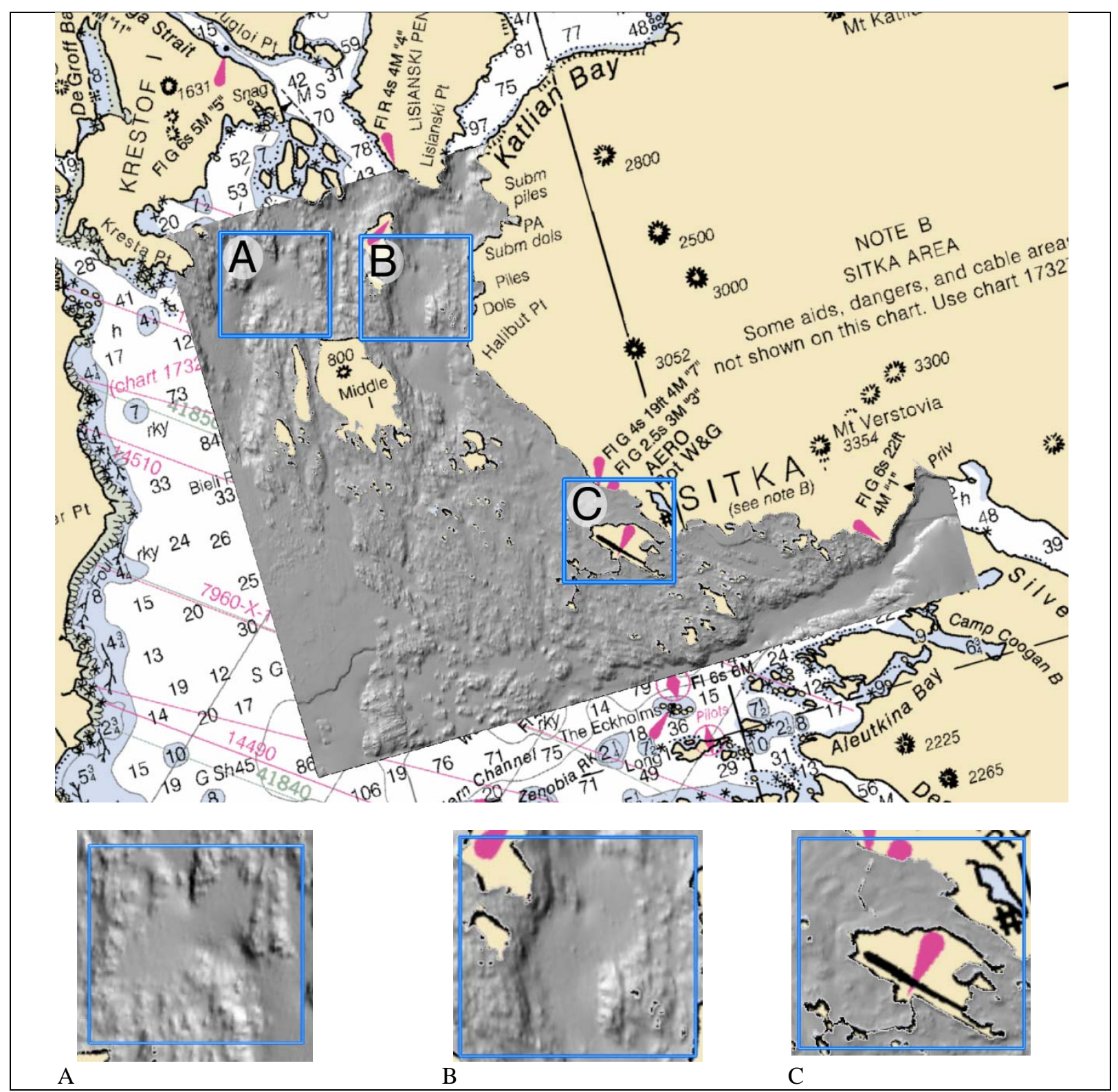

Figure 11. Top: Shaded-relief map of second iteration bathymetric pre-surface of Sitka Harbor and Sitka Sound. Only non-overlapping hydrographic survey data points of the most current date and highest spatial resolution were incorporated into this iteration. Bottom: Inset A demonstrates correction of gridding errors identified in the first iteration grid. Inset B shows correction of the stripping errors that were identified in the first iteration grid. Inset $C$ illustrates correction of the bathymetric pre-surface after discarding erroneous data points (removal of non-existent features). 


\section{Topography Data}

We evaluated several sources of topographic data for use in this project. In the end, six topographic data sources were selected: (1) Delta Aerial Surveys, Ltd. 2003 Digital Terrain Model (DTM), (2) NASA ASTER GlobalDEM (http://asterweb.jpl.nasa.gov), (3) NASA Shuttle Radar Topography Mission DEM (SRTM, http://www.jpl.nasa.gov/srtm), (4) Alaska Department of Transportation \& Public Facilities (DOTPF) Survey Control and Monument point data, (5) U.S. Army Corps of Engineers (USACE) topographic surveys, and (6) manually digitized elevation points. Figure 12 shows the approximate spatial coverage of these datasets. The rest of this section contains a discussion of the processing steps we performed to make each dataset suitable for use in the construction of the 8/15 arc-second bathymetric-topographic grid.

\section{Delta Aerial Surveys, Ltd. DTM}

The Delta Aerial Surveys, Ltd. DTM we used earlier to generate the final coastline also came packaged with a 3D point shapefile (figs. 13 and 14). According to the metadata for this dataset, it was photogrammetrically derived in reference to the Alaska State Plane, Zone 1 Projection, NAD83 horizontal datum in U.S. survey feet with elevation in reference to the Mean Lower Low Water (MLLW) vertical datum.

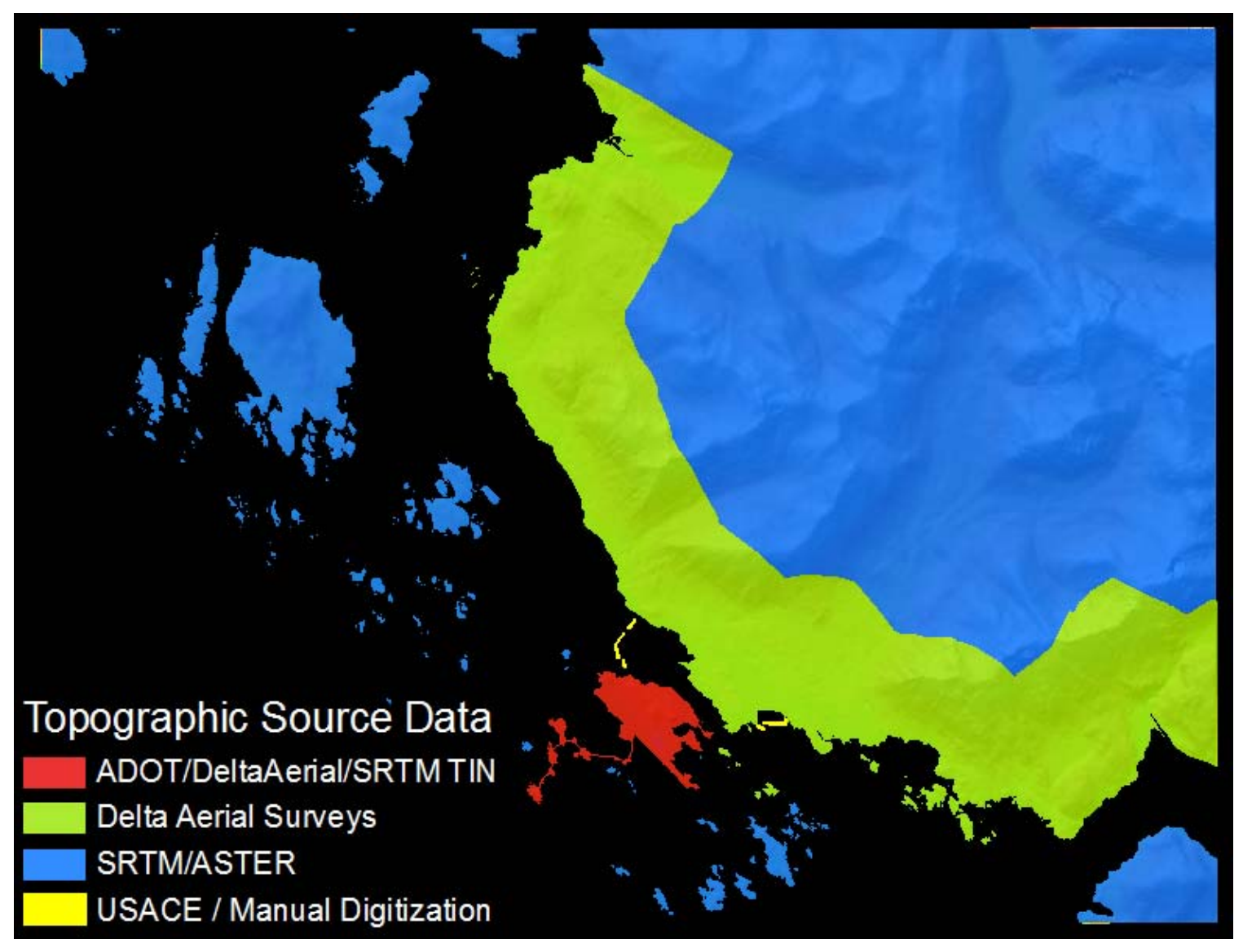

Figure 12. Map showing approximate coverage of topographic data sources used to build the 8/15 arc-second bathymetric-topographic DEM. 


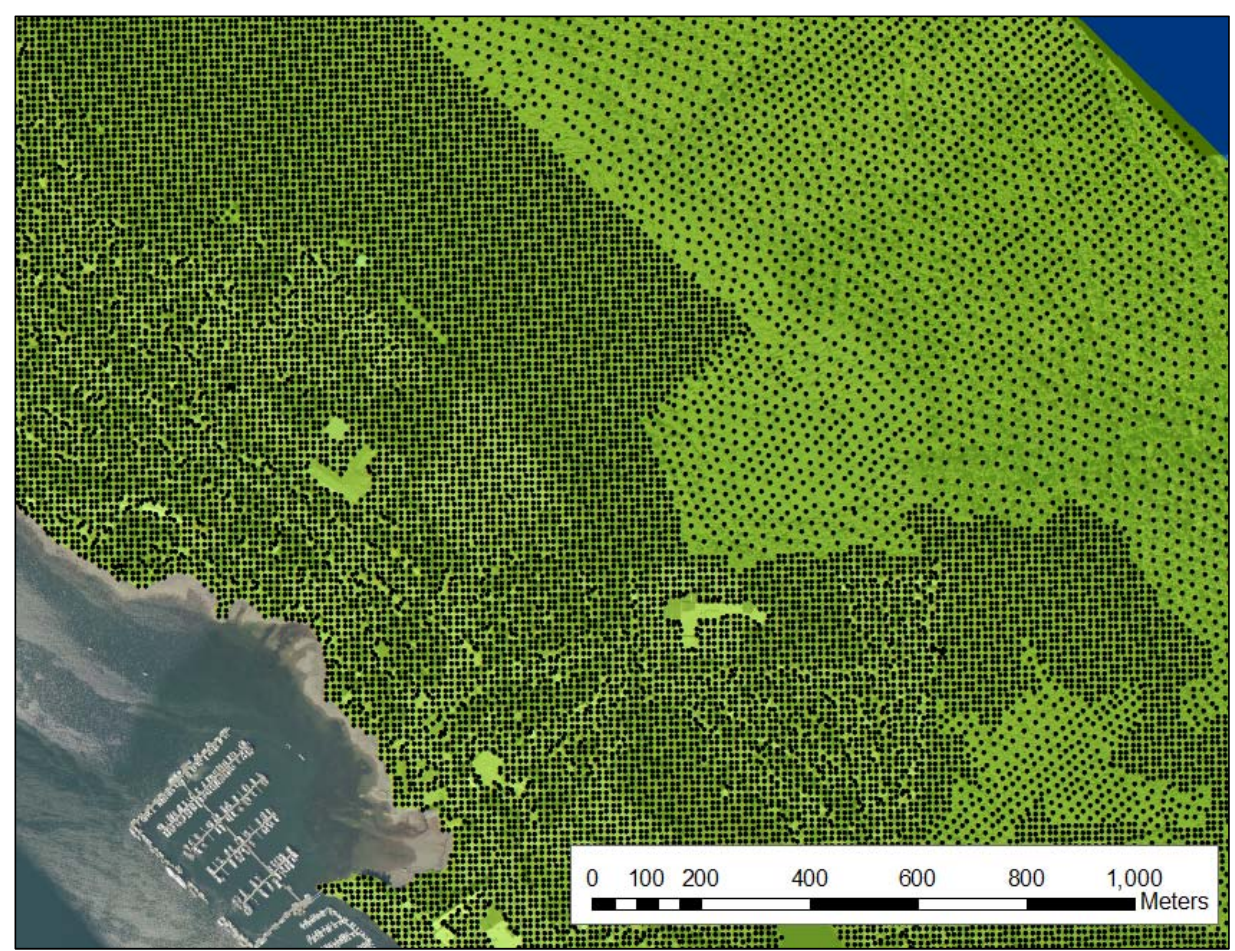

Figure 13. Horizontal distribution of Delta Aerial Surveys, Ltd. photogrammetrically derived topographic data points.

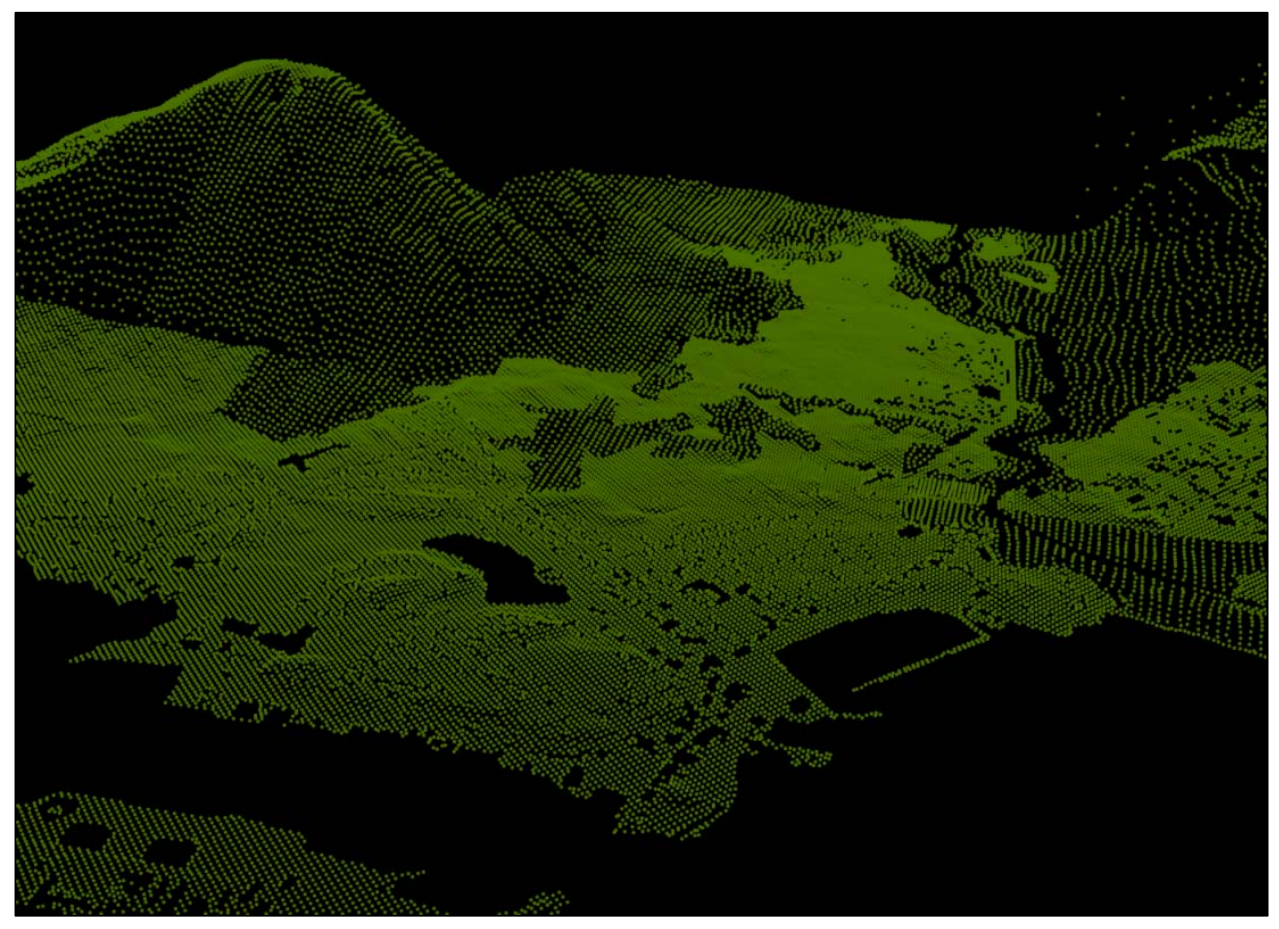

Figure 14. Vertical distribution of Delta Aerial Surveys, Ltd. photogrammetrically derived topographic data points. 
Because the elevations of features in 3D shapefiles are properties of the shapefile geometry and are not included as values in the attribute table, these values had to be manually extracted. We used ArcGIS 3D Analyst FeatureClass-to-ASCII to create an output comma-delimited text file in XYZ format containing the elevation values of each point. As units for these values were still in feet referenced to the MLLW vertical datum, we divided these values by a factor of 3.2808 to convert them to meters. We then subtracted the difference between MLLW and MHHW specific to Sitka, 3.029 meters according to the NOAA Tidal Station Benchmark Sheet for Sitka (Appendix B, http://tidesandcurrents.noaa.gov), to convert them from MLLW to MHHW. Using ArcGIS, we projected this dataset into the Geographic Coordinate System referenced by the WGS84 horizontal datum specifying the "From_NAD_1983_To_WGS_1984_5” geographic transformation parameter (http://resources.arcgis.com/content/kbase?fa=articleShow\&d=21327). We calculated the longitude and latitude coordinates using the ArcGIS Add-X-Y-Coordinates tool.

\section{ASTER Global DEM}

One limitation of the Delta Aerial Surveys, Ltd. dataset was that it covered only a portion of the DEM boundary (fig. 12). Therefore, we had to find additional topographic data to finish the project.

We obtained a version of NASA's ASTER GDEM dataset via the Alaska Statewide Digital Mapping Initiative (SDMI, http://www.alaskamapped.org) Web Coverage Service (WCS, http://wms.alaskamapped.org/wCs). Using ArcGIS, we were able to bring the WCS directly into ArcMap as a layer, then subset the WCS to the DEM boundary (fig. 3) and store it locally in the GeoTIFF raster format. We visually evaluated the subset ASTER DEM by generating and reviewing a shaded-relief map of the dataset (fig. 15). This dataset was found to have very poor coastline representation and numerous data artifacts commonly referred to as 'worm tracks', so we assigned a low priority to this dataset in terms of its usefulness in this project.

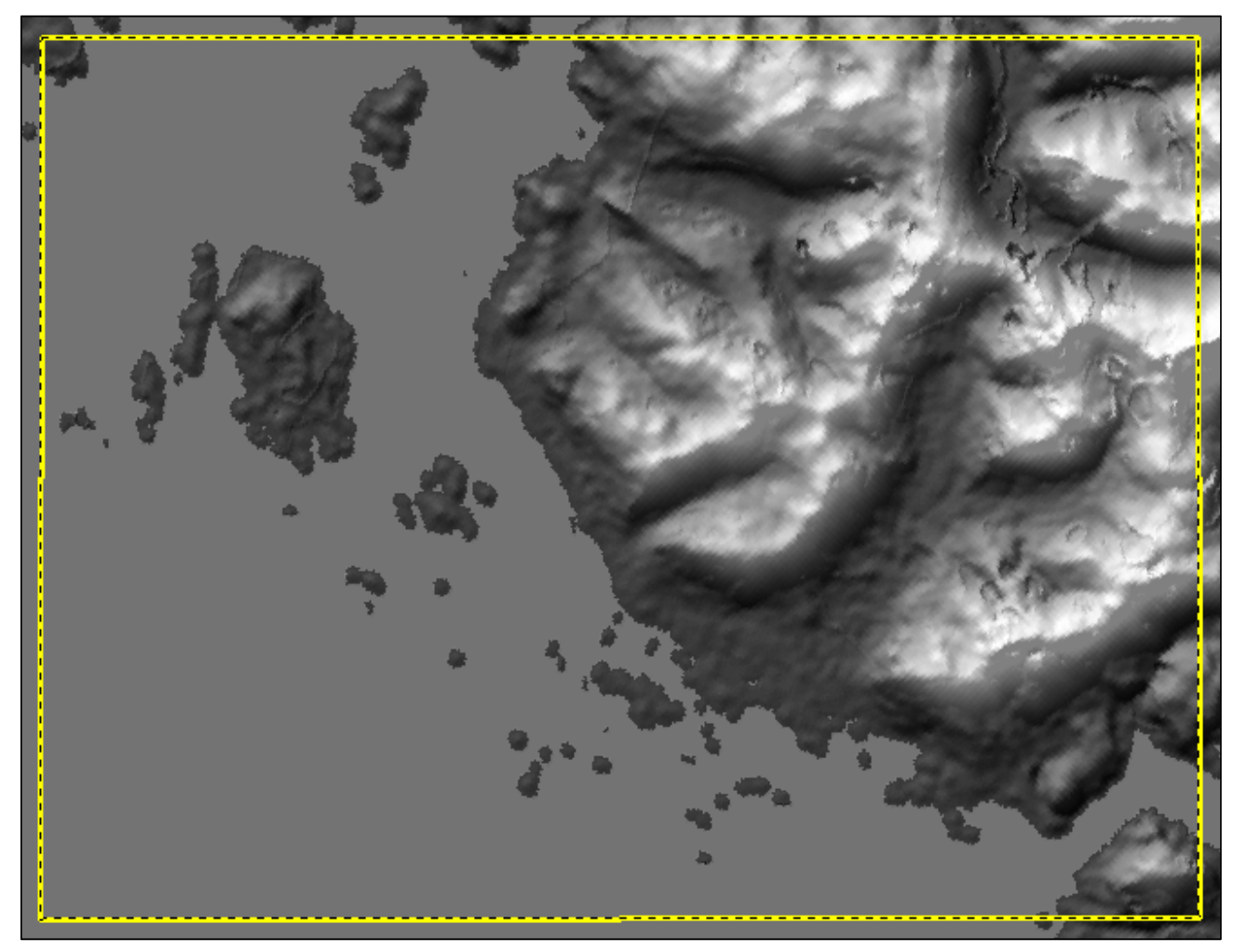

Figure 15. Shaded-relief model of the ASTER GDEM WCS subset. 
The Geographic Information Network of Alaska (GINA) produces and hosts the SDMI ASTER GDEM WCS. One of the steps that GINA performs during the production of this WCS is to re-project the original raw ASTER data-tiles into the Alaska Albers Equal Area Conic map projection, NAD83 horizontal datum with map units in meters (the approved statewide map projection of the State of Alaska,

http://mms.gina.alaska.edu/supp/StandardMapProjection.doc). This is done using GDAL software and specifying 'nearest neighbor' as the resampling technique. The result is that the resampled SDMI ASTER GDEM WCS is of a horizontal resolution of $17.61 \mathrm{~m}$ in contrast to the original ASTER GDEM resolution of one arc-second. Since there is nothing done to manipulate the elevation posting values during resampling, the SDMI ASTER GDEM is still referenced to the original vertical datum of Earth Gravitational Model 1996 (EGM96). EGM96 is a geoid model that represents the surface of the Earth's gravitational equipotential (http://www.ngs.noaa.gov/GEOID/geoid def.html). Geoid models are commonly assumed to be equivalent to the Mean Sea Level (MSL) tidal datum. In order to use this dataset, we converted its elevation values from the MSL vertical datum to the MHHW vertical datum, and reprojected it to the Geographic Coordinate System referencing the WGS84 horizontal datum.

\section{Shuttle Radar Topography Mission (SRTM) DEM}

We also obtained a version of NASA's SRTM DEM Version 2 dataset via the SDMI WCS as described in the "Delta Aerial Survey, Ltd. DTM" section above. We processed this dataset in exactly the same way that we processed the SDMI ASTER GDEM WCS, to include subsetting to the DEM boundary. The SDMI SRTM WCS is also produced and hosted by GINA and undergoes the same pre-processing steps as the SDMI ASTER GDEM WCS. The result is that the horizontal spatial resolution has been resampled to $21.01 \mathrm{~m}$.

A significant disadvantage of SRTM data is the presence of large "NoData" holes located predominantly on hilltops and mountain peaks (fig. 16). An advantage of the SRTM DEM is that it is free from 'worm-track' data artifacts. Another advantage of the SRTM DEM is that both the National Geospatial Intelligence Agency (NGA), and the U.S. Geological Survey (USGS) have extensively edited version 2 of the SRTM DEM to better define the coastline (http://dds.cr.usgs.gov/srtm/version2_1/Documentation/SRTM_Topo.pdf).

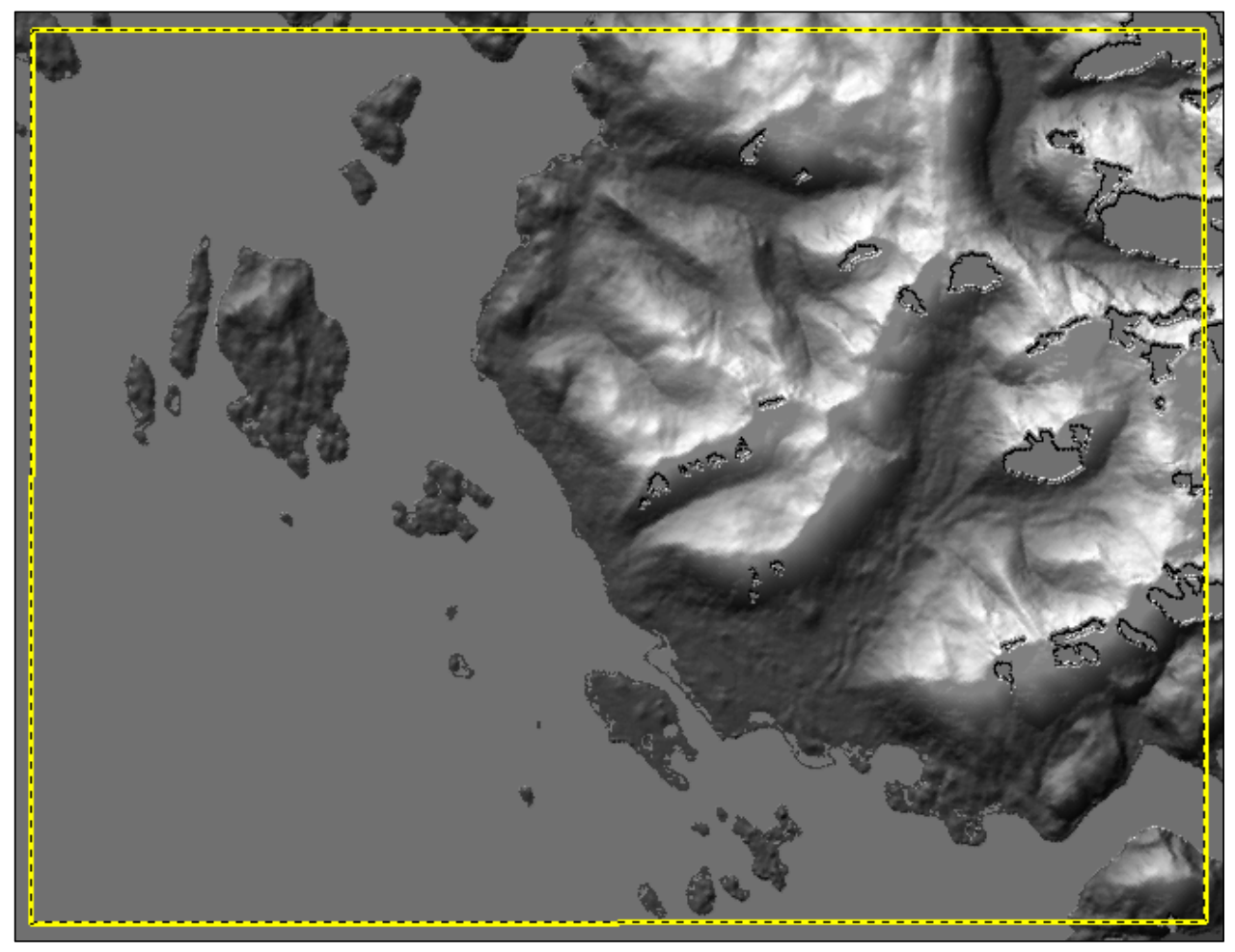

Figure 16. Shaded-relief model of SRTM DEM coverage used for visual evaluation. 
Barring the "NoData" holes, our visual evaluation of the SRTM DEM is that it provides a better overall definition of the topography and coastline of the study area than does the ASTER GDEM. Also, since the goal of this project is to construct an 8/15 arc-second DEM for use primarily in modeling tsunami wave inundation, and since the lowest elevations of the "NoData" holes in the SRTM DEM within the study area occur at $250 \mathrm{~m}$ above MHHW, we placed little importance on filling these "NoData" holes.

\section{SRTM/ASTER DEM Mosaic}

Even though the "NoData" holes in the SRTM DEM were of no significance to numerical tsunami modeling as discussed in the previous section, we chose to fill in these "NoData" holes by replacing them with values extracted from the ASTER GDEM. To do this, we first made a mask of the "NoData" holes in the SRTM DEM. We then used the ArcGIS Spatial Analyst "Expand" tool to grow the area of each "NoData" hole by 5 pixels in width. Next, using the mask, we were able to subset a version of the ASTER GDEM containing data only within the areas of the mask. We then mosaicked the SRTM DEM and the ASTER GDEM subset into a new SRTM/ASTER DEM mosaic, specifying that the mean value of the overlapping 5 pixels from the SRTM DEM and the underlying ASTER GDEM pixels became the new elevation value of the output DEM, and the "maximum of inputs" parameter as the output DEM cell size (fig. 17).

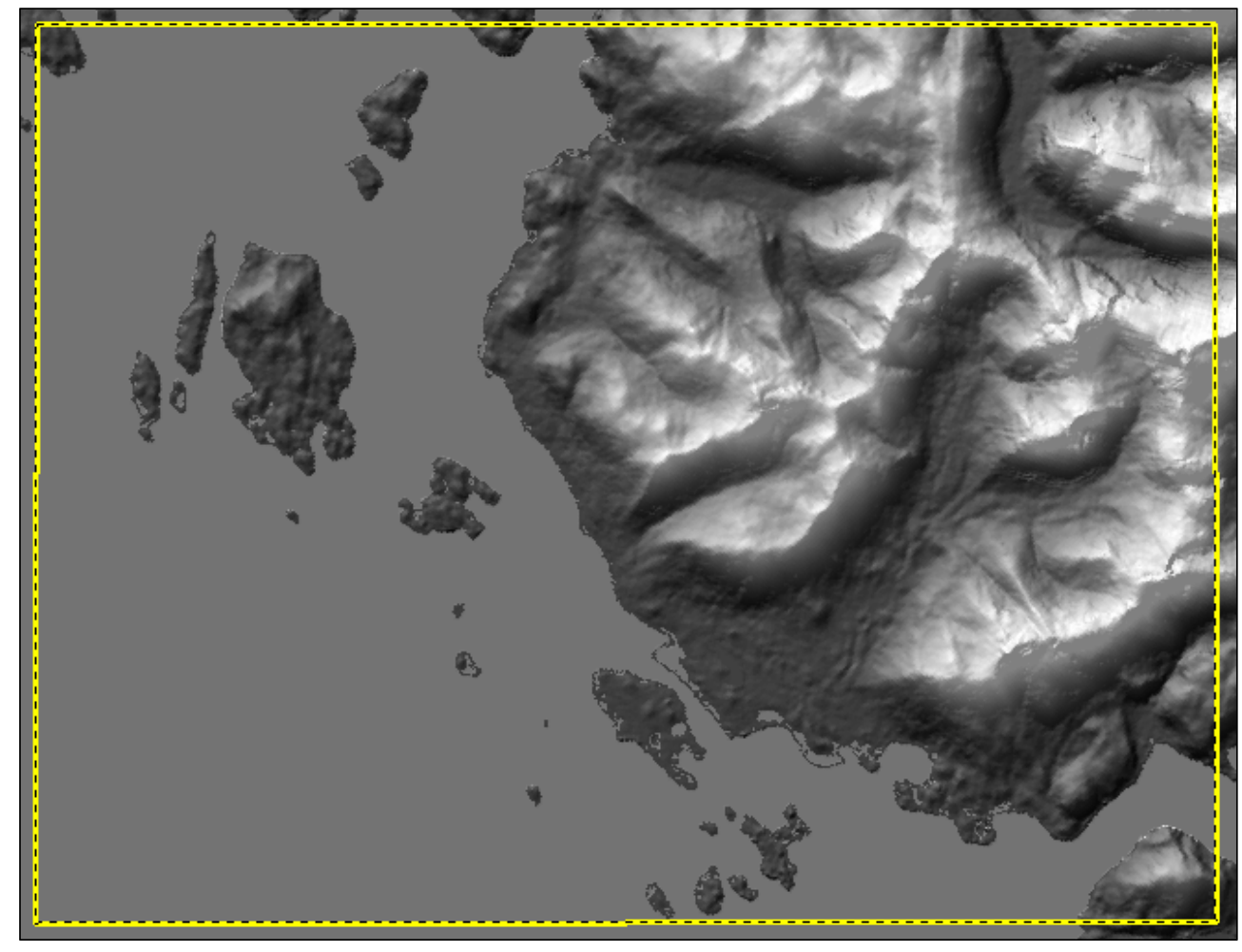

Figure 17. Shaded-relief model of the SRTM/ASTER DEM mosaic showing the "NoData" holes filled in using values extracted from the ASTER GDEM.

We processed the SRTM/ASTER DEM mosaic using the DEM2XYZ process discussed in the "Bathymetry Data" section, above, stopping at the shapefile and making sure to convert the elevation values from MSL to MHHW by subtracting 1.419 from the elevation of each point (Appendix B).

We used ArcGIS to select and delete all of the SRTM/ASTER DEM-based topographic data points that fell within a distance of $30 \mathrm{~m}$ of the Delta Aerial Surveys, Ltd. DTM-based data points (a width of approximately 2 pixels at 8/15 arc-second grid resolution). This process removed the overlap between the Delta Aerial Surveys, 
Ltd. data points and the SRTM/ASTER DEM-based data points, to ensure that we retained only the Delta Aerial Surveys, Ltd. data points, and to allow the surface interpolation algorithm a sufficient gap to smooth the transition between the two topographic datasets.

Although we understand that the best practice in this case would have been to obtain original raw ASTER and SRTM data that had been neither resampled nor reprojected, we made the decision to employ the SDMI WCS because the spatial extent of these SRTM and ASTER datasets is far enough inland (fig. 12) to have little interaction with numerical tsunami modeling. Also, working within the time constraints involved this project, the SDMI WCS proved to be a valuable time-saving alternative.

\section{Japonski Island Triangulated Irregular Network}

Partial data coverage of Japonski Island (fig. 18) posed an obstacle during the preparation of topography data for this project. The problem was that the Delta Aerial Surveys, Ltd. DTM covered only the far northeast onethird of the Island (fig. 19).

Since the SRTM/ASTER DEM-based data points covered Japonksi Island entirely, we hoped that we could simply remove the overlapping SRTM/ASTER data points where there were Delta Aerial Survey's, Ltd. data points just as we did for Baranof Island, and use the SRTM/ASTER data points to cover the remaining twothirds of the island. However, because the island is home to much infrastructure and is of obvious importance to the "Tsunami Inundation Mapping of Alaska Coastal Communities" project, we first conducted a quality assessment of the SRTM/ASTER DEM based data points, focusing our attention on large areas of relatively uniform surface type (such as the airstrip tarmac and parking lots). Figure 20 lists summary statistics of 1,461 SRTM/ASTER DEM-derived point elevations of the Sitka Airport airstrip. According to the SRTM/ASTER elevation values, the mean elevation value of the airstrip is $2.06 \mathrm{~m}$ above MHHW.

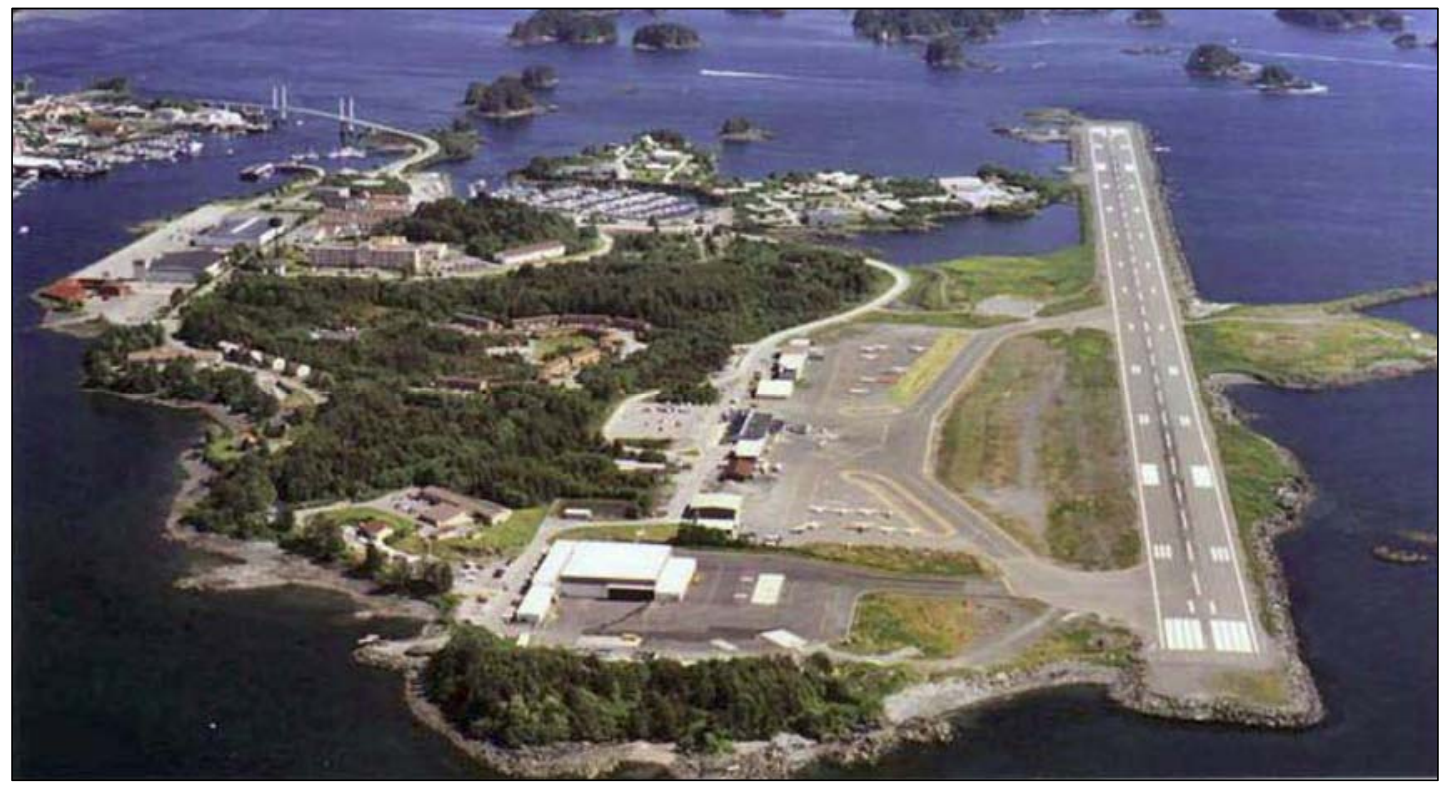

Figure 18. Perspective view of Japonski Island and the Sitka Airport, looking toward the east. Source: http://www.sitka.net 


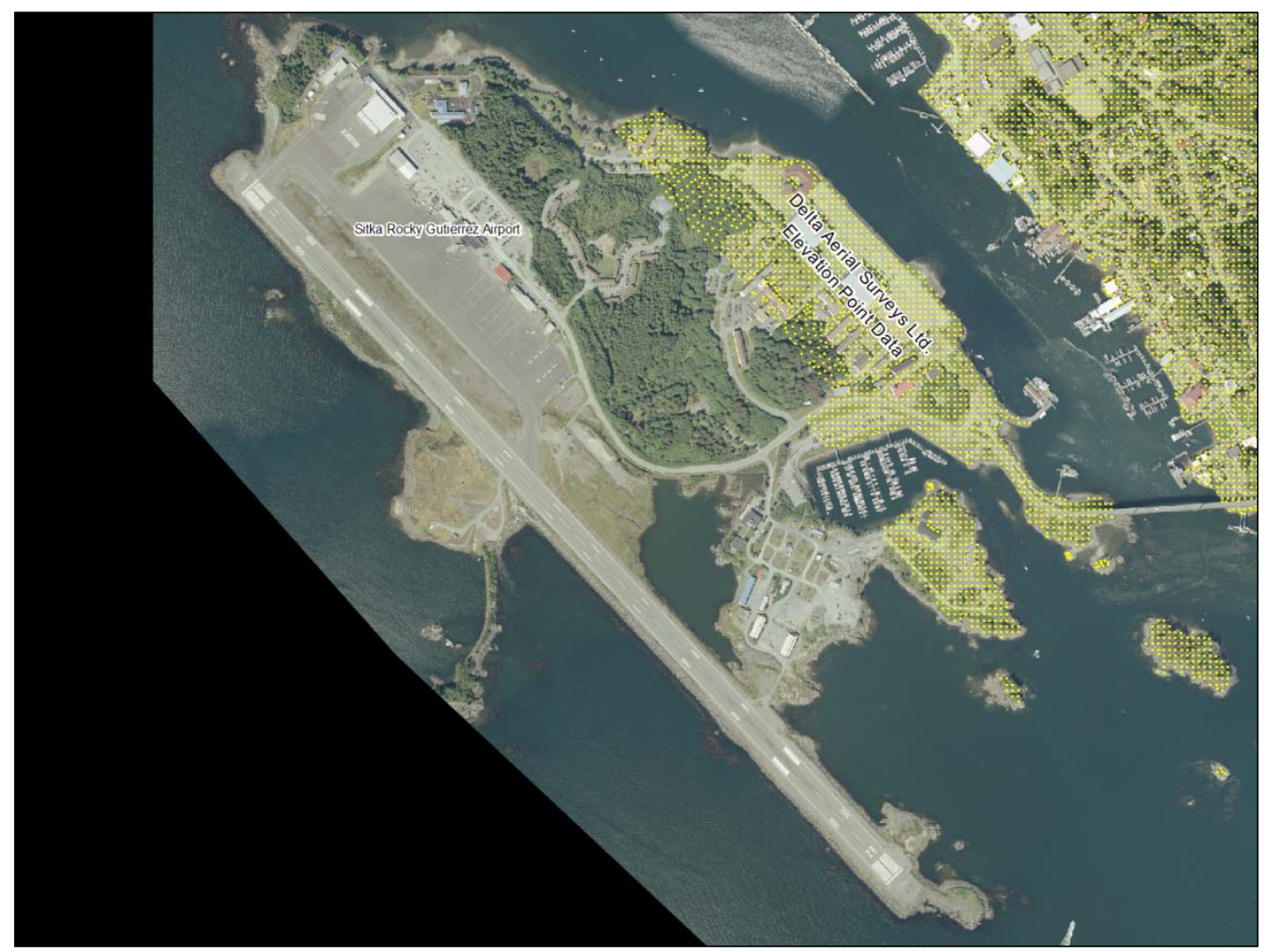

Figure 19. Delta Aerial Surveys, Ltd. topography data coverage of Japonski Island.

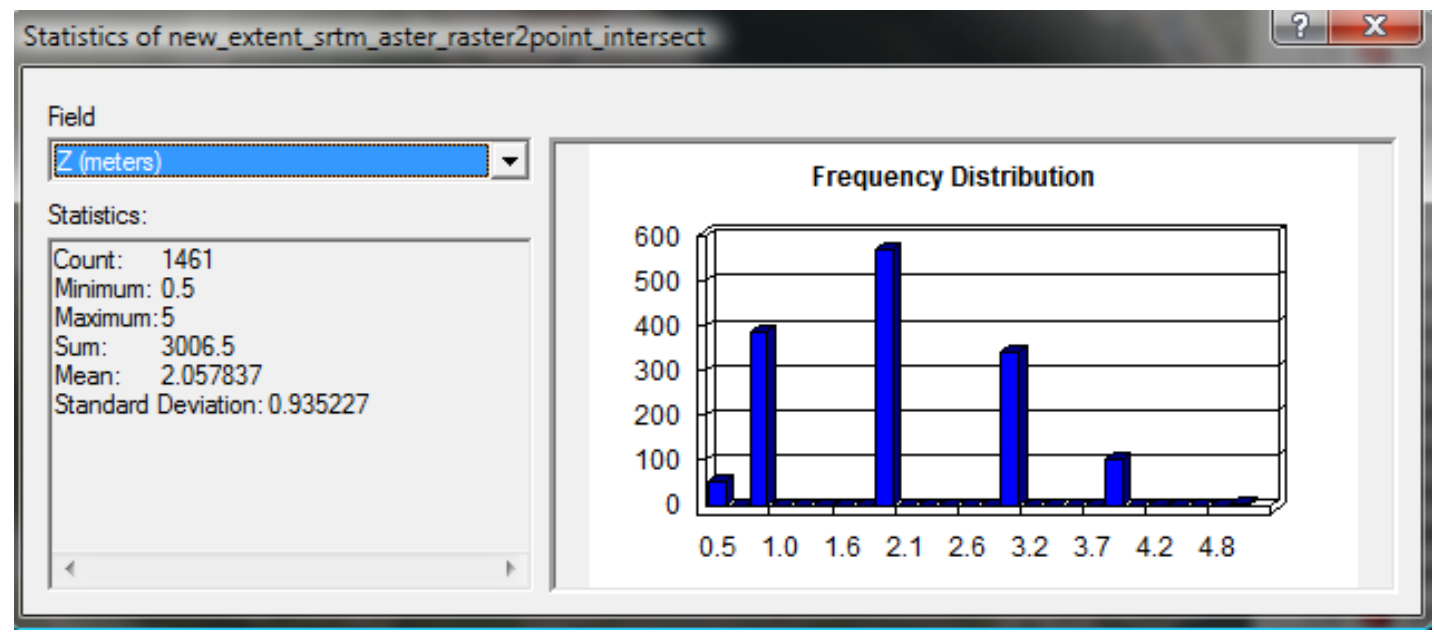

Figure 20. Summary statistics of the Sitka Airport runway tarmac elevations (m) derived from the SRTM/ASTER mosaic DEM.

We compared the SRTM/ASTER DEM-based summary statistics to those of survey monuments obtained from Tim Reed of the Alaska Department of Transportation \& Public Facilities (DOTPF) for the same area.

According to the DOTPF survey monuments, the mean elevation of the runway is $4.18 \mathrm{~m}$ in reference to the MHHW vertical datum (fig. 21). This analysis brought into question the suitability of the SRTM/ASTER DEM based data points for the remainder of the island as well. 


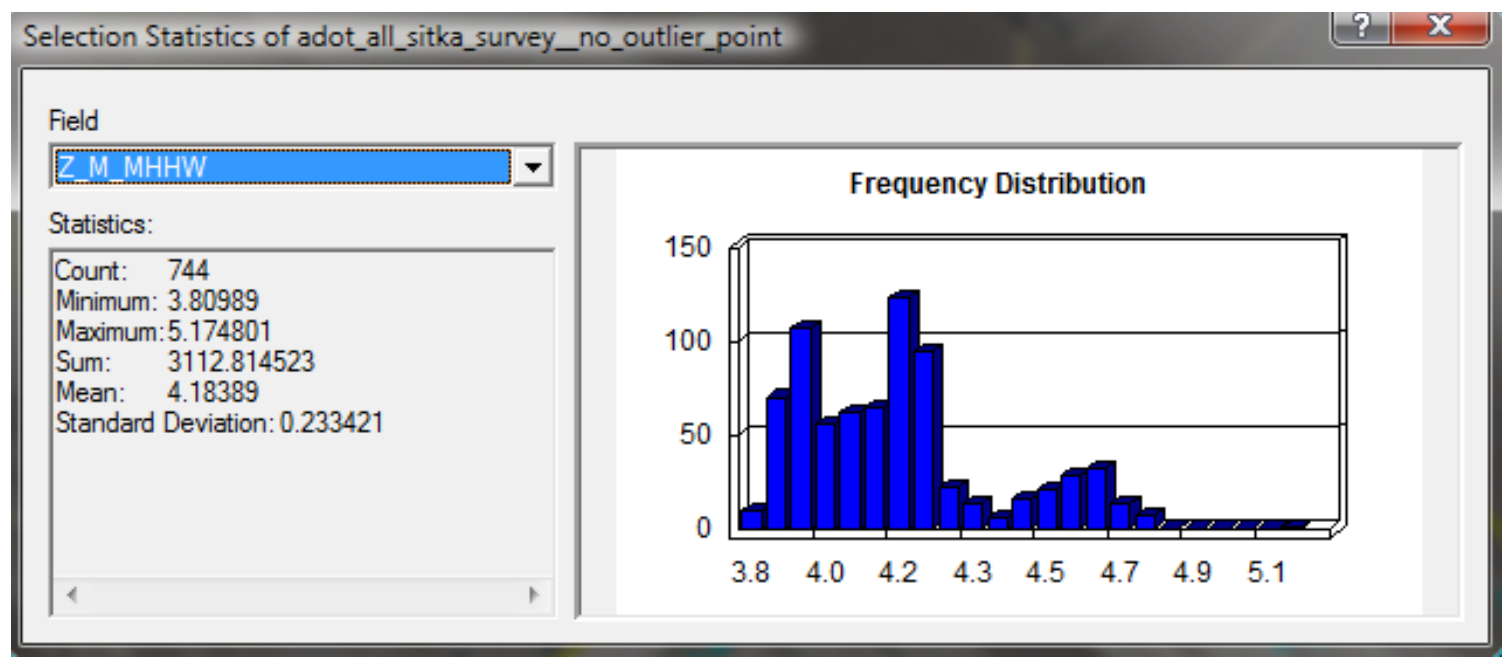

Figure 21. Summary statistics of the Sitka Airport runway tarmac elevations (m) derived from DOTPF survey monuments.

We also received CAD drawings of the airport from Mr. Reed, the DOTPF Southeast Region Survey Coordinator. These drawings contained topographic contour lines attributed with elevation values in U.S. Survey Feet in reference to the MLLW vertical datum. Through written communication with Mr. Reed, we also learned that the survey data used to generate these contour lines is based on the previous 1960-1978 tidal epoch, which in Sitka is 0.21 feet lower in elevation than the most current 1983-2001 tidal epoch (Appendix B). Unfortunately, we could not use these contour lines exclusively as the topographic data source for Japonski Island because they were discontinuous and only covered small areas of the island.

No additional topographic datasets were discovered for Japonski Island, therefore we made the decision to use the best available datasets we had assembled to generate our own DEM. First we constructed a Triangulated Irregular Network (TIN) dataset for the island (fig. 22). To do this, we converted DOTPF contour line elevation values to the MHHW vertical datum in meters and in the current tidal epoch. This entailed dividing elevations in feet by 3.2808 to convert to meters, then subtracting 3.093 from the elevation values of the contour lines to convert to MHHW vertical datum in the current tidal epoch (the difference of 3.029 meters between MLLW and MHHW, plus the difference of 0.064 meters between the tidal epochs; Appendix B). Using ArcGIS, we induced a small gap of $10 \mathrm{~m}$ between DOTPF contour lines and Delta Aerial Surveys, Ltd. point-cloud data. A slightly larger gap was induced between SRTM/ASTER DEM data points and the other datasets because of the subjectivity of the SRTM DEM elevation data of the island. Further, in an attempt to minimize errors during TIN generation, we manually smoothed SRTM data points over large areas of relatively uniform surface elevations (such as the airstrip, tarmac, and parking lots). The resulting aggregation of non-overlapping datasets was used as mass points and soft breaklines during our TIN generation (fig. 23).

Also included in the DOTPF CAD drawing were lines demarcating the end of pavement for the airstrip as well as a subset of roads on the island. We introduced these lines, along with our final coastline, as hard breaklines during the TIN generation. From this TIN (fig. 22), we generated a $5 \mathrm{~m}$ horizontal-resolution DEM in grid format (fig. 24), then processed this DEM according to the DEM2XYZ method previously discussed in the "Bathymetry Data" section. 


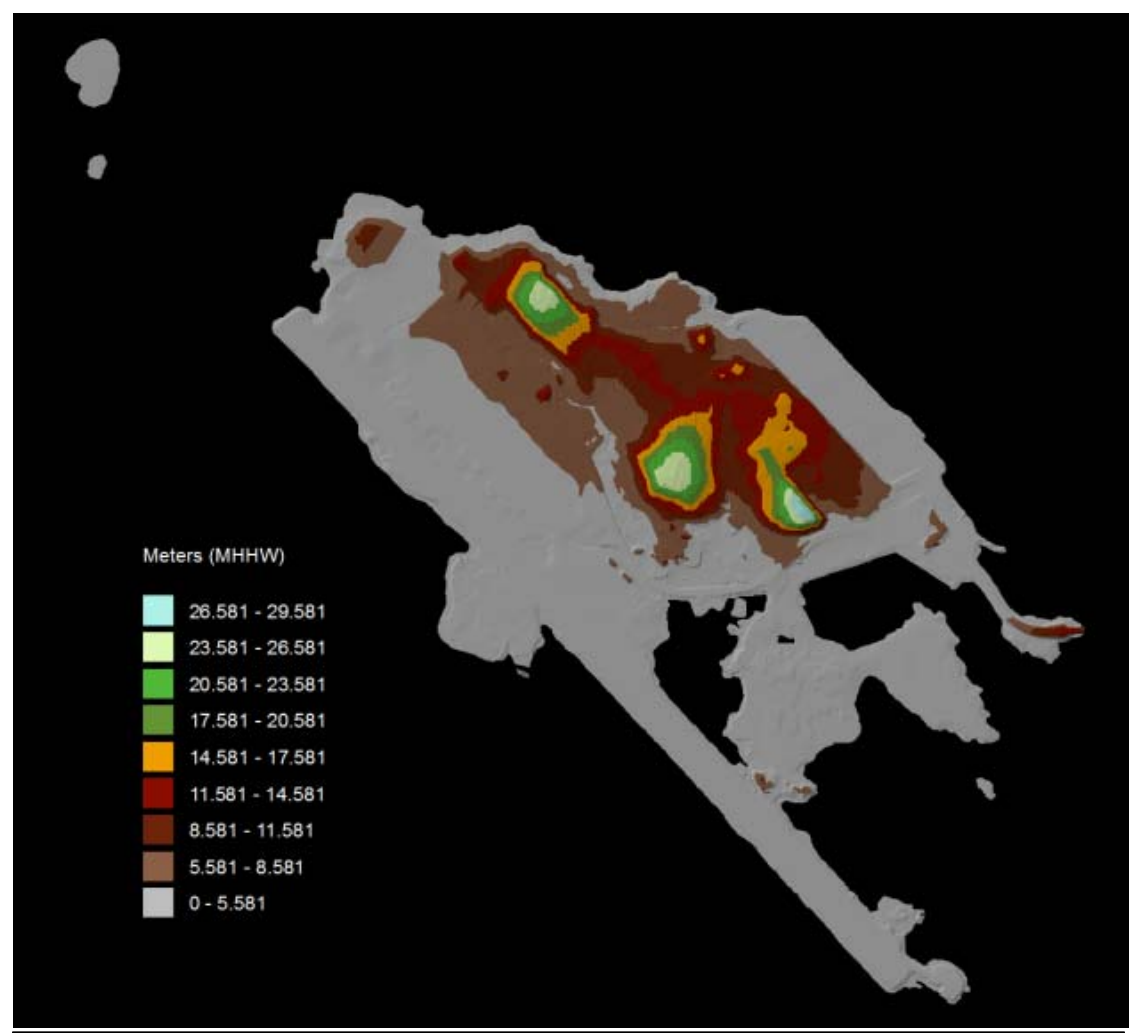

Figure 22. Japonski Island Triangulated Irregular Network (TIN).

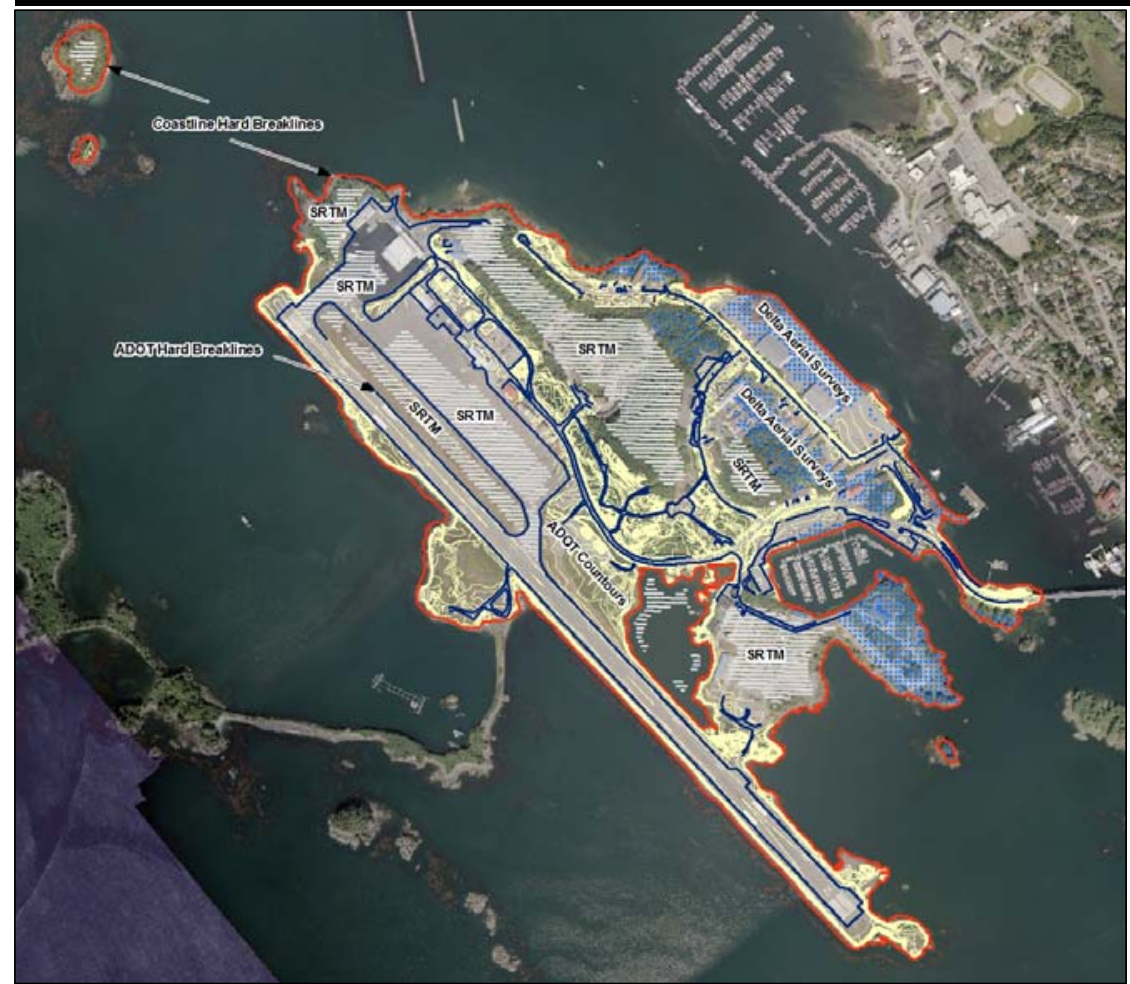

Figure 23. Diagram showing datasets used to create a new elevation Triangulated Irregular Network (TIN) of Japonski Island. Elevation contour lines and edge-of-pavement lines were obtained from DOTPF, Delta Aerial Surveys, Ltd. point elevations, and SRTM point elevations. The SRTM data points were manually edited to smooth large regular surfaces such as the airstrip, tarmac, and parking lots. 


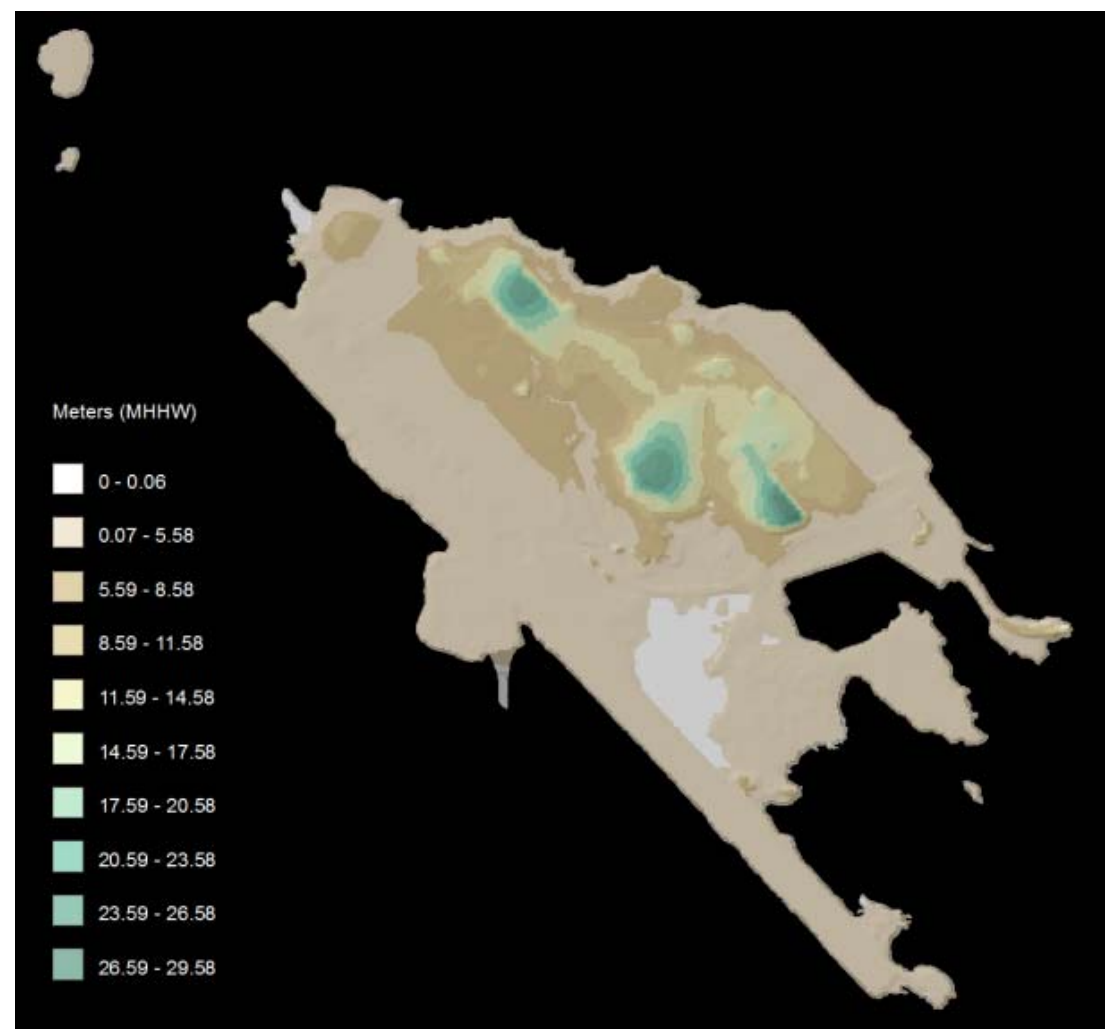

Figure 24. Japonski Island 5 $m$ Digital Elevation Model (DEM).

\section{Manually Digitized Elevation Points}

Sitka Harbor contains numerous breakwaters (fig. 25). NGDC provided detailed USACE topographic and hydrographic surveys of the western anchorage breakwaters (Appendix A), but these surveys proved to be too fine-grained to be resolved at the resolution of the 8/15 arc-second grid. Also, because the breakwaters measure approximately $12 \mathrm{~m}$ (fig. 26), early iterations of the MB-System interpolation algorithm left parts of the breakwaters underwater. It was therefore necessary to manually digitize elevation points along the breakwaters to ensure that they were properly represented in the 8/15 arc-second grid (fig. 27).

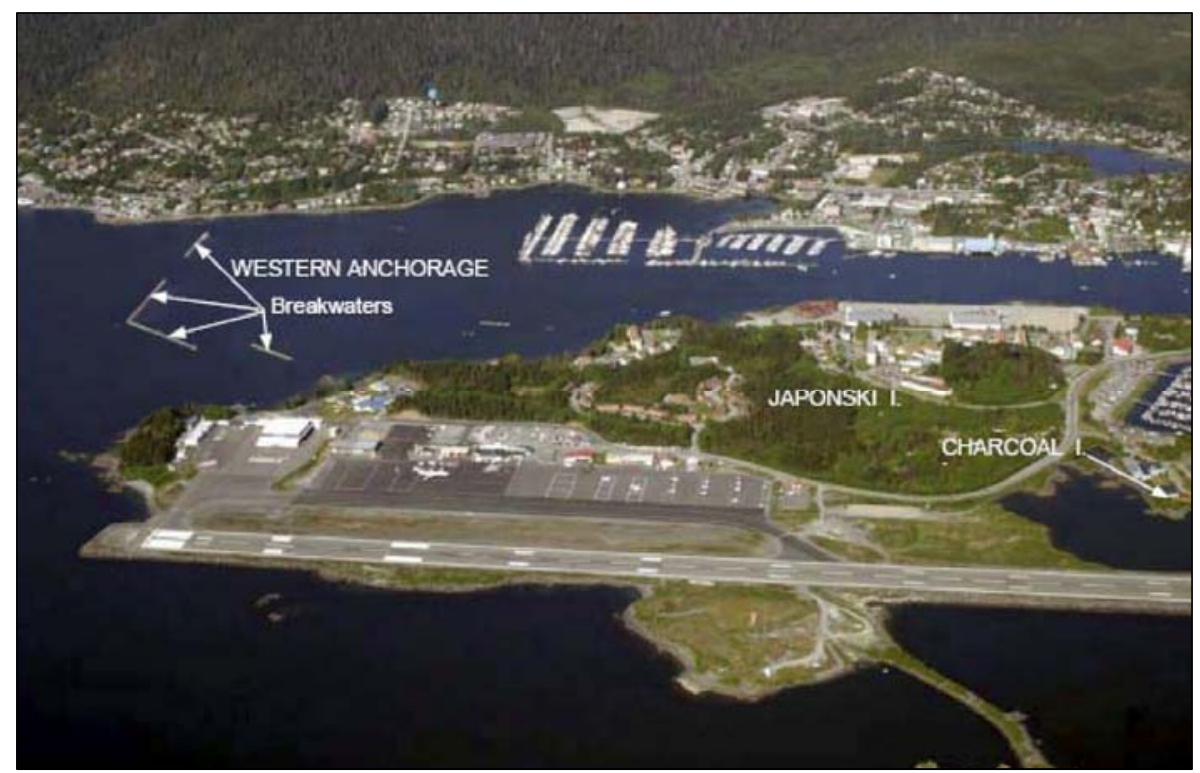

Figure 25. View of Sitka Harbor, looking to the north. Note the location of the western anchorage breakwaters. 


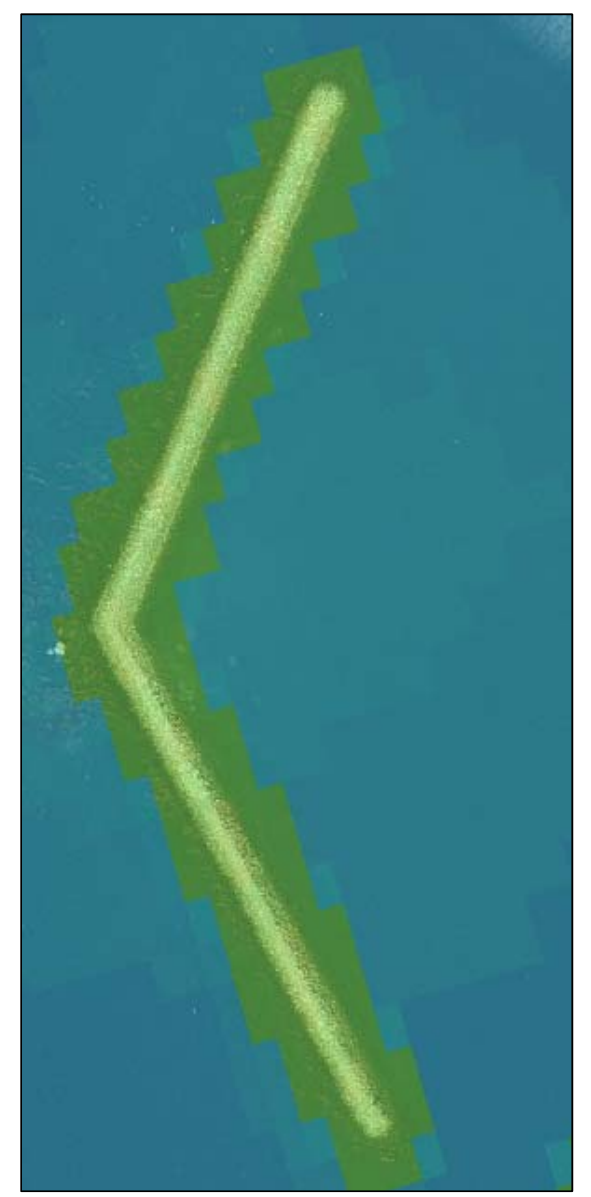

Figure 26. Orthophoto showing middle of the western anchorage breakwaters, U.S. Army Corps of Engineers (USACE) survey data, with manually digitized points.

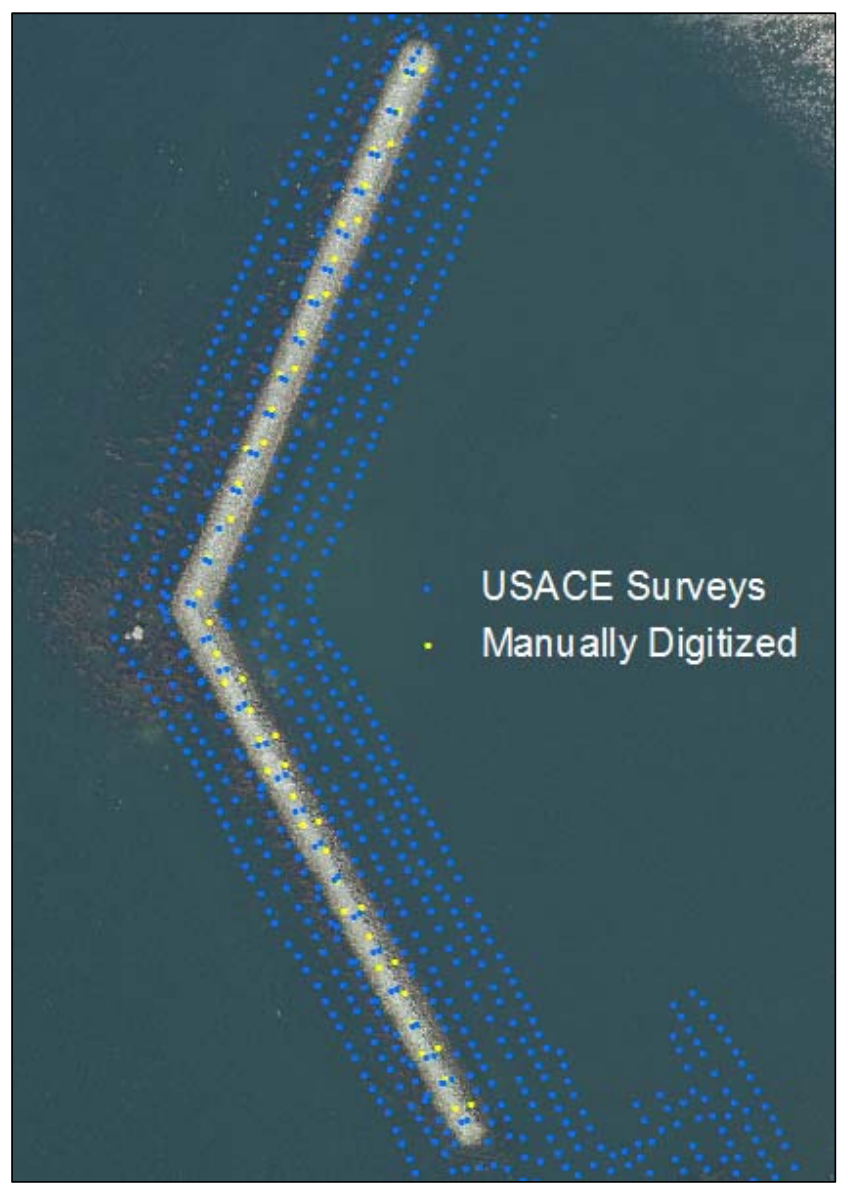

Figure 27. Western anchorage breakwater with 8/15 arcsecond grid overlay. 


\section{Creating the Seamless 8/15 arc-second DEM}

We used the xyz files discussed in the preceding sections of this report as input into MB-System for construction of the seamless bathymetric-topographic DEM (Caldwell and others, 2011). Specifically, MB-System (http://www.ldeo.columbia.edu/res/pi/MB-System) performs a spline interpolation of input data-point values to build an output GMT grid file of the interpolated surface. An ascii file is also created and output by MB-System, which we used as input in ArcGIS to generate a GeoTIFF version of the DEM. This made it easier to manipulate during our quality assessment. Figure 28 shows a shaded relief model that has been color-classified to highlight the difference between topography and bathymetry elevations in reference to the MHHW vertical datum.

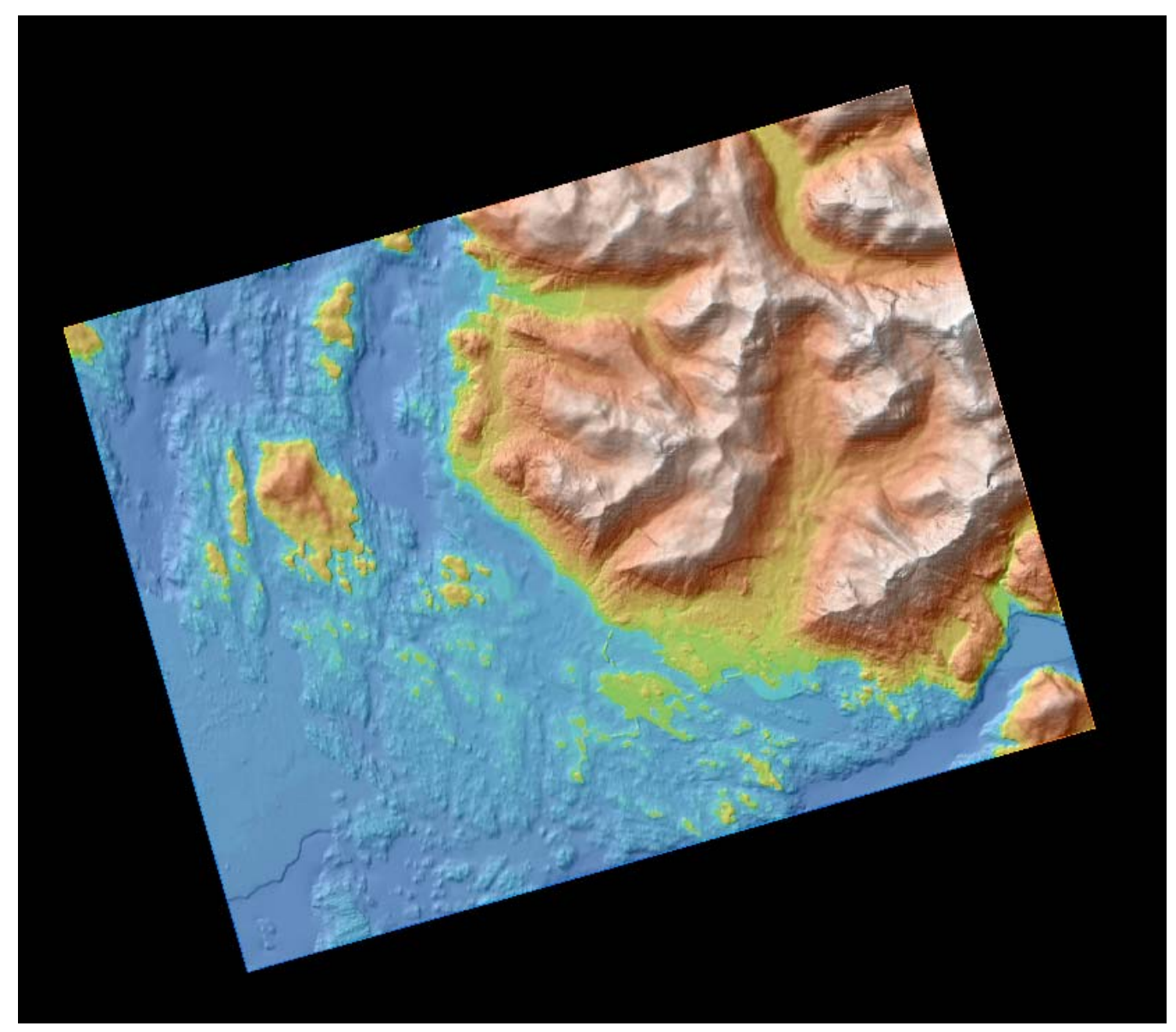

Figure 28. Shaded-relief map of the final seamless 8/15 arc-second bathymetric-topographic grid of Sitka, Alaska. Blue represents the bathymetry. 


\section{Quality Assessment}

\section{$\underline{\text { Horizontal Accuracy }}$}

Quality control was performed by AEIC and GINA at UAF and by NGDC in Boulder, CO. A color classification was applied to the seamless DEM to separate positive and negative values. The coastline was meticulously scrutinized with respect to both the final coastline vector data and the city of Sitka orthophotography. We used ArcGIS Spatial Analyst to create a shaded-relief map of the older (2005) 1.0 arc-second grid and applied the same color classification (http://www.ngdc.noaa.gov/dem/archive/download/924) to visually compare that grid with the new 8/15 arc-second grid (figs. 29 and 30). We used ArcScene (www.esri.com) to generate 3-dimensional perspective views of the $8 / 15$ arc-second grid superimposed on the 3 arc-second grid (http://www.ngdc.noaa.gov/dem/squareCellGrid/download/523) to assess the transition between the lower horizontal-resolution grid to the higher horizontal-resolution grid (figs. 31-33).

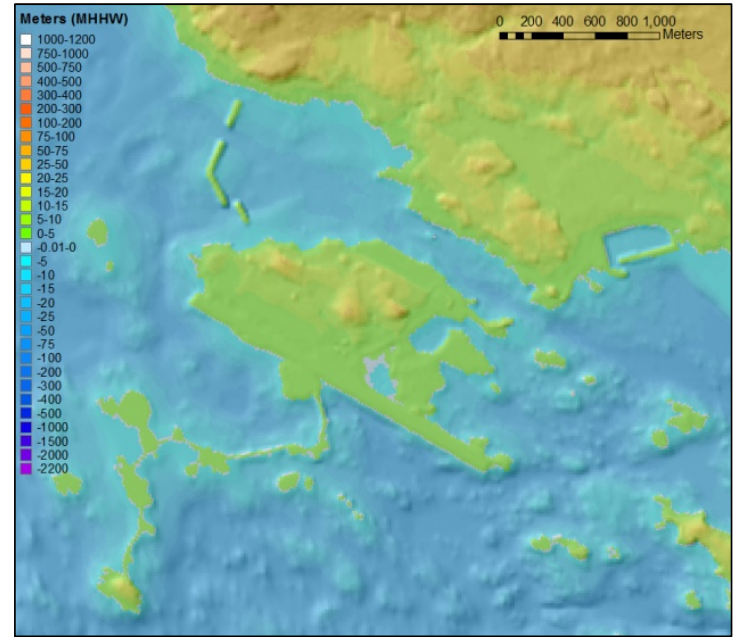

Figure 29. Shaded-relief view of the final 8/15 arcsecond grid, centered on Sitka Harbor and Japonski Island.

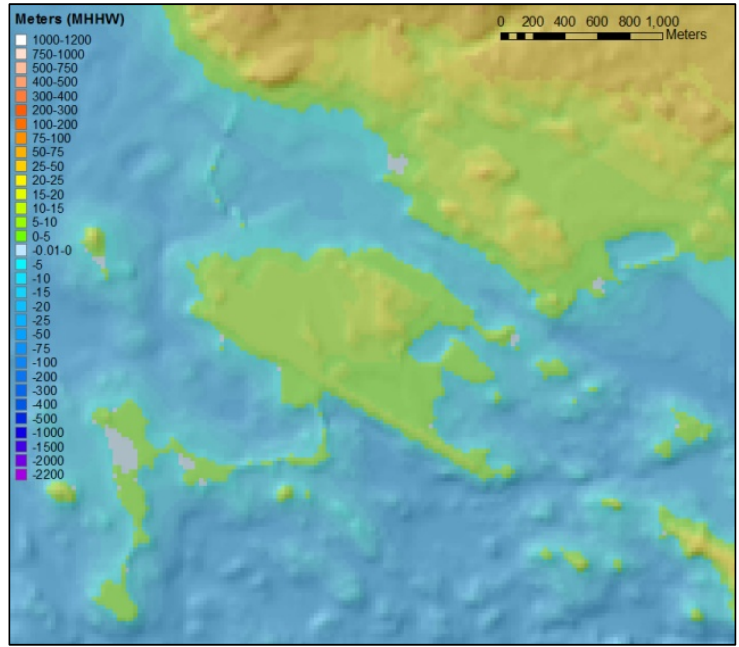

Figure 30. Shaded-relief view of the 20051 arcsecond grid, centered on Sitka Harbor and Japonski Island.

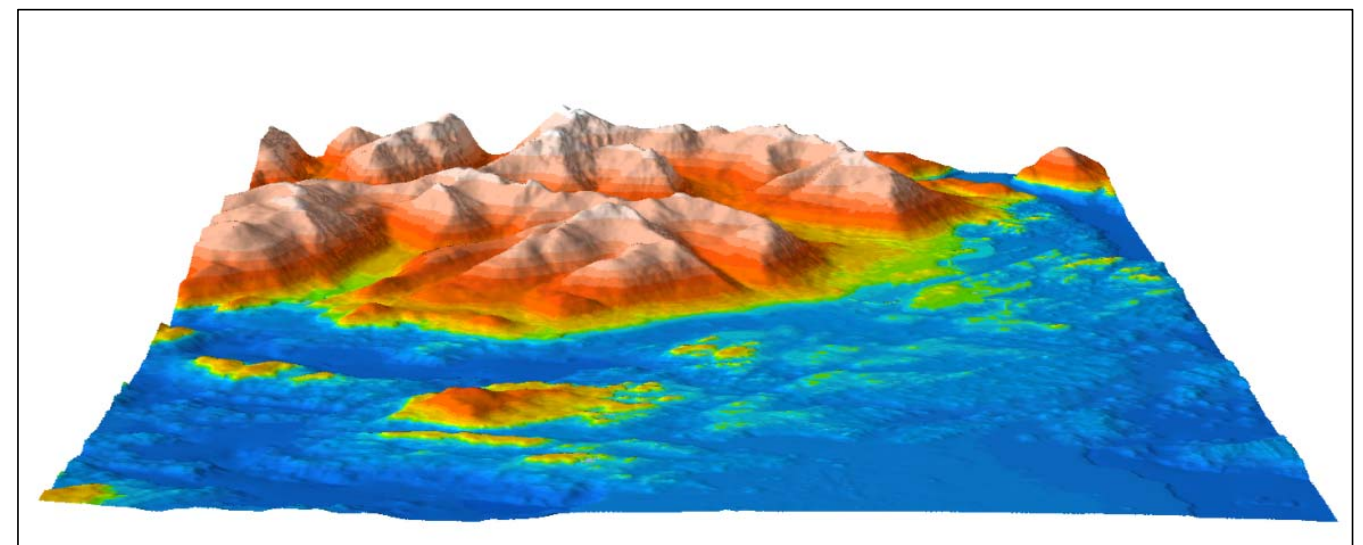

Figure 31. Three-dimensional (3-D) perspective of the Sitka 8/15 arc-second DEM rendered using ArcScene. 


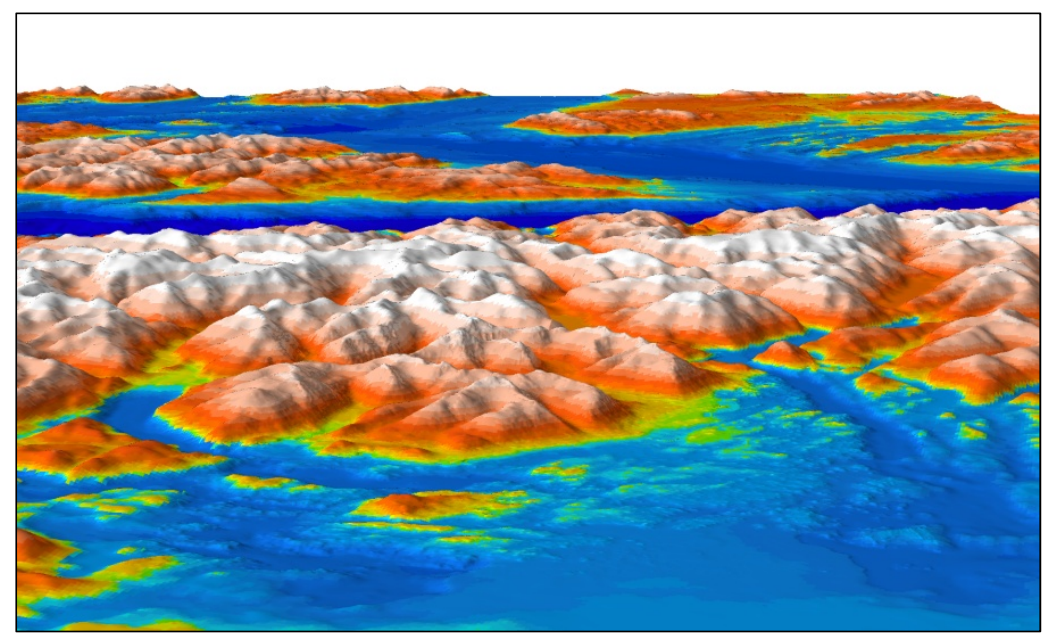

Figure 32. Same perspective as shown in figure 31, with the 8/15 arc-second DEM superimposed over the NGDC Southeast Alaska 3 arc-second DEM.

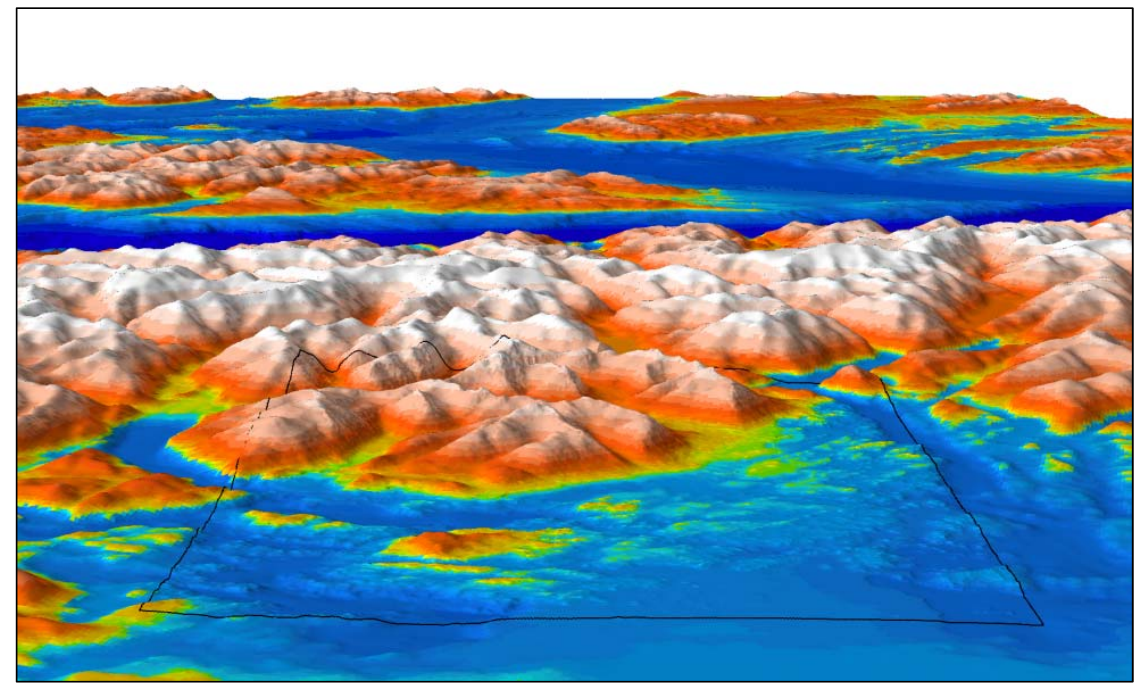

Figure 33. Same perspective as in figures 31 and 32, with the addition of the study area boundary (black line) to clearly identify the transition, or seam, between the 8/15 and 3 arc-second DEMs.

\section{Vertical Accuracy}

\section{Bathymetry}

We assessed the bathymetric vertical accuracy by comparing the original hydrographic depth soundings with corresponding values extracted from the 8/15 arc-second DEM. Using this method of comparison, we found that preliminary versions of our DEM, which incorporated all of the bathymetric pre-surface data points, resulted in an unacceptably large mean difference between the original survey data and the DEM. Our review of the reports for similar coastal DEM developments (Caldwell and others, 2011; 2010) brought to our attention that the purpose of the bathymetric pre-surface is primarily to fill in areas of sparse hydrographic survey data points (for example, areas for which multi-beam swath surveys have not been conducted). In our case, the entire Sitka 8/15 arc-second DEM boundary has been 'blanketed' by multibeam swath surveys (fig. 10). Further investigation led to the conclusion that in our case specifically, the bathymetric pre-surface induced a larger difference between the 8/15 arc-second DEM and the original 
hydrographic survey data in areas where these two datasets overlap. However, when we completely excluded these bathymetric pre-surface data points, interpolation errors occurred within the inter-tidal zone along Baranof Island.

To resolve both the erroneous influence of the bathymetric pre-surface on the hydrographic survey data points, and the absence of hydrographic survey data points within the inter-tidal zone, we used ArcGIS to select only those bathymetric pre-surface data points within $30 \mathrm{~m}$ of the coastline and that were at least a distance of $15 \mathrm{~m}$ from any original hydrographic survey data-point. Furthermore, the MB-System software also allowed us to weight the input data-point XYZ files. We assigned a weight of 0.1 to the bathymetric pre-surface as compared to a weight of 100 for the original hydrographic survey data points. The resulting $8 / 15$ arc-second grid generated a mean difference of $0.02 \mathrm{~m}$ when compared to all original hydrographic survey data points. Histograms and specific summary statistics of these results are provided in figures 3443. According to reports of similar coastal DEM developments, large outlier differences are often the result of more than one data-point being averaged by the interpolation for a single grid cell, and that these outliers mainly occur on steep bathymetric slopes (Caldwell and others, 2011).

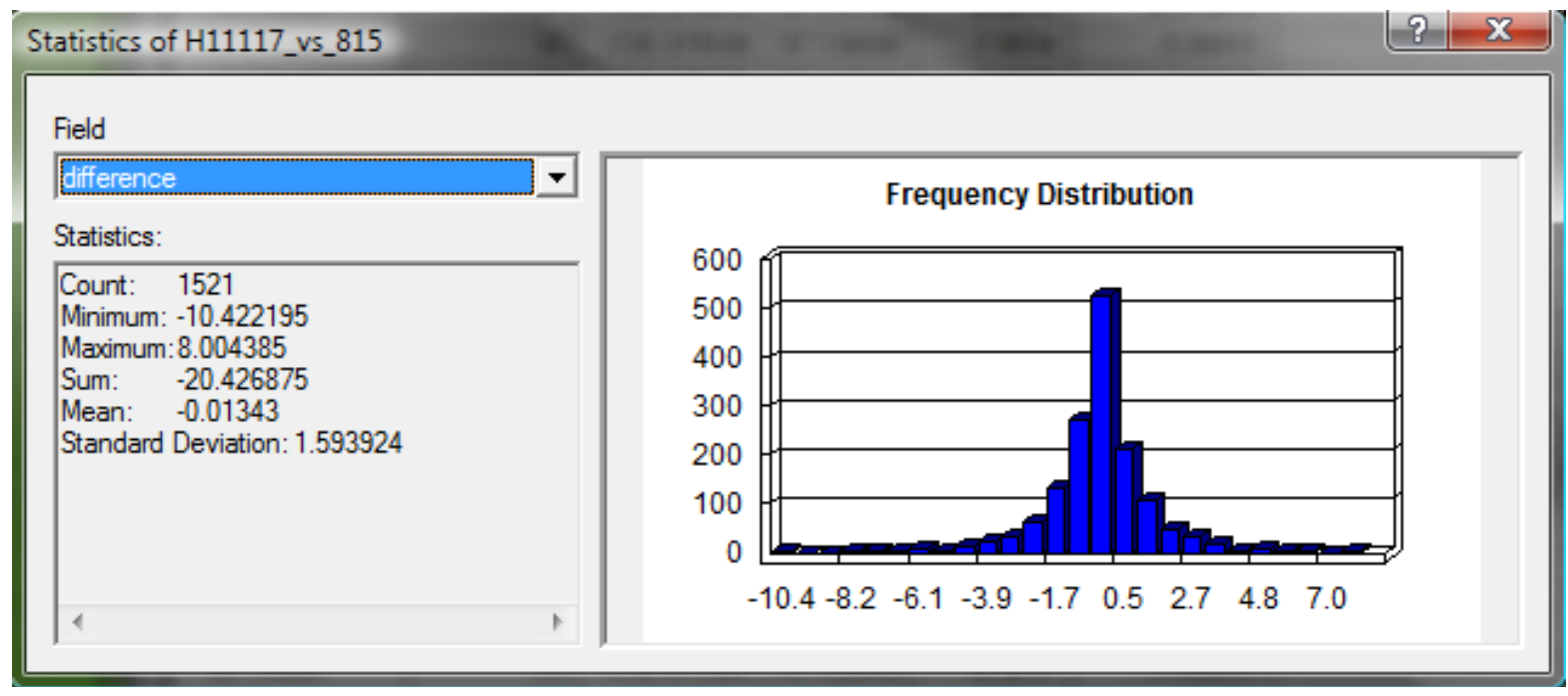

Figure 34. Histogram comparing NOS H11117 depth values (m) to the Sitka 8/15 arc-second DEM.

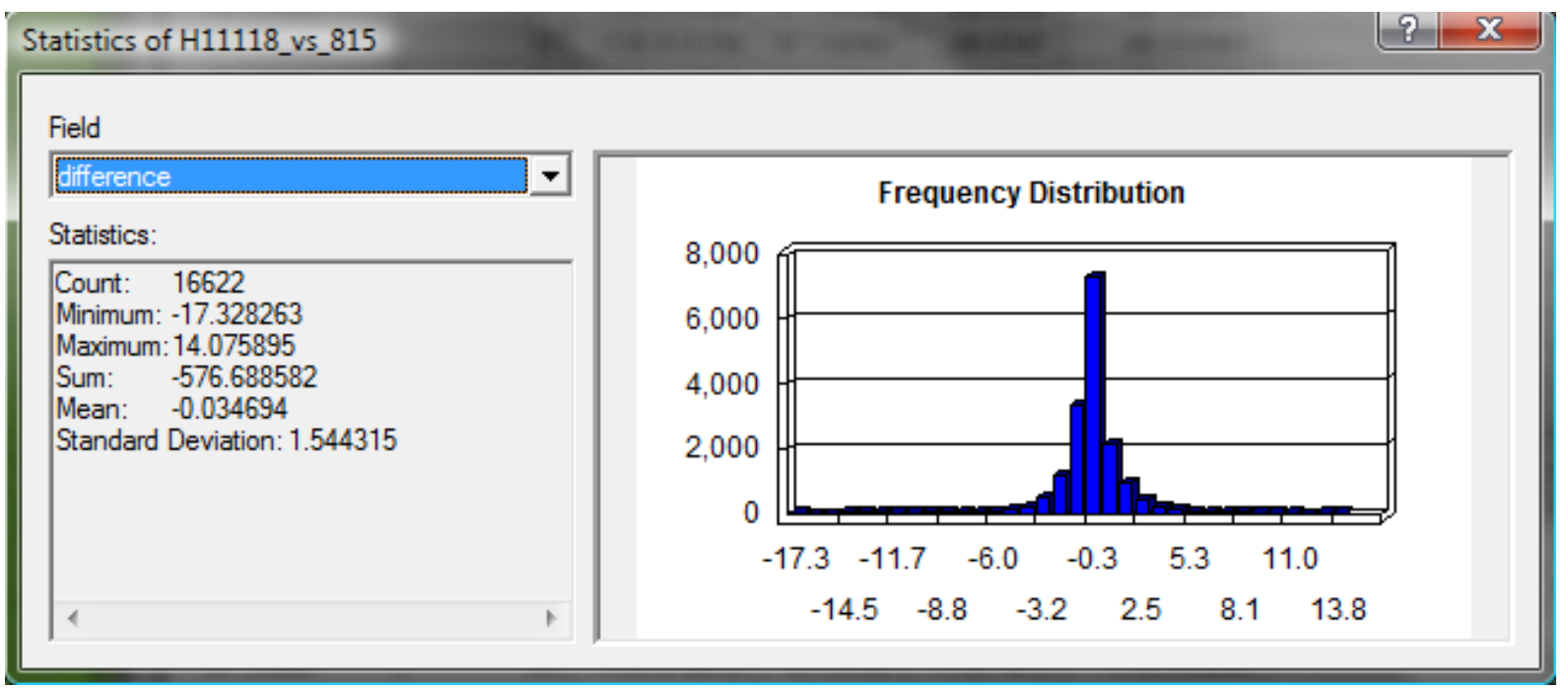

Figure 35. Histogram comparing NOS H11118 depth values (m) to the Sitka 8/15 arc-second DEM. 


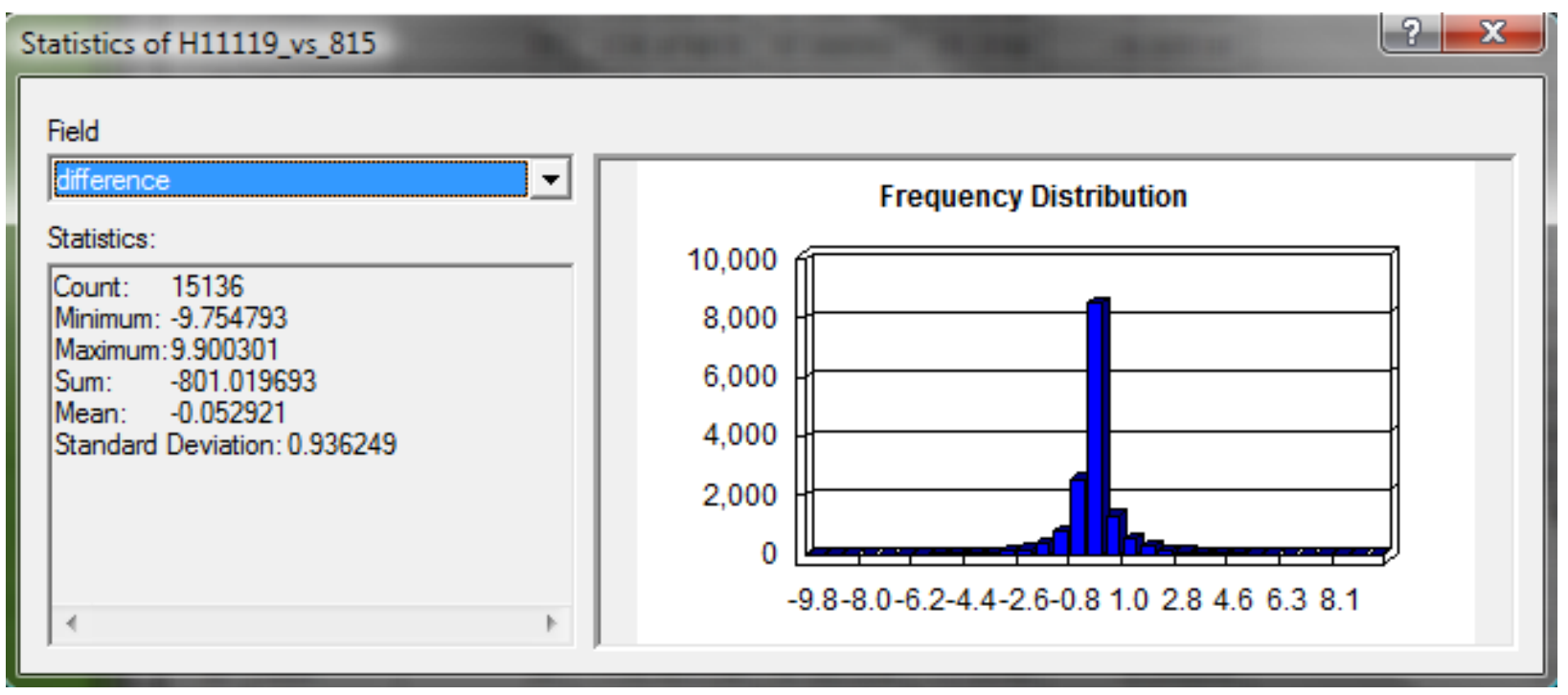

Figure 36. Histogram comparing NOS H11119 depth values (m) to the Sitka 8/15 arc-second DEM.

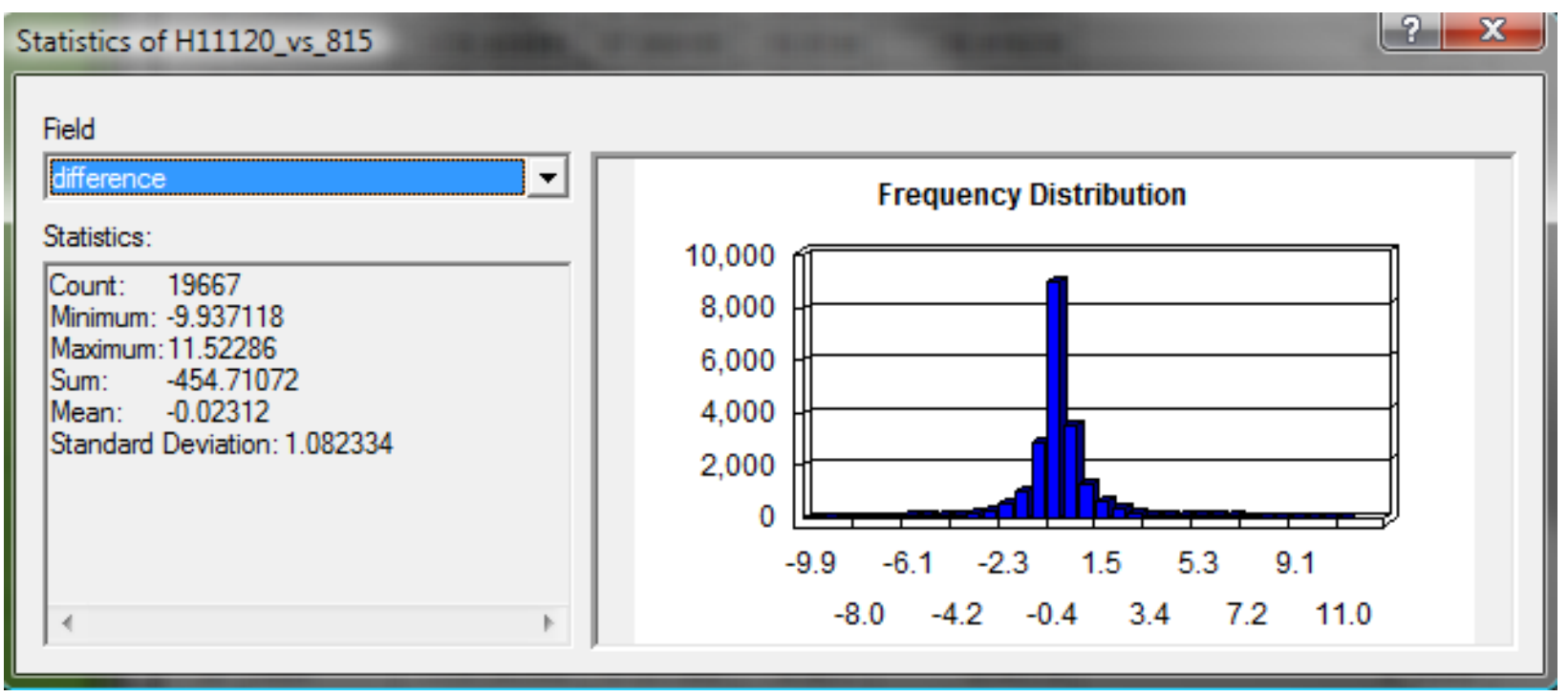

Figure 37. Histogram comparing NOS H11120 depth values (m) to the Sitka 8/15 arc-second DEM. 


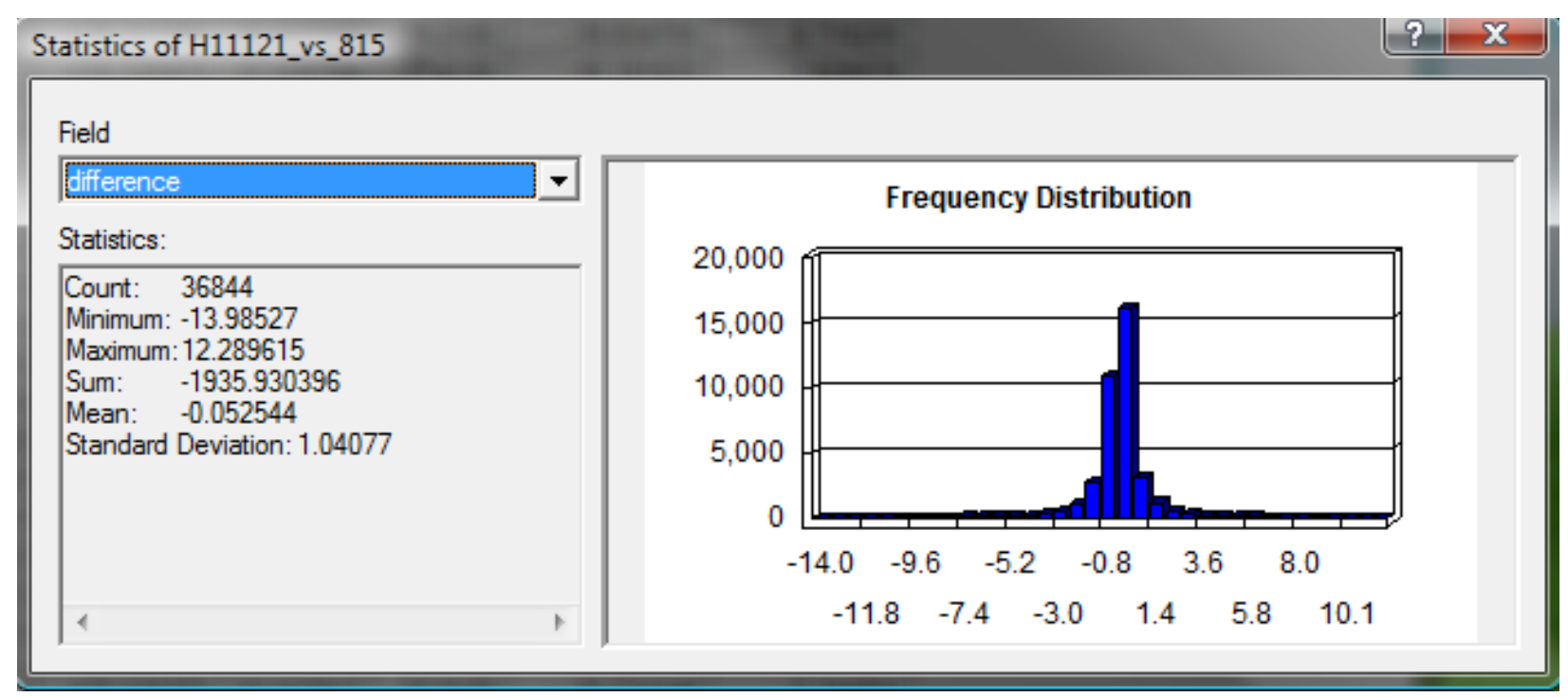

Figure 38. Histogram comparing NOS H11121 depth values (m) to the Sitka 8/15 arc-second DEM.

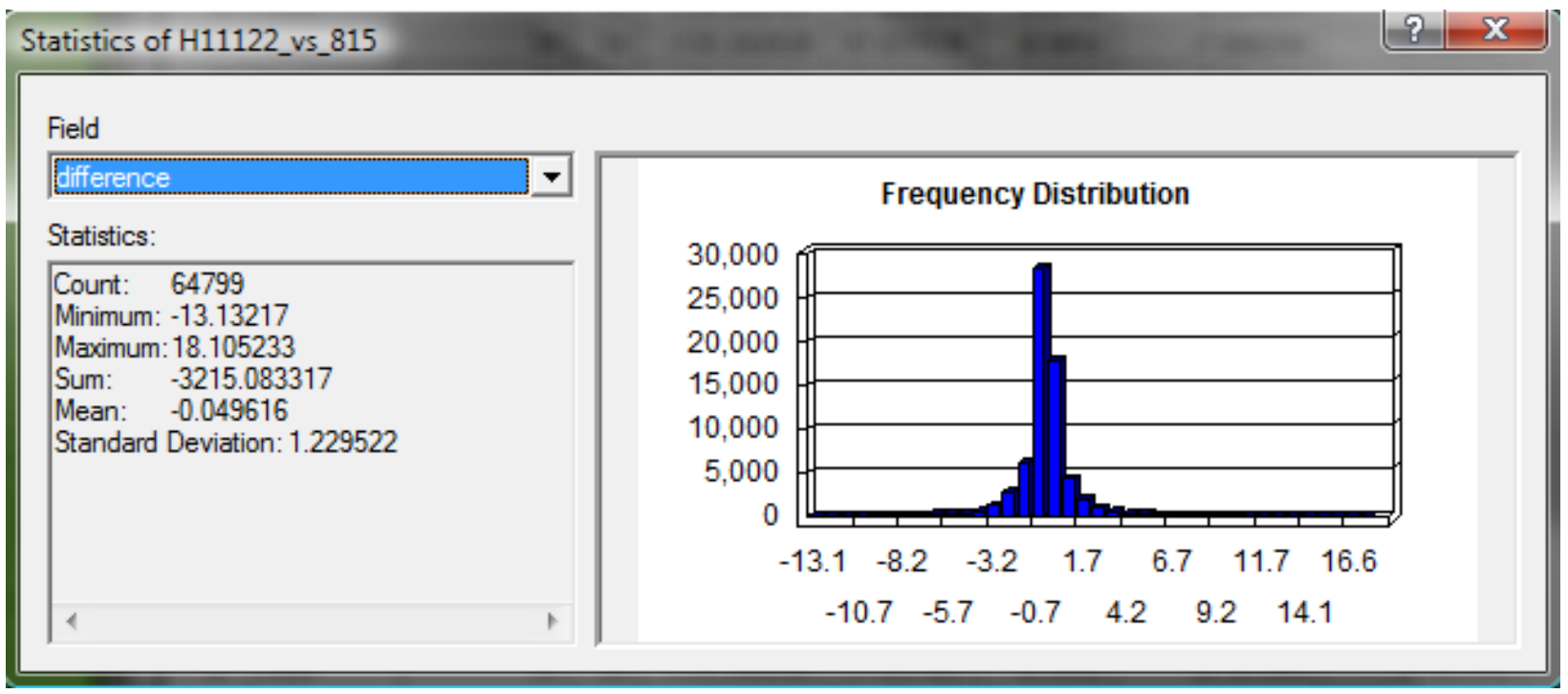

Figure 39. Histogram comparing NOS H11122 depth values (m) to the Sitka 8/15 arc-second DEM. 


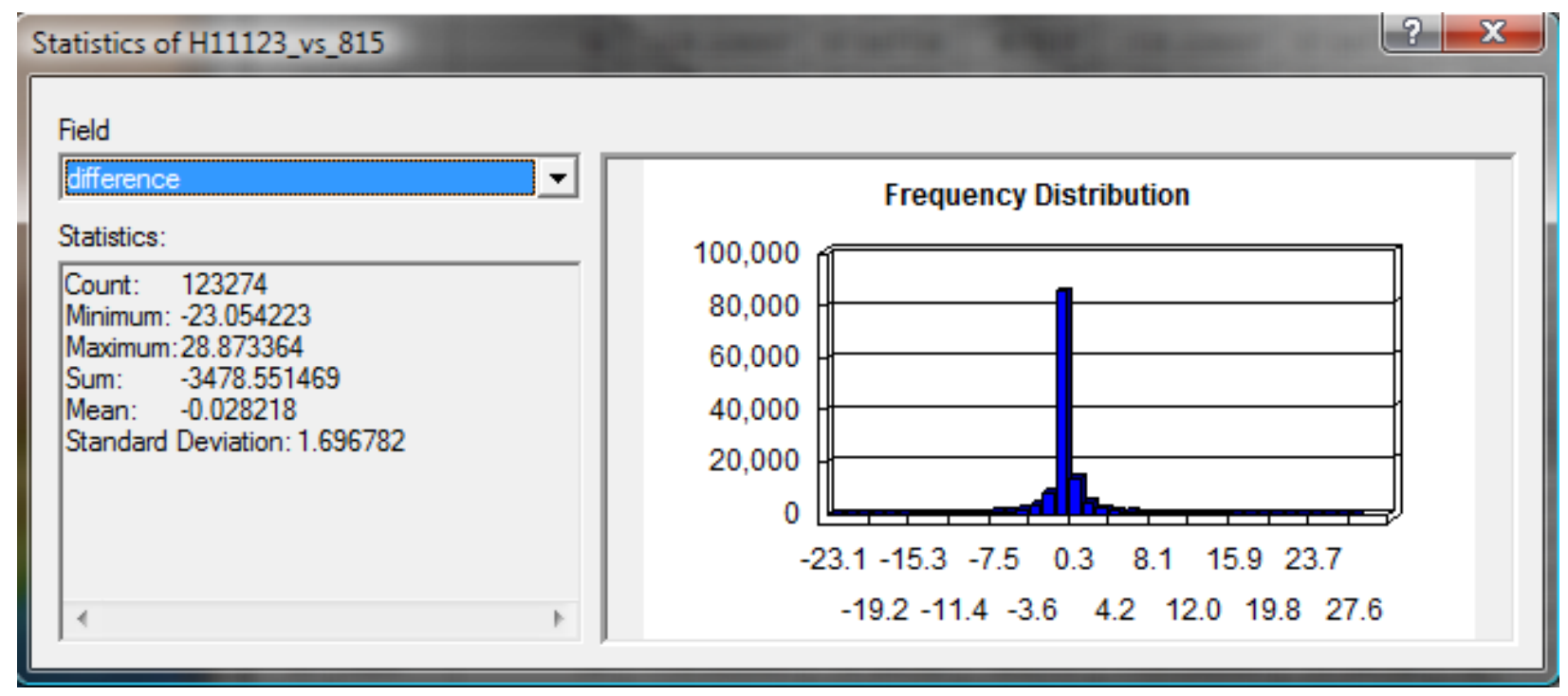

Figure 40. Histogram comparing NOS H11123 depth values (m) to the Sitka 8/15 arc-second DEM.

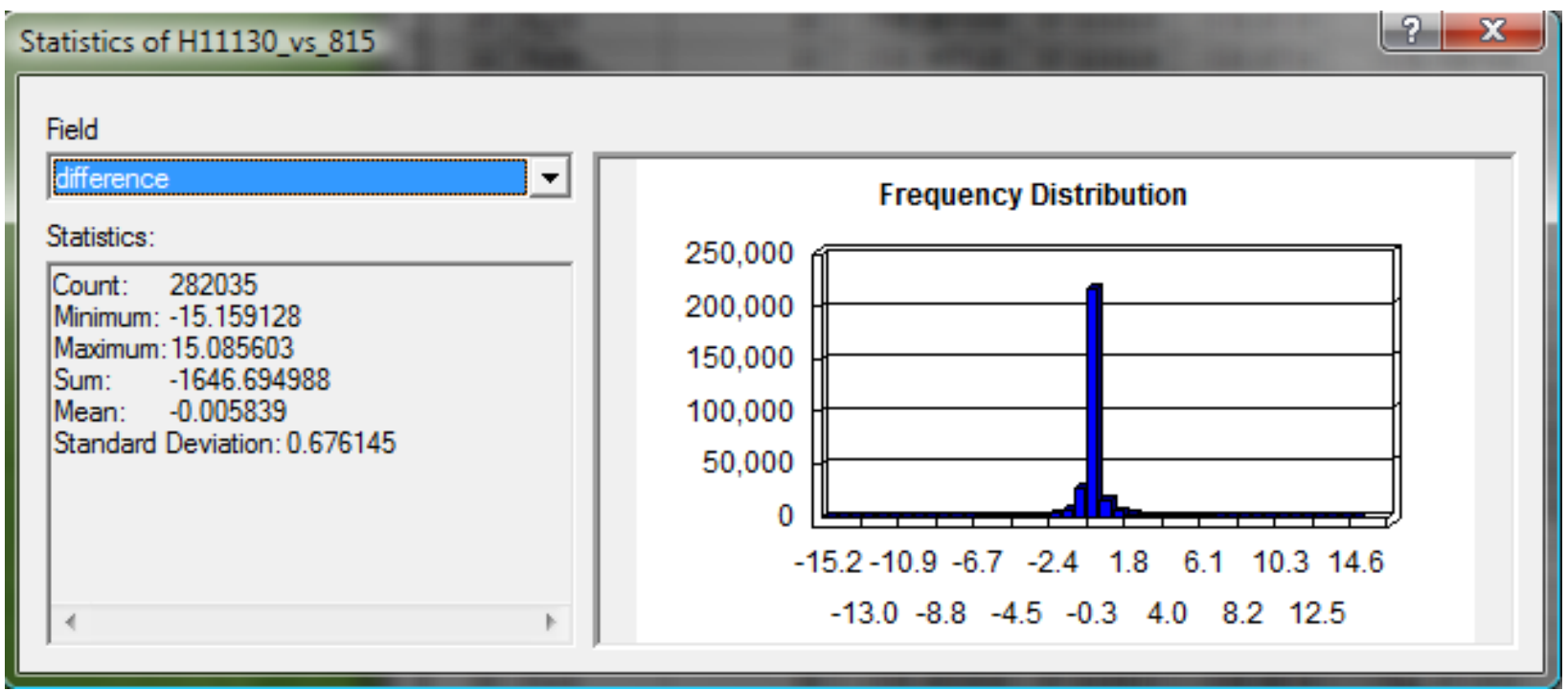

Figure 41. Histogram comparing NOS H11130 depth values (m) to the Sitka 8/15 arc-second DEM. 


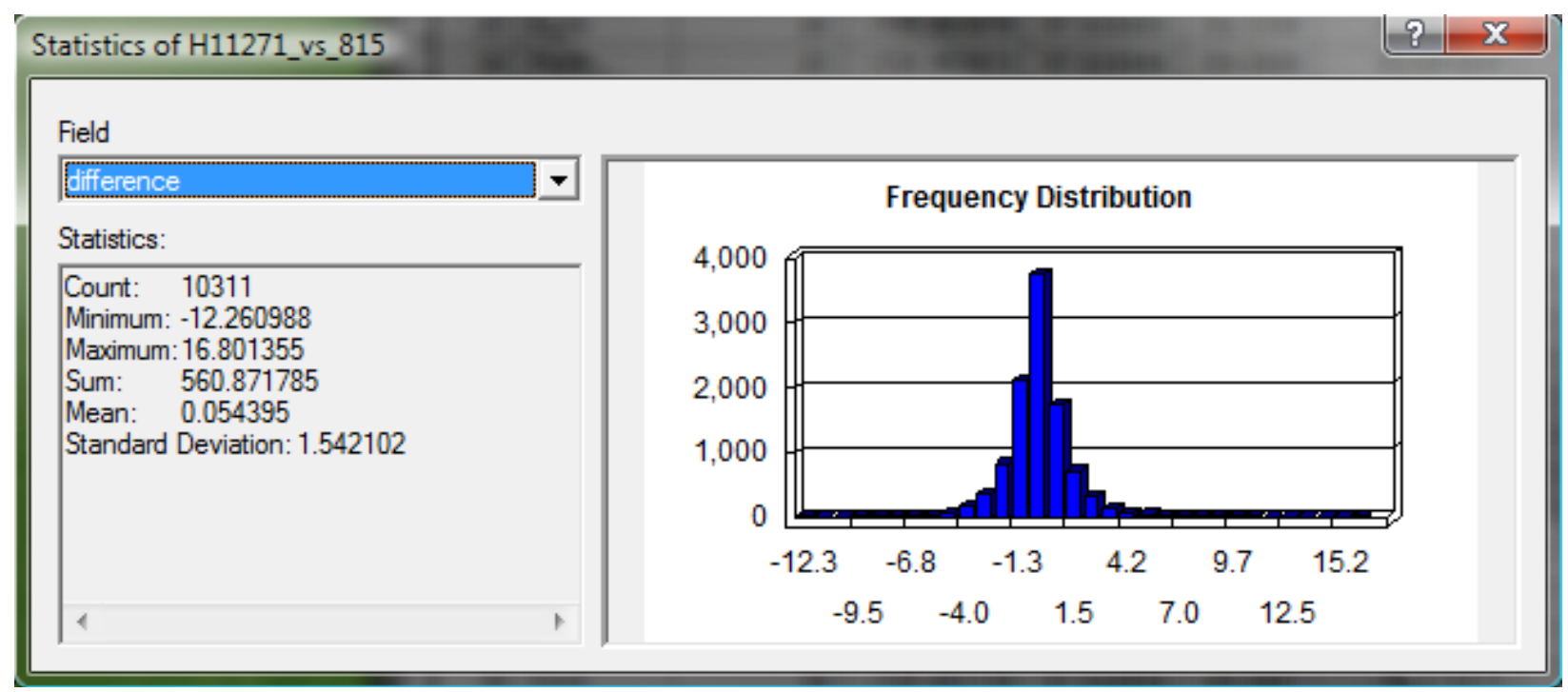

Figure 42. Histogram comparing NOS H11271 depth values (m) to the Sitka 8/15 arc-second DEM.

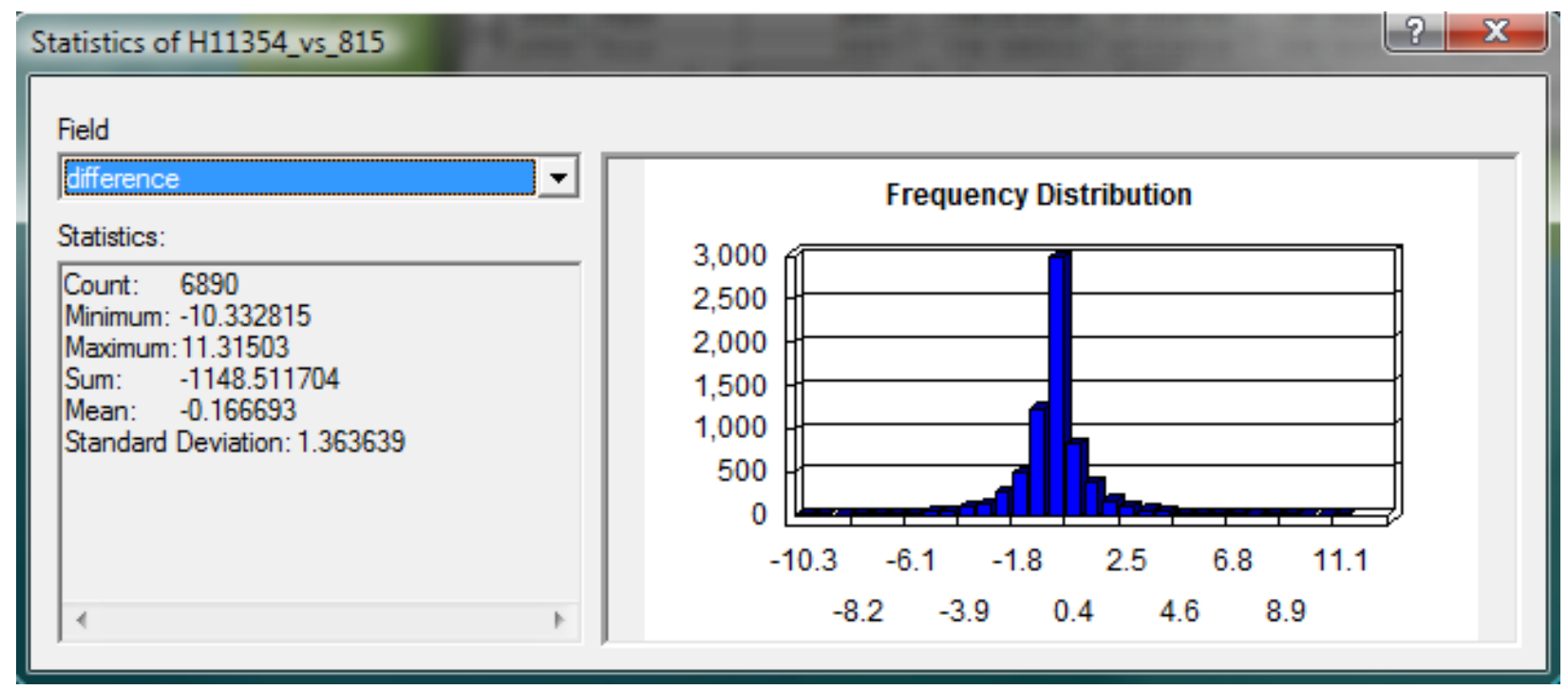

Figure 43 Histogram comparing NOS H11354 depth values (m) to the Sitka 8/15 arc-second DEM. 


\section{Topography}

We used the same method to assess the vertical accuracy of the topography of the 8/15 arc-second grid. We obtained 12,172 survey control points from DOTPF. Our comparison of these control points with the 8/15 arc-second grid resulted in an overall mean difference of $0.14 \mathrm{~m}$ (fig. 44).

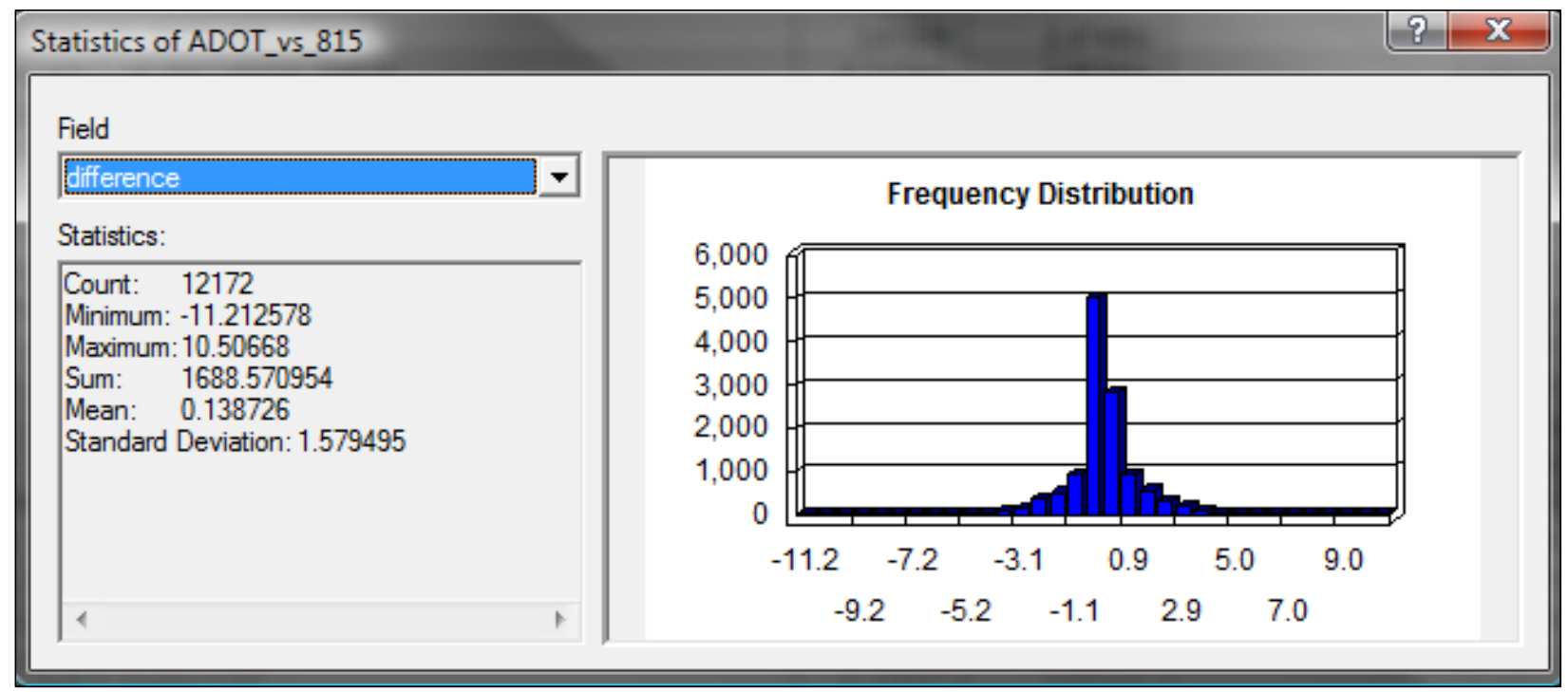

Figure 44. Histogram comparing the DOTPF topographic survey control elevation values to the Sitka 8/15 arcsecond DEM.

\section{Conclusion}

We constructed a new 8/15 arc-second bathymetric-topographic DEM for the purpose of numerical tsunami-wave inundation modeling and mapping. This DEM is centered on the city of Sitka, Sitka Harbor, and Sitka Sound, Alaska. We constructed this DEM in accordance with NGDC best practices; in so doing, we used the highest resolution and most current hydrographic surveys, and the best topographic datasets available to us at this date and time. We took great care to ensure that the horizontal geographic coordinates for all of the data points we incorporated during the construction of this DEM are correctly referenced to the WGS84 horizontal datum and that all of the depth values are in reference to the MHHW vertical datum. This report summarizes these data sources and the methodologies used to integrate these data into the single DEM

We make the following suggestions to improve DEM resolution and mapping accuracy in the future:

1. Obtain high-resolution topographic and inter-tidal zone LIDAR surveys of the city of Sitka and the islands within Sitka Sound containing infrastructure.

2. If possible, we suggest that SDMI serve DEM data via WCS in the original resolution and spatial reference of the source data.

3. Whenever topographic or bathymetric data is constructed, even if as an ancillary dataset to another project (such as orthophoto rectification), that it be included as a deliverable to the client and licensed so that it can be used to benefit applications and agencies well beyond the scope of the immediate project and well beyond the needs of the vendor or client. 


\section{Acknowledgments}

We offer our thanks to Dr. Barry Eakins, Pamela Grothe, and Jason Caldwell (NGDC); Tim Reed (DOTPF); Wells Williams (City and Borough of Sitka); Dr. Roger Hansen (UAF-AEIC); and Tom Heinrichs and Dayne Broderson (UAF-GINA). This work was funded by the Geophysical Institute of the University of Alaska Fairbanks and by the NOAA National Tsunami Hazard Mitigation Program through the State of Alaska, Division of Homeland Security \& Emergency Management, Reimbursable Services Agreement 0911032.

\section{References}

Caldwell, R.J., Eakins, B.W., and Lim, E., 2011, Digital Elevation Models of Prince William Sound, AlaskaProcedures, Data Sources, and Analysis: Boulder, CO, U.S. Department of Commerce, NOAA, Marine Geology and Geophysics Division, National Geophysical Data Center, Technical Memorandum NESDIS NGDC-40, http://www.ngdc.noaa.gov/dem/squareCellGrid/getReport/735.

Caldwell, R.J, Eakins, B.W., Taylor, L.A., Carignan, K.S., and Collins, S., 2010, Digital Elevation Models of Southeast Alaska—Procedures, Data Sources and Analysis: Boulder, CO, U.S. Department of Commerce, NOAA, National Geophysical Data Center, http://www.ngdc.noaa.gov/dem/report/download/1337.

National Geodetic Survey, undated, Geoid Definition: Silver Spring, MD, National Oceanic and Atmospheric Administration, retrieved April 18, 2011, from http://www.ngs.noaa.gov/GEOID/geoid_def.html

National Geophysical Data Center, 2010, Coastal DEM Development Best Practices: Boulder, CO, retrieved July 18, 2010, from http://www.ngdc.noaa.gov/mgg/coastal/ngdc_dem_best_practices.pdf

National Oceanic and Atmospheric Administration, undated, Shoreline Website: Washington, DC, retrieved April 21, 2011, from http://shoreline.noaa.gov/data/datasheets/ocsshore.html

U.S. Fish \& Wildlife Service (USFWS), 2006, Region 7, Division of Conservation, Planning and Policy, January 01, 2006, ak_crm_fin_clp: U.S. Fish \& Wildlife Service, Anchorage, AK

U.S. Geological Survey, undated, SRTM Topography: Reston, VA, retrieved February 23, 2011, from http://dds.cr.usgs.gov/srtm/version2_1/Documentation/SRTM_Topo.pdf

\section{Data Processing Software}

ArcGIS v. 9.3.1—Developed and licensed by ESRI, Redlands, California, http://www.esri.com/

FME 2009—Feature Manipulation Engine: Vancouver, BC, Canada, developed and licensed by Safe Software, http://www.safe.com/

GMT v. 4.3.0 - Generic Mapping Tools, shareware developed and maintained by Paul Wessel and Walter Smith, funded by the National Science Foundation, http://gmt.soest.hawaii.edu/

MB-System v. 5.1.0—Shareware developed and maintained by David W. Caress and Dale N. Chayes, funded by the National Science Foundation, http://www.ldeo.columbia.edu/res/pi/MB-System/ 


\section{Appendix A-Hydrographic Surveys Evaluated in Developing the Sitka 8/15 arc-second DEM}

\begin{tabular}{|c|c|c|c|c|c|c|c|}
\hline Source & Name & Year & Scale & $\begin{array}{c}\text { Original } \\
\text { Horizontal Datum } \\
\end{array}$ & $\begin{array}{c}\begin{array}{c}\text { Original Vertical } \\
\text { Datum }\end{array} \\
\end{array}$ & $\begin{array}{c}\text { Horizontal Pt } \\
\text { Spacing (m) }\end{array}$ & Used \\
\hline NGDC & EW0408 & 2004 & & NAD83 & Local Surface & 50 & $\mathrm{n}$ \\
\hline NGDC & $\underline{\text { HLY09TD }}$ & 2009 & & Unknown & Unknown & 50 & $\mathrm{n}$ \\
\hline NOS & H04432 & 1924 & 80,000 & Undetermined & MLLW & Undetermined & $\mathrm{n}$ \\
\hline NOS & $\underline{\mathrm{H} 04530}$ & 1925 & 20,000 & Undetermined & MLLW & Undetermined & $\mathrm{n}$ \\
\hline NOS & $\underline{\mathrm{H} 04842}$ & 1928 & 20,000 & Undetermined & MLLW & Undetermined & $\mathrm{n}$ \\
\hline NOS & $\underline{\mathrm{H} 04843}$ & 1928 & 20,000 & Undetermined & MLLW & Undetermined & $\mathrm{n}$ \\
\hline NOS & $\underline{\mathrm{H} 04847}$ & 1928 & 20,000 & Undetermined & MLLW & Undetermined & $n$ \\
\hline NOS & $\underline{\mathrm{H} 06351}$ & 1938 & 1,000 & Undetermined & MLLW & Undetermined & $\mathrm{n}$ \\
\hline NOS & $\underline{\mathrm{H} 06352}$ & 1938 & 5,000 & Undetermined & MLLW & Undetermined & $\mathrm{n}$ \\
\hline NOS & $\underline{\mathrm{H} 06353}$ & 1938 & 5,000 & Undetermined & MLLW & Undetermined & $n$ \\
\hline NOS & $\underline{\mathrm{H} 06354}$ & 1938 & 10,000 & Undetermined & MLLW & Undetermined & $\mathrm{n}$ \\
\hline NOS & H06355 & 1938 & 10,000 & Undetermined & MLLW & Undetermined & $\mathrm{n}$ \\
\hline NOS & H06655 & 1941 & 20,000 & Undetermined & MLLW & Undetermined & $n$ \\
\hline NOS & $\underline{\mathrm{H} 06666}$ & 1941 & 10,000 & Undetermined & MLLW & Undetermined & $\mathrm{n}$ \\
\hline NOS & H06667 & 1941 & 20,000 & Undetermined & MLLW & Undetermined & $\mathrm{n}$ \\
\hline NOS & $\underline{\mathrm{H} 06764}$ & 1942 & 5,000 & Undetermined & MLLW & Undetermined & $\mathrm{n}$ \\
\hline NOS & H06947 & 1943 & 10,000 & Undetermined & MLLW & Undetermined & $\mathrm{n}$ \\
\hline NOS & $\underline{\mathrm{H} 06948}$ & 1943 & 10,000 & Undetermined & MLLW & Undetermined & $\mathrm{n}$ \\
\hline NOS & $\underline{\mathrm{H} 07096}$ & 1945 & 10,000 & Undetermined & MLLW & Undetermined & $\mathrm{n}$ \\
\hline NOS & $\underline{\mathrm{H} 07097}$ & 1945 & 5,000 & Undetermined & MLLW & Undetermined & $\mathrm{n}$ \\
\hline NOS & $\underline{\mathrm{H} 07163}$ & 1945 & 1,200 & Undetermined & MLLW & Undetermined & $\mathrm{n}$ \\
\hline NOS & $\underline{\mathrm{H} 07189}$ & 1947 & 10,000 & Undetermined & MLLW & Undetermined & $\mathrm{n}$ \\
\hline NOS & $\underline{\mathrm{H} 07190}$ & 1947 & 10,000 & Undetermined & MLLW & Undetermined & $\mathrm{n}$ \\
\hline NOS & $\underline{\mathrm{H} 07191}$ & 1947 & 10,000 & Undetermined & MLLW & Undetermined & $n$ \\
\hline NOS & $\underline{\mathrm{H} 07193}$ & 1947 & 10,000 & Undetermined & MLLW & Undetermined & $\mathrm{n}$ \\
\hline NOS & $\underline{\mathrm{H} 07673}$ & 1952 & 5,000 & Undetermined & MLLW & Undetermined & $\mathrm{n}$ \\
\hline NOS & $\underline{\mathrm{H} 07674}$ & 1948 & 5,000 & Undetermined & MLLW & Undetermined & $\mathrm{n}$ \\
\hline NOS & $\underline{\mathrm{H} 07675}$ & 1948 & 5,000 & Undetermined & MLLW & Undetermined & $\mathrm{n}$ \\
\hline NOS & $\underline{\mathrm{H} 07676}$ & 1948 & 10,000 & Undetermined & MLLW & Undetermined & $\mathrm{n}$ \\
\hline NOS & H07787 & 1949 & 10,000 & Undetermined & MLLW & Undetermined & $\mathrm{n}$ \\
\hline NOS & $\underline{\mathrm{H} 07788}$ & 1949 & 10,000 & Undetermined & MLLW & Undetermined & $\mathrm{n}$ \\
\hline NOS & $\underline{\mathrm{H} 07860}$ & 1951 & 10,000 & Undetermined & MLLW & Undetermined & $\mathrm{n}$ \\
\hline NOS & $\underline{\mathrm{H} 07861}$ & 1951 & 10,000 & Undetermined & MLLW & Undetermined & $\mathrm{n}$ \\
\hline NOS & $\underline{\mathrm{H} 08501}$ & 1959 & 1,000 & NAD27 & MLLW & Undetermined & $n$ \\
\hline NOS & H11112 & 2003 & 10,000 & NAD83 & MLLW & 10 & $\mathrm{n}$ \\
\hline NOS & $\underline{\mathrm{H} 11113}$ & 2003 & 10,000 & NAD83 & MLLW & 25 & $\mathrm{n}$ \\
\hline NOS & $\underline{\mathrm{H} 11114}$ & 2004 & 10,000 & NAD83 & MLLW & 25 & $\mathrm{n}$ \\
\hline NOS & $\underline{\mathrm{H} 11115}$ & 2004 & 10,000 & NAD83 & MLLW & 50 & $\mathrm{n}$ \\
\hline NOS & $\underline{\text { H11116 }}$ & 2004 & 10,000 & NAD83 & MLLW & 25 & $\mathrm{n}$ \\
\hline NOS & $\underline{\mathrm{H} 11117}$ & 2003 & 10,000 & NAD83 & MLLW & 50 & $\mathrm{y}$ \\
\hline NOS & $\underline{\mathrm{H} 11118}$ & 2004 & 10,000 & NAD83 & MLLW & 25 & $\mathrm{y}$ \\
\hline NOS & $\underline{\mathrm{H} 11119}$ & 2004 & 10,000 & NAD83 & MLLW & 25 & $\mathrm{y}$ \\
\hline NOS & $\underline{\mathrm{H} 11120}$ & 2003 & 10,000 & NAD83 & MLLW & 25 & $\mathrm{y}$ \\
\hline NOS & $\underline{\mathrm{H} 11121}$ & 2002 & 5,000 & NAD83 & MLLW & 10 & $\mathrm{y}$ \\
\hline
\end{tabular}




\begin{tabular}{|c|c|c|c|c|c|c|c|}
\hline Source & Name & Year & Scale & $\begin{array}{c}\text { Original } \\
\text { Horizontal Datum }\end{array}$ & $\begin{array}{c}\text { Original Vertical } \\
\text { Datum }\end{array}$ & $\begin{array}{l}\text { Horizontal Pt } \\
\text { Spacing (m) }\end{array}$ & Used \\
\hline NOS & $\underline{\mathrm{H} 11134}$ & 2003 & 20,000 & NAD83 & MLLW & 50 & $\mathrm{n}$ \\
\hline NOS & $\underline{\mathrm{H} 11354}$ & 2,004 & 10,000 & NAD83 & MLLW & 10 & $\mathrm{y}$ \\
\hline NOS BAG & $\underline{\mathrm{H} 11122}$ & 2005 & 10,000 & NAD 83 & MLLW & 10 & $\mathrm{y}$ \\
\hline NOS BAG & $\underline{\mathrm{H} 11123}$ & 2004 & 10,000 & NAD 83 & MLLW & 5 & $\mathrm{y}$ \\
\hline NOS BAG & $\underline{\mathrm{H} 11124}$ & 2004 & 10,000 & NAD 83 & MLLW & 10 & $\mathrm{y}$ \\
\hline NOS BAG & $\underline{\mathrm{H} 11126}$ & 2009 & 10,000 & NAD 83 & MLLW & 5 & $\mathrm{n}$ \\
\hline NOS BAG & $\underline{\mathrm{H} 11127}$ & 2006 & 10,000 & NAD 83 & MLLW & 10 & $\mathrm{n}$ \\
\hline NOS BAG & $\underline{\mathrm{H} 11128}$ & 2006 & 10,000 & NAD 83 & MLLW & 10 & $\mathrm{n}$ \\
\hline NOS BAG & $\underline{\mathrm{H} 11130}$ & 2004 & 10,000 & NAD 83 & MLLW & 5 & $\mathrm{y}$ \\
\hline NOS BAG & $\underline{\mathrm{H} 11135}$ & 2005 & 20,000 & NAD 83 & MLLW & 10 & $\mathrm{n}$ \\
\hline NOS BAG & $\underline{\mathrm{H} 11270}$ & 2005 & 10,000 & NAD 83 & MLLW & 10 & $\mathrm{n}$ \\
\hline NOS BAG & H11271 & 2005 & 10,000 & NAD 83 & MLLW & 10 & $\mathrm{y}$ \\
\hline NOS BAG & H11427 & 2005 & 10,000 & WGS 84 & MLLW & 10 & $\mathrm{n}$ \\
\hline NOS BAG & $\underline{\mathrm{H} 11428}$ & 2005 & 10,000 & NAD 83 & MLLW & 5 & $\mathrm{n}$ \\
\hline NOS BAG & $\underline{\mathrm{H} 11538}$ & 2006 & 10,000 & NAD 83 & MLLW & 3 & $n$ \\
\hline NOS BAG & $\underline{\text { H11539 }}$ & 2006 & 10,000 & NAD 83 & MLLW & 3 & $\mathrm{n}$ \\
\hline NOS BAG & $\underline{\mathrm{H} 11540}$ & 2006 & 10,000 & NAD 83 & MLLW & 3 & $\mathrm{n}$ \\
\hline NOS BAG & $\underline{\mathrm{H} 11677}$ & 2007 & 10,000 & NAD 83 & MLLW & 10 & $n$ \\
\hline NOS BAG & $\underline{\mathrm{H} 11844}$ & 2008 & 10,000 & NAD 83 & MLLW & 8 & $n$ \\
\hline NOS BAG & $\underline{\mathrm{H} 11845}$ & 2008 & 10,000 & NAD 83 & MLLW & 8 & $\mathrm{n}$ \\
\hline NOS BAG & $\underline{\mathrm{H} 11846}$ & 2008 & 10,000 & NAD 83 & MLLW & 4 & $\mathrm{n}$ \\
\hline USACE & $\begin{array}{l}\text { sitka bathy_5ft sort } \\
\text { reformatted_use.xyz }\end{array}$ & 2008 & & NAD83 & MLLW & & $\mathrm{y}$ \\
\hline USACE & $\underline{\text { crescent-ptfile.txt }}$ & 2005 & & NAD83 & MLLW & & $\mathrm{y}$ \\
\hline USACE & $\begin{array}{c}\text { western_channel_2001_8ft } \\
\text { mapper_grid.xyz }\end{array}$ & 2002 & & NAD83 & MLLW & & $\mathrm{y}$ \\
\hline USACE & CRB-ptfile.txt & 2005 & & NAD83 & MLLW & & $\mathrm{y}$ \\
\hline USACE & dtmfile_1.xyz & 2005 & & NAD83 & MLLW & & $\mathrm{n}$ \\
\hline
\end{tabular}




\section{Appendix B-NOAA BM Sheet for Tidal Station ID 9451600}

Station ID: 9451600 PUBLICATION DATE: 04/21/2003

Name: SITKA, BARANOF ISLAND, SITKA SOUND ALASKA

NOAA Chart: 17327 Latitude: $57^{\circ} 3.1^{\prime} \mathrm{N}$

USGS Quad: SITKA A-4 Longitude: $135^{\circ} 20.5^{\prime} \mathrm{W}$

\section{TIDAL DATUMS}

Tidal datums at SITKA, BARANOF ISLAND, SITKA SOUND based on:

LENGTH OF SERIES: 19 Years

TIME PERIOD: January 1983-December 2001

TIDAL EPOCH: 1983-2001

CONTROL TIDE STATION:

Elevations of tidal datums refer to Mean Lower Low Water (MLLW), in METERS:

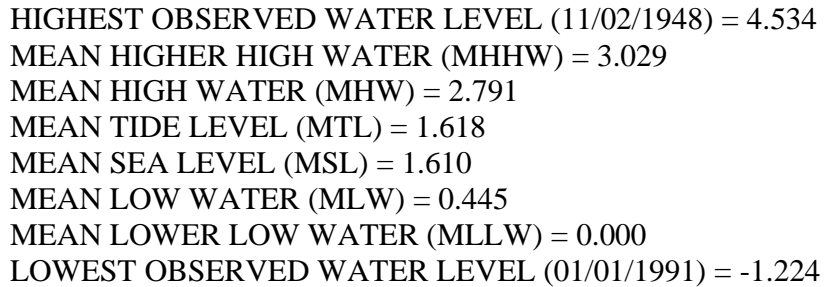

National Geodetic Vertical Datum (NGVD 29)

Bench Mark Elevation Information In METERS above:

$\begin{array}{lrr}\text { Stamping or Designation } & \text { MLLW } & \text { MHW } \\ \text { 1600 L 1982 } & 12.290 & 9.499 \\ \text { 16 1941 } & 6.269 & 3.478 \\ \text { TIDAL 24 1974 } & 6.124 & 3.333 \\ \text { TIDAL BM 1600 K 1978 } & 6.393 & 3.603 \\ \text { 945 0460 BM M } & 5.982 & 3.191 \\ \text { NO 18 1947 } & 10.711 & 7.920 \\ \text { 1600 N 1997 } & 12.137 & 9.346 \\ \text { 1600 P 1998 } & 6.957 & 4.167 \\ \text { 1600 R 1998 } & 4.721 & 1.931 \\ \text { 1600 S 1999 } & 5.596 & 2.805\end{array}$

Source: http://tidesandcurrents.noaa.gov/data_menu.shtml?stn=9451600\%20Sitka,\%20AK\&type=Bench\%20Mark\%20Sheets U.S. DEPARTMENT OF COMMERCE

National Oceanic and Atmospheric Administration, National Ocean Service 


\section{Appendix C-NGDC Workflow Documentation}

NGDC DEM Methodology

\section{A. Create the Bathymetry Pre-Surface}

1. Determine Extents and Cell Size

2. Collect all federal, state, and local digital data in extents. Note that extents need to be 5 percent greater than grid extent required.

NGDC tsunami inundation page (reports for example)

http://www.ngdc.noaa.gov/mgg/inundation/tsunami/inundation.html

NOS download page

http://www.ngdc.noaa.gov/mgg/bathymetry/hydro.html

Multibeam

http://www.ngdc.noaa.gov/mgg/bathymetry/multibeam.html

NOAA ENCS

http://www.nauticalcharts.noaa.gov/mcd/enc/index.htm

Trackline

http://www.ngdc.noaa.gov/mgg/geodas/trackline.html

NOAA Tidal Datums

http://tidesandcurrents.noaa.gov/station_retrieve.shtml?type=Datums

3. Transform all data to common horizontal datum such as WGS 84 geographic

4. Determine the best method for converting data to common vertical datum

a. Solo tide station offset (http://tidesandcurrents.noaa.gov/station_retrieve.shtml?type=Datums)

b. Tidal conversion grid from multiple tide stations (such as krig mllwmhhw.fmw)

5. Convert all data to common vertical data such as MHHW (enc_mllw_mhhw shape.fmw)

6. Make all point data into shapefile for visualization and editing to remove older survey in favor of newer, color ramp to look for outliers, double-check all conversions.

7. Important! Generate/edit coastline carefully to match newest bathy, imagery, lidar, or rnc (line data)

8. Convert all point shapefile bathy to xyz (still in individual survey file format)

9. Convert coastline line data to xyz points (using ArcMap Divide tool or GEODAS)

10. Set up file directory structure on linux/unix and move all xyz files into their appropriate directory.

$$
\begin{gathered}
4 \text { sitka_ak } \\
\text { bathy } \\
\text { enc } \\
\text { nos } \\
\text { nos_bag } \\
\text { surface } \\
\text { usace } \\
\text { coastline } \\
\text { topo } \\
\text { D. Dinux aster } \\
\text { ngdc_mb } \\
\text { software } \\
\text { mb_system }
\end{gathered}
$$

11. Cat all xyz into one master xyz file for each source directory (such as all_nos_bag.xyz) cat *.xyz > all_nos.xyz

12. Place all cat files into surface folder. Note: MUST include coastline xyz.

13. Ensure gmt defaults file and surface cmd script files are in surface folder.

14. Edit surface cmd file changing extents, cell size, and output name. Note that extents need to be $5 \%$ greater than grid extent required.

15. Run surface ./*.cmd

16. Edit *.asc output file to read xllcenter and yllcenter.

17. Once surface is finished, move output bathymetry ascii file to Windows to sanity check in ArcMap...

18. Proof for errors, edit source, and re-iterate with shapefile data (edit, re-xyz, re-surface).

19. Clip final resulting bathy surface to coastline (using ArcGIS or optionally, clip_bathy.sh).

20. Convert clipped bathymetry raster to xyz (optional use gdal2xyz.py, fme workbench, or ArcGIS Raster-toPoint). 
21. Move bathy xyz to the surface folder on linux/unix workstation that has MB-System installed and configured correctly.

\section{B. Create the Seamless Bathymetric-Topographic DEM using MB-System software:}

1. On to topo data: Determine which topo datasets are best (aster, ned, lidar, etc...)

2. Clip all topo data to coastline.

3. Polygon extent of LIDAR, buffer to allow MB to smooth between high and low res, clip lesser res to high res poly (ensures small gap exists, again allowing MB to smooth between).

4. Convert all topo datasets to xyz files (keep individual for input into MB, aster_arcviewgrid2xyz.fmw).

5. Move all topo xyz files to linux/unix into the topo dir (see screen capture above).

6. Place RUNxyz_list file in each data folder (bathy/enc/.., bathy/nos/.., topo/aster/..). Note that coastline dir is optional. Coastline xyz is used as breakline if used.

7. Edit output datalist name for appropriate data directory (such as coast.datalist for the coastline dir)

8. Rename file ext for all input bathy xyz files (i.e. nos_all.xyz) to *.xyd to avoid inclusion in the list. The only bathy input xyz for MB should be the result of the clipped bathy surface.

9. Execute RUNxyz_list for each dir to create datalist and info files. .RUNxyz_list

10. Navigate to software/mb_system folder on linux/unix and ensure that the *.grid.cmd file exists (copy, rename, and edit from other work). Edit range, name, and data lines. Ensure correct cell size for desired output. Note: MB can only handle 2GB. May have to tile if too large. Note also that range values are in 0360 format. Add 360 to the lon dd coordinate. Range order is $\mathrm{l} / \mathrm{r} / \mathrm{b} / \mathrm{t}$.

11. Make datalist in mb_system dir (for example, sitka.datalist). Copy from other work if possible and manually edit path to all datalists created with RUNxyz_list. Note that last digit in each list item is weight of importance (higher are of greater importance). Typical is 0.1 to 100 in increments of 10 (optionally change to see if this has any noticeable influence in output).

12. Run *.grid.cmd ./sitka815.grid.cmd

13. Reiterate as many times as necessary to correct interpolation errors.

14. Send NGDC final for proof and approval. 


\section{Appendix D - List of Abbreviations and Acronyms}

\begin{tabular}{|c|c|}
\hline AEIC & Alaska Earthquake Information Center \\
\hline ASTER & Advanced Spaceborne Thermal Emission and Reflection Radiometer \\
\hline CAD & Computer Aided Drafting \\
\hline DEM & Digital Elevation Model \\
\hline DOTPF & Alaska Department of Transportation \& Public Facilities \\
\hline DTM & Digital Terrain Model \\
\hline ENC & Electronic Nautical Chart \\
\hline GINA & Geographic Information Network of Alaska \\
\hline GIS & Geographic Information System \\
\hline GMT & Generic Mapping Tools \\
\hline MHHW & Mean Higher High Water \\
\hline MHW & Mean High Water \\
\hline MLLW & Mean Lower Low Water \\
\hline MSL & Mean Sea Level \\
\hline NAD83 & North American Datum 1983 \\
\hline NGA & National Geospatial Intelligence Agency \\
\hline NGDC & National Geophysical Data Center \\
\hline NGS & National Geodetic Survey \\
\hline NOAA & National Oceanic and Atmospheric Administration \\
\hline NOS & National Ocean Service \\
\hline OCS & Office of Coast Survey \\
\hline OGC & Open Geospatial Consortium \\
\hline SDMI & Alaska Statewide Digital Mapping Initiative \\
\hline SRTM & Shuttle Radar Topography Mission \\
\hline TIN & Triangulated Irregular Network \\
\hline USACE & U.S. Army Corps of Engineers \\
\hline USFWS & U.S. Fish \& Wildlife Service \\
\hline USGS & U.S. Geological Survey \\
\hline WCS & Web Coverage Service \\
\hline WGS84 & World Geodetic System 1984 \\
\hline WMS & Web Map Service \\
\hline
\end{tabular}

